Mario Luis Pires Gonçalves Ribeiro

\title{
Dopagem carbono em camadas epitaxiais de InAlAs
}

Dissertação apresentada ao Departamento de Engenharia Elétrica da Pontifícia Universidade Católica do Rio de Janeiro como parte dos requisitos para obtenção do título de Mestre em Ciências de Engenharia Elétrica.

Orientadora: Professora Patrícia Lustoza de Souza

Centro de Estudos em Telecomunicações

Departamento de Engenharia Elétrica

Pontifícia Universidade Católica do Rio de Janeiro

Rio de Janeiro, 10 de abril de 2002 
Dedicada à minha família e aos meus pais 
Agradecimento especial a Prof ${ }^{\mathrm{a}}$. Patrícia Lustoza de Souza pela sua dedicação ao presente trabalho, pela sua constante contribuição a minha formação científica e amizade. 


\section{Agradecimentos}

Agradeço ao Maurício Pamplona Pires pelo apoio constante e por tudo que me ensinou.

Agradeço aos colegas de laboratório Paulo, Guilherme, Maria Cristina, Sandra e Christiana pelo convívio muito agradável.

Agradeço ao Iracildo, por estar sempre à disposição e à Amália por sempre nos ajudar.

Agradeço ao Boris Yavich pelas amostras.

Agradeço ao Prof. Joel de Souza da Universidade Federal do Rio Grande do Sul, pelas implantações iônicas.

Agradeço ao Prof. Márcio Pudenzi da Universidade Estadual de Campinas pelas medidas SIMS.

Agradeço a todos os colegas estrangeiros que passaram pelo laboratório.

Esse trabalho foi apoiado por:

(i) Centro de Desenvolvimento e Pesquisa, Ericsson Telecomunicações S. A., Brasil;

(ii) CAPES - Coordenação de Aperfeiçoamento de Pessoal de Nível Superior 


\section{Resumo}

É reconhecido o potencial de usar carbono como um dopante tipo $p$ em InAlAs devido a obtenção de elevados níveis de dopagem [1,2]. Entretanto, níveis elevados de dopagem só são alcançados em baixas temperaturas de crescimento ( $\mathrm{Tg}$ inferiores a $\left.600^{\circ} \mathrm{C}\right)$. Nessas temperaturas, as camadas crescidas apresentam qualidade ótica inferior quando comparadas com camadas crescidas em temperaturas mais altas, o que é prejudicial para dispositivos de optoeletrônica. Neste trabalho, é apresentada uma investigação sistemática das propriedades de transporte e óticas em camadas de InAlAs dopadas com carbono para diferentes temperaturas de crescimento.

É observado que quanto mais baixa for a $\mathrm{T}_{\mathrm{g}}$ maior será a incorporação de carbono e maior a atividade elétrica. Este resultado indica que o carbono é incorporado de diversas maneiras, bem como um aceitador raso. O carbono também pode ser incorporado como um doador raso, pois é um dopante anfotérico. Entretanto, este fato, não é suficiente para explicar os resultados de transporte. A diferença entre a concentração Hall e a concentração $C V$ indica a incorporação de doadores profundos. Provavelmente, o carbono participa na formação desses doadores profundos, uma vez que a concentração de doador profundo varia linearmente com a densidade atômica de carbono, determinada pela técnica SIMS.

Por outro lado, centros não radiativos são mais facilmente incorporados em baixas $T_{g}$ e a eficiência da fotoluminescência é reduzida. Essa degradação da fotoluminescência é independente da concentração de carbono, consequentemente, pode-se concluir que essa redução na eficiência da fotoluminescência não está associada à presença de doadores profundos.

Com a finalidade de obter um incremento na atividade elétrica do carbono e melhoria na qualidade ótica das camadas, as amostras foram submetidas a tratamentos térmicos. Os tratamentos térmicos aumentaram a concentração de buracos mas não influenciaram na densidade de doadores profundos ou na qualidade ótica das camadas. Para a utilização de InAlAs dopado com carbono em dispositivos, deve-se obter simultaneamente uma boa qualidade ótica e elevada atividade elétrica das camadas. Então, deve-se identificar o doador profundo, que está associado ao carbono, com o 
objetivo de reduzí-lo ou eliminá-lo e consequentemente, obter um incremento na atividade elétrica das camadas. Desta forma as camadas podem ser crescidas a temperaturas mais altas adequadas para uma emissão de fotoluminescência eficiente. Cálculos teóricos são apresentados de modo a ajudar essa identificação. Outra possibilidade é usar diferentes fontes de arsina em que as moléculas se dissociem em temperaturas mais baixas. 


\section{Abstract}

The potential of using carbon as a p-type dopant for InAlAs has already been recognized due to the achievable high hole concentration $[1,2]$. However, high doping levels are reached only for low growth teperatures $\left(\mathrm{T}_{\mathrm{g}}\right.$ below $\left.600^{\circ} \mathrm{C}\right)$. These temperatures produce layers with poor optical quality as compared to those grown at higher temperatures, which can be detrimental for optoeletronic device. In this work we present crystal, transport and optical properties of such layers grown at different temperatures.

We find that the lower $T_{g}$, the more efficient the carbon incorporation and its electrical activity are. This result indicates that carbon is incorporated in forms different from a shallow acceptor, as well. Carbon can also be incorporated as a shallow donor since it is an amphoteric dopant. However, this alone does not explain the transport results. The difference between the net free charge density determined from capacitance measurements indicates that a deep donor is also incorporated. Carbon most likely participates in the deep donor formation since the inferred deep donor concentration varies linearly with the carbon atomic density measured by SIMS.

On the other hand, non-radiative deep levels are more efficiently incorporated as $\mathrm{T}_{\mathrm{g}}$ is reduced degrading the photoluminescence characteristics. Such degration is independent of the carbon doping. Therefore, one concludes that the decrease in the photoluminescence efficiency cannot be related to the presence of the deep donor mentioned in the previous paragraph.

To further probe the carbon electrical activity and its effect on the optical properties of the layers, the samples have been subjected to a heat-treatment. Annealing the samples increases the hole concentration, but neither affects the deep donor density nor improves the layers optical quality. In order to use carbon doped InAlAs in devices which simultaneously require good optical quality and high electrical activity of the layers, one should identify the deep donor involving carbon in order to try to reduce its concentration or even eliminate it, consequently improving the electrical activity of the layers. In such a way the layers can be grown at higher temperatures, adequate for an efficient photoluminescence emission. Theoretical calculations are being carried out to help with such identification. Another possibility is to use other arsine sources which crack at lower temperatures. 


\section{Sumário}

1. Introdução 1

2. Aspectos conceituais 5

2.1. Estrutura dos materiais 5

2.1.1. Parâmetro de rede no crescimento epitaxial 5

2.1.2. Bandas de energia $\quad 6$

2.1.3. Metal, semicondutor e isolante $\quad 8$

2.1.4. Gap direto e indireto 9

2.2. Dopagem 12

2.2.1. Elementos dopantes 12

2.2.2. Aspectos da dopagem 14

2.2.3. Incorporação durante o crescimento 15

3. Técnica de crescimento e detalhes experimentais 19

3.1. MOVPE 19

3.2. SIMS 21

3.3. Difração de raios-x 22

3.4. Efeito Hall 25

$\begin{array}{lll}3.5 . & \mathrm{CV} & 27\end{array}$

3.6. Fotoluminescência 29

3.7. Tratamento térmico 34

4. Resultados e discussão 35

4.1. Transporte 36

4.2. Estrutura $\quad 49$

4.3. Ótica 51 
5. Conclusão

A. Apêndice $\quad 59$

$\begin{array}{lll}\text { A.1. O átomo } & 59\end{array}$

$\begin{array}{lll}\text { A.2. } & \text { Ligações atômicas } & 60\end{array}$

$\begin{array}{lll}\text { A.3. } & \text { Distância interatômica } & 61\end{array}$

$\begin{array}{lll}\text { A.4. } & \text { Estrutura cristalina } & 63\end{array}$

$\begin{array}{ll}\text { Bibliografia } & 65\end{array}$

$\begin{array}{ll}\text { Trabalhos publicados } & 71\end{array}$ 


\section{Introdução}

A parte ótica de um espectro de frequência eletromagnética é dividida em três bandas: (i) infravermelho, (ii) visível e (iii) ultravioleta. O comprimento de onda e a freqüência estão relacionados por $c=v \lambda$, onde $c$ é a velocidade da luz, $v$ é a frequiência e $\lambda$ é o comprimento de onda eletromagnética. O espectro ótico com comprimentos de ondas e freqüências correspondentes está exemplificado na tabela 1.

\begin{tabular}{cccc}
\hline & Cor & Comprimento de onda $(\mu \mathrm{m})$ & Freqüência $(\mathrm{Hz})$ \\
\hline & Ultravioleta & $0.005-0.39$ & $6.0 \times 10^{16}-7.69 \times 10^{14}$ \\
& violeta & $0.40-0.45$ & $7.5-6.6 \times 10^{14}$ \\
Resposta visual & azul & $0.45-0.50$ & $6.6-6.0 \times 10^{14}$ \\
& verde & $0.50-0.57$ & $6.0-5.27 \times 10^{14}$ \\
& amarelo & $0.57-0.59$ & $5.27-5.01 \times 10^{14}$ \\
& laranja & $0.59-0.61$ & $5.01-4.92 \times 10^{14}$ \\
& vermelho & $0.61-0.70$ & $4.92-4.28 \times 10^{14}$ \\
& infravermelho & $0.70-20$ & $4.28 \times 10^{14}-1.5 \times 10^{13}$ \\
\hline
\end{tabular}

Tabela 1: Espectro ótico.

Nos dispositivos optoeletrônicos usados em sistemas de telecomunicações, a emissão de luz, detecção, modulação, processamento de sinal e etc., são funções extremamente importantes. Dependendo da aplicação, a luz é transmitida por vários meios. Os dispositivos utilizados para guiamento da luz em sistemas de comunicação ótica, são constituídos por diferentes materiais.

A escolha do material depende largamente da aplicação e do meio de transmissão. Conforme as figuras 1 (a) e (b), a menor perda e a menor dispersão numa fibra ótica ocorrem em $1.55 \mu \mathrm{m}$ e $1.3 \mu \mathrm{m}$, respectivamente. 

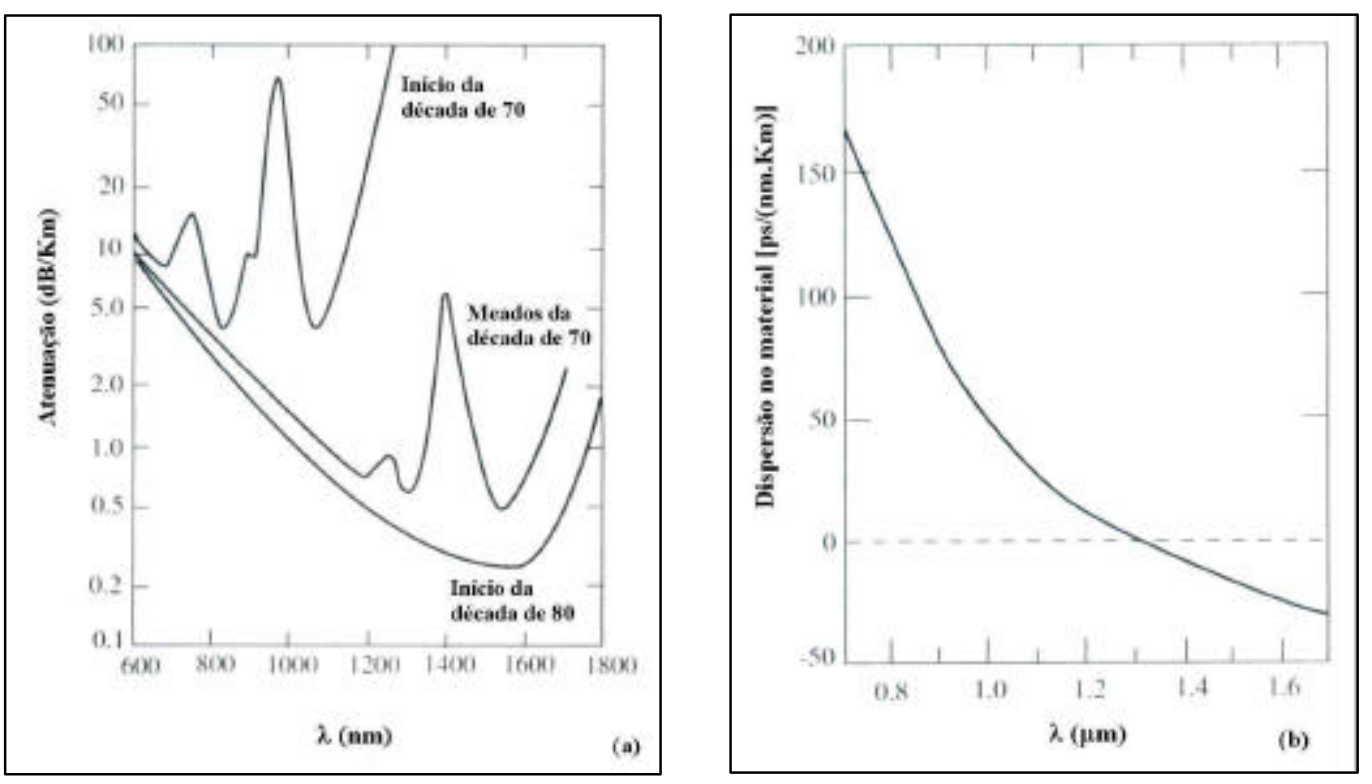

Figura 1: (a) Atenuação e (b) dispersão [3].

Na região do infravermelho próximo, os materiais de maior importância para dispositivos optoeletrônicos são o InP e ligas ternárias e quaternárias casadas ou não com o InP. As ligas de $\operatorname{In}_{\mathrm{x}} \mathrm{Al}_{1-\mathrm{x}} \mathrm{As}$ e $\mathrm{In}_{\mathrm{x}} \mathrm{Ga}_{1-\mathrm{x}} \mathrm{As}$ são casadas com o substrato de InP para $x=0.52$ e $x=0.53$, respectivamente. O gap na liga de $\operatorname{In}_{\mathrm{x}} \mathrm{Al}_{1-\mathrm{x}} \mathrm{As}$ varia de gap direto em InAs para gap indireto em AlAs. A dependência da energia de gap com a composição em $\operatorname{In}_{\mathrm{x}} \mathrm{Al}_{1-\mathrm{x}} \mathrm{As}$, está mostrada na figura 2.

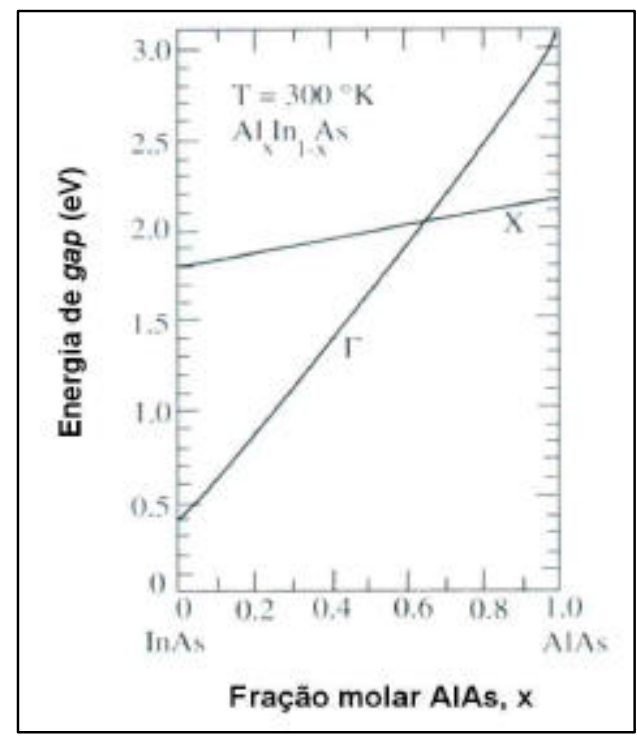

Figura 2: Dependência da energia de gap direto $\Gamma$ e a energia de gap indireto $\mathrm{X}$ com a composição para $\mathrm{In}_{\mathrm{X}} \mathrm{Al}_{1-\mathrm{x}} \mathrm{As}$ em $300 \mathrm{~K}$ [3]. 
Importantes dispositivos que operam em $1.55 \mu \mathrm{m}$ podem ser fabricados a partir da combinação desses dois materiais. Como exemplo, a liga de $\operatorname{In}_{0.52} \mathrm{Al}_{0.48} \mathrm{As}$ é muito utilizada como barreira em poços quânticos múltiplos de $\operatorname{In}_{\mathrm{x}} \mathrm{Ga}_{1-\mathrm{x}} \mathrm{As}$ em substituição ao InP, pois apresenta um off-set da banda de valência menor. Em moduladores de eletroabsorção esta característica é de extrema importância, porque facilita o escape dos buracos. A utilização de InAlAs em dispositivos eletrônicos e optoeletrônicos depende da possibilidade de se obter elevada dopagem, tanto $p$ quanto $n$. A dopagem $n$ não apresenta dificuldades em ser obtida [4].

Em particular, uma série de dispositivos utiliza a dopagem planar (delta), que consiste em uma dopagem onde as impurezas ficam confinadas numa pequena região de cerca de $10 \AA$ A. Moduladores de amplitude baseados no efeito Stark devem melhorar seu desempenho se uma superrede de dopagem delta nipi for introduzida na região de poços quânticos múltiplos [5]. Isso requer que o material da barreira tenha uma dopagem delta tipo $p$. Nesse caso, deve-se escolher um dopante que praticamente não difunda.

O carbono (C) é um importante dopante tipo $p$, especialmente no crescimento de semicondutores III-V pela técnica MOVPE (metalorganic vapor phase epitaxy) por apresentar uma série de vantagens como baixo coeficiente de difusão [6] e a possibilidade de se obter elevadas concentrações de buracos $\left(1.8 \times 10^{19} \mathrm{~cm}^{-3}\right)$ [2] em relação a outros dopantes como o belírio (Be) [7] e zinco (Zn) [8,9]. A dopagem com o carbono, pode ser aplicada em diversos materiais sem maiores dificuldades, como GaAs [10], AlGaAs [11], InGaAs, InP [12], GaP [13], InGaP [13,14] e GaN [14,15]. Poucos estudos foram apresentados sobre a dopagem de carbono em InAlAs. Conforme a literatura, a incorporação de carbono é afetada pelas condições de crescimento como a temperatura de crescimento $\left(\mathrm{T}_{\mathrm{g}}\right)$ e a razão de fluxos V/III. Para obter elevada concentração de buracos, é geralmente preferível baixa $\mathrm{T}_{\mathrm{g}}$ e baixa razão V/III. Para $T_{g}=530^{\circ} \mathrm{C}$ e razão $V / I I I=20$, a concentração de buracos é superior a $10^{19} \mathrm{~cm}^{-3}$, tornando-se altamente atrativo para a fabricação de dispositivos eletrônicos de alta velocidade e optoeletrônicos [2]. Entretanto, baixa temperatura de crescimento é indesejável pelo fato de favorecer a incorporação de defeitos. Portanto é fundamental conhecer os limites da dopagem de carbono em InAlAs para o desenvolvimento de dispositivos. 
Neste trabalho, será apresentada uma investigação sistemática das propriedades de transporte e óticas em camadas de InAlAs dopadas com carbono para diferentes temperaturas de crescimento. É demostrado que para temperaturas de crescimento em que as propriedades de transporte da camada são apropriadas, as características ópticas são inadequadas. 


\section{Aspectos conceituais}

\subsection{Estrutura dos materiais}

\subsubsection{Parâmetro de rede no crescimento epitaxial}

Quando crescemos camadas epitaxiais de silício ( $\mathrm{Si}$ ) num substrato de $\mathrm{Si}$, é natural obter camadas epitaxiais com o mesmo parâmetro do cristal e com uma alta qualidade resultante do cristal. Mas por outro lado, é freqüentemente desejável obter camadas epitaxiais cujo parâmetro de rede difere um pouco daquele do substrato [16].

GaAs e AlAs, ambos possuem estrutura zincblend, com parâmetro $5.6532 \AA \mathrm{e}$ $5.6611 \AA$ respectivamente, que são quase iguais. Como resultado, as camadas epitaxiais da liga ternária AlGaAs, podem ser crescidas sobre um substrato de GaAs com um pequeno descasamento. Similarmente GaAs pode ser crescido num substrato de germânio. Como exemplo, a energia do gap da liga ternária $\mathrm{Al}_{\mathrm{x}} \mathrm{Ga}_{1-\mathrm{x}} \mathrm{As}(0 \leq x \leq 1)$ depende da fração molar $x$ do AlAs na solução sólida e varia continuamente de $1.43 \mathrm{eV}$ (GaAs, $x=0$ ) até $2.1 \mathrm{eV}$ (AlAs, $x=1$ ). A figura 2.1 mostra que para uma certa composição, a liga, dependendo da natureza dos constituíntes binários possui gap indireto. As linhas tracejadas representam materiais de gap indireto. Materiais de gap direto e indireto serão discutidos na seção 2.1.4. Para exemplo, $\mathrm{Al}_{\mathrm{x}} \mathrm{Ga}_{1-\mathrm{x}} \mathrm{As}$ possui gap indireto para $x \geq 0.43$.

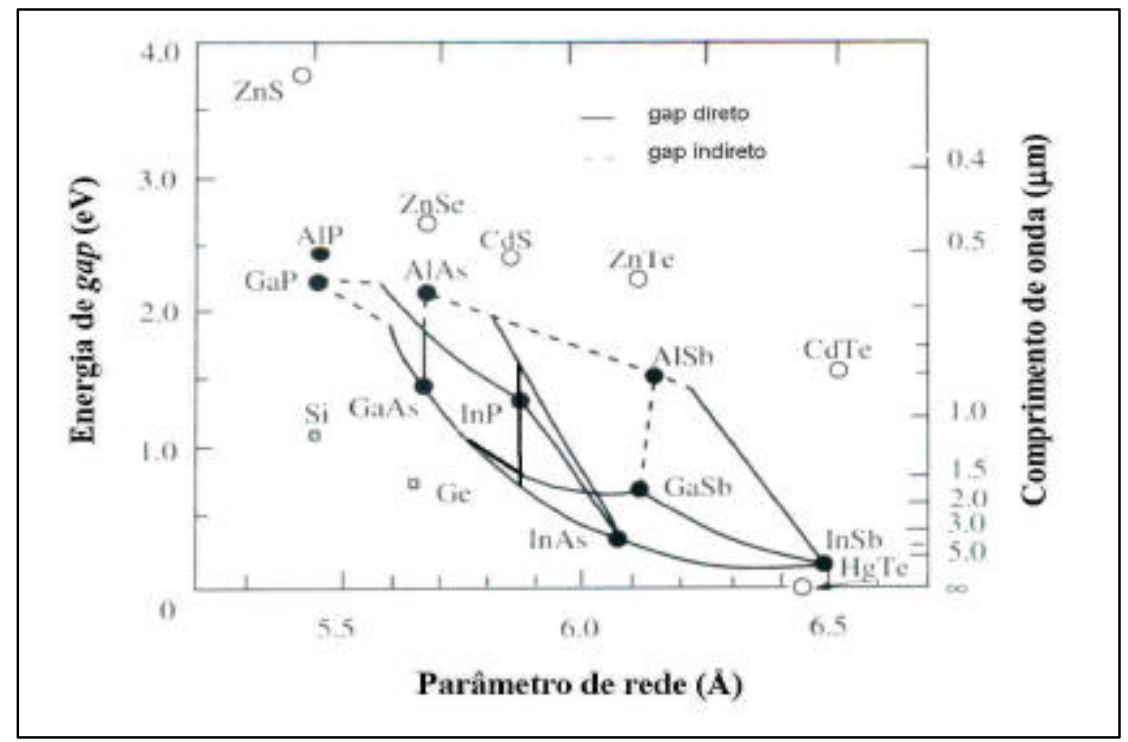

Figura 2.1: Energia de gap vs. parâmetro de rede e o tipo de gap para diversas ligas. 
No caso do InAlAs o parâmetro de rede é intermediário entre o parâmetro de rede do AlAs e do InAs, dependendo apenas da composição. A liga ternária $\operatorname{In}_{0.52} \mathrm{Al}_{0.48} \mathrm{As}$ apresenta-se casada com o InP. A figura 2.1 apresenta diversas ligas em função do parâmetro de rede.

Quando crescemos o material com o mesmo parâmetro de rede de seu substrato, não existe nenhuma tensão extra sobre o material crescido conforme figura 2.2 (a). Neste caso $a=a_{0}$. Chamamos esse material de casado pois as duas redes de cada material "casam" uma sobre a outra. Porém, como observado na figura 2.2 (b), quando o material está sobre um substrato com um parâmetro de rede que difere do seu, introduz-se uma tensão sobre o material. Caso o material esteja muito tensionado, a partir de uma certa espessura relaxará levando ele à formação de defeitos de estrutura chamados discordâncias.

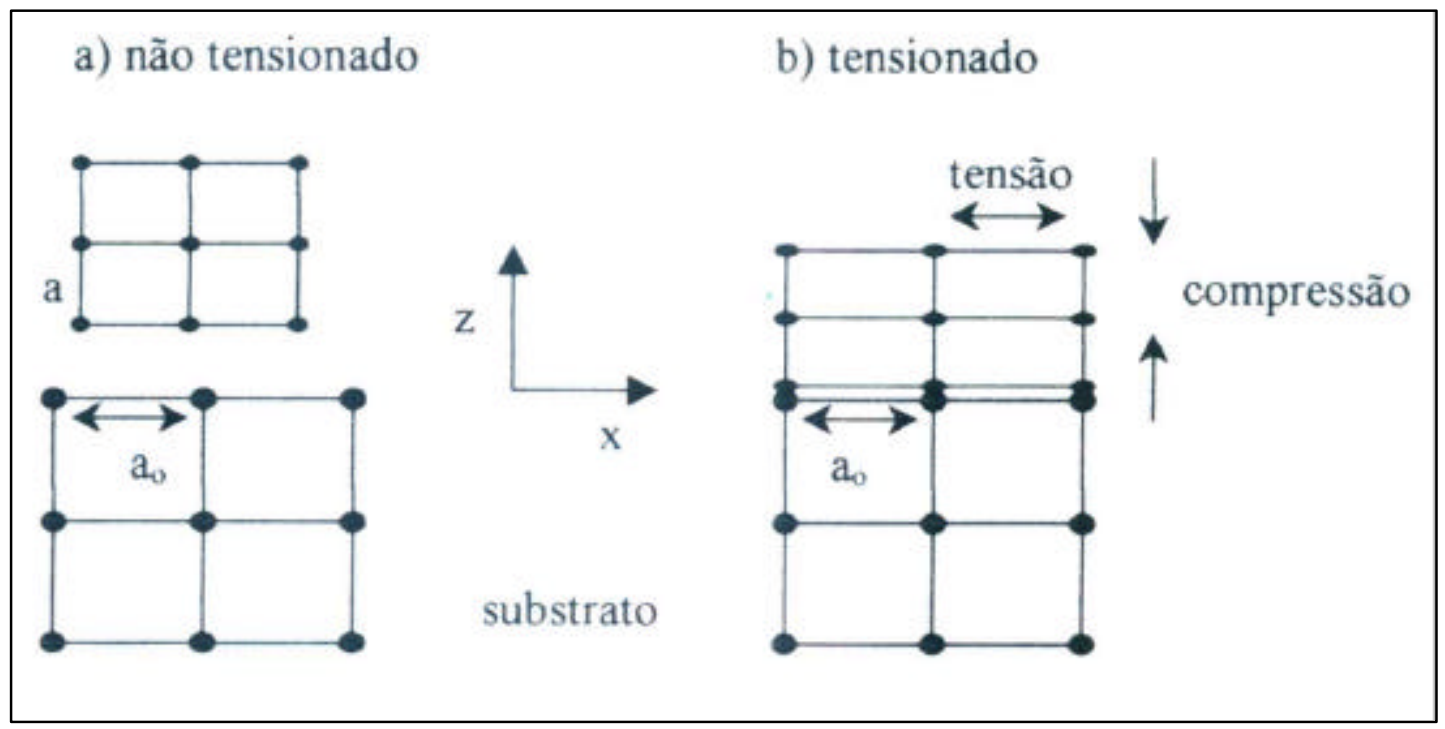

Figura 2.2: (a) camada epitaxial casada com o substrato, ou seja, possui mesmo parâmetro de rede do substrato e (b) camada epitaxial tensionada com o substrato.

\subsubsection{Bandas de energia}

Para a formação dos sólidos, os átomos isolados devem ser agrupados. Em virtude desse agrupamento, ocorrem várias interações entre átomos vizinhos, já descritas anteriormente. As forças de atração e repulsão entre os átomos estarão balanceadas, numa determinada distância interatômica para o cristal. Neste processo, importantes mudanças 
ocorrem na configuração do nível de energia do elétron, resultando em variações nas propriedades elétricas dos sólidos.

Qualitativamente, ao agrupar os átomos, o princípio de exclusão de Pauli, torna-se importante. Quando dois átomos estão completamente isolados um do outro, não existe interação entre as respectivas funções de onda do elétron, e eles podem ter estrutura eletrônica idêntica. Conforme o espaço entre os dois átomos diminui, as funções de onda do elétron se sobrepõem. O princípio de exclusão dita que os dois elétrons não podem estar no mesmo estado quântico, então deve existir uma divisão nos níveis discretos de energia do átomo isolado. Nos sólidos, muitos átomos são colocados juntos, então a divisão dos níveis de energia forma essencialmente bandas contínuas de energia. Como exemplo, a figura 2.3 ilustra a formação de um cristal de diamante a partir de átomos isolados de carbono. Cada átomo isolado de carbono possui estrutura eletrônica $1 s^{2} 2 s^{2}$ $2 p^{2}$ no seu estado de equilíbrio. Cada átomo possui dois estados disponíveis $1 \mathrm{~s}$, dois estados $2 s$, e seis estados $2 p$. Considerando $N$ átomos, obteremos $2 N, 2 N$ e $6 N$ estados do tipo $1 s, 2 s$ e $2 p$, respectivamente. Conforme o espaçamento interatômico diminui, esses níveis de energia dividem-se em bandas. A banda formada por níveis $2 s$ e $2 p$ contém $8 N$ estados disponíveis. À medida que a distância entre os átomos de carbono se aproxima do espaçamento interatômico de equilíbrio do diamante, a banda é dividida em duas bandas separadas por uma energia de gap $E_{g}$. A banda superior (denominada de banda de condução) contém $4 N$ estados, assim como a banda inferior (valência).

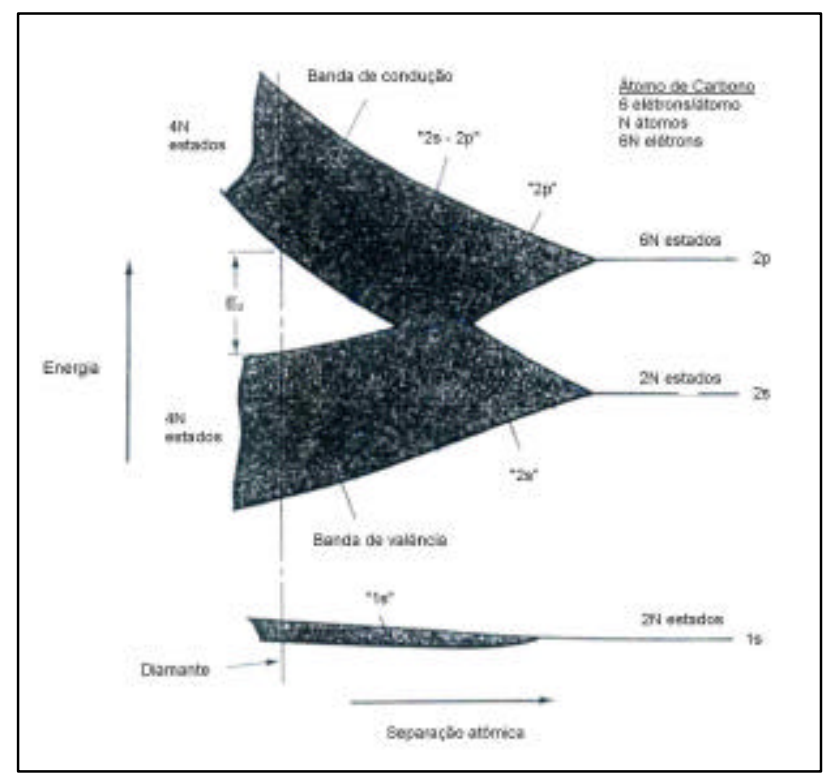

Figura 2.3: Formação da energia de banda para um cristal diamante 
A menor banda $1 s$ está preenchida com $2 N$ elétrons, entretanto, existe $4 N$ elétrons na camada isolada ( $2 N$ no estado $2 s$ e $2 N$ no estado $2 p$ ). Estes $4 N$ elétron podem ocupar estados na banda de valência ou de condução do cristal. Em 0K, todos os estados na banda de valência estarão preenchidos, enquanto que a banda de condução estará completamente vazia. Este arranjo de bandas de energia preenchidas e vazias tem um importante efeito na condutividade elétrica dos sólidos.

\subsubsection{Metal, semicondutor e isolante}

Todos os sólidos possuem características próprias na estrutura de bandas de energia. A variação na estrutura de bandas é responsável por uma larga faixa de características elétricas observadas em vários materiais. A estrutura de bandas do diamante na figura 2.3, como exemplo, é uma figura ideal para explicar o motivo pelo qual o carbono na estrutura de diamante é um excelente isolante. A fim de chegar a uma conclusão, devemos considerar as propriedades das energias de bandas completamente preenchidas e completamente vazias no processo de condução de corrente.

Os elétrons quando submetidos à ação de um campo elétrico, apresentam uma aceleração, podendo mover-se para outros estados de energia, caso existam estados disponíveis para eles. Como exemplo, se relativamente poucos elétrons residem numa banda, esta estará parcialmente preenchida, e haverá um número suficiente de estados não ocupados disponíveis, então os elétrons poderão se mover. Por outro lado, um isolante possui a banda de valência completamente preenchida por elétrons em $0 \mathrm{~K}$ e a banda de condução vazia. Não pode haver transporte de cargas na banda de valência, pois não existem estados disponíveis para os elétrons se moverem. Como não existem elétrons na banda de condução, também não existirá transporte de carga. Desta maneira, o diamante possui elevada resistividade, típica de isolantes.

Materiais semicondutores em $0 \mathrm{~K}$ possuem basicamente a mesma estrutura dos isolantes, ou seja, a banda de valência totalmente preenchida separada da banda de condução completamente vazia por uma energia de gap. A diferença encontra-se no tamanho da energia de gap, que é muito menor em semicondutores do que em isolantes. Por exemplo, o semicondutor silício tem $E_{g}=1.1 \mathrm{eV}$, enquanto o diamante, que tem a 
mesma estrutura do Si formada por átomos de carbono, tem $E_{g}=5 \mathrm{eV}$, sendo um excelente isolante [17]. A energia de gap relativamente pequena permite uma excitação de elétrons da banda de menor energia (valência) para a banda de maior energia (condução) por meio de uma excitação térmica ou ótica. Então, uma cosequência desta diferença de energia de gap entre semicondutores e isolantes, conduzirá à uma diferença no número de elétrons disponíveis para a condução. Quando o elétron é excitado para a banda de condução, o elétron deixa um défict na banda de valência. Essa ausência é denominada buraco. Portanto, o buraco terá carga positiva.

Em metais, a banda de condução está parcialmente ocupada. Isso ocorre para um número ímpar de elétrons. É esperado pela estrutura de banda metálica da figura 2.4 (c), que metais possuam elevada condutividade elétrica.

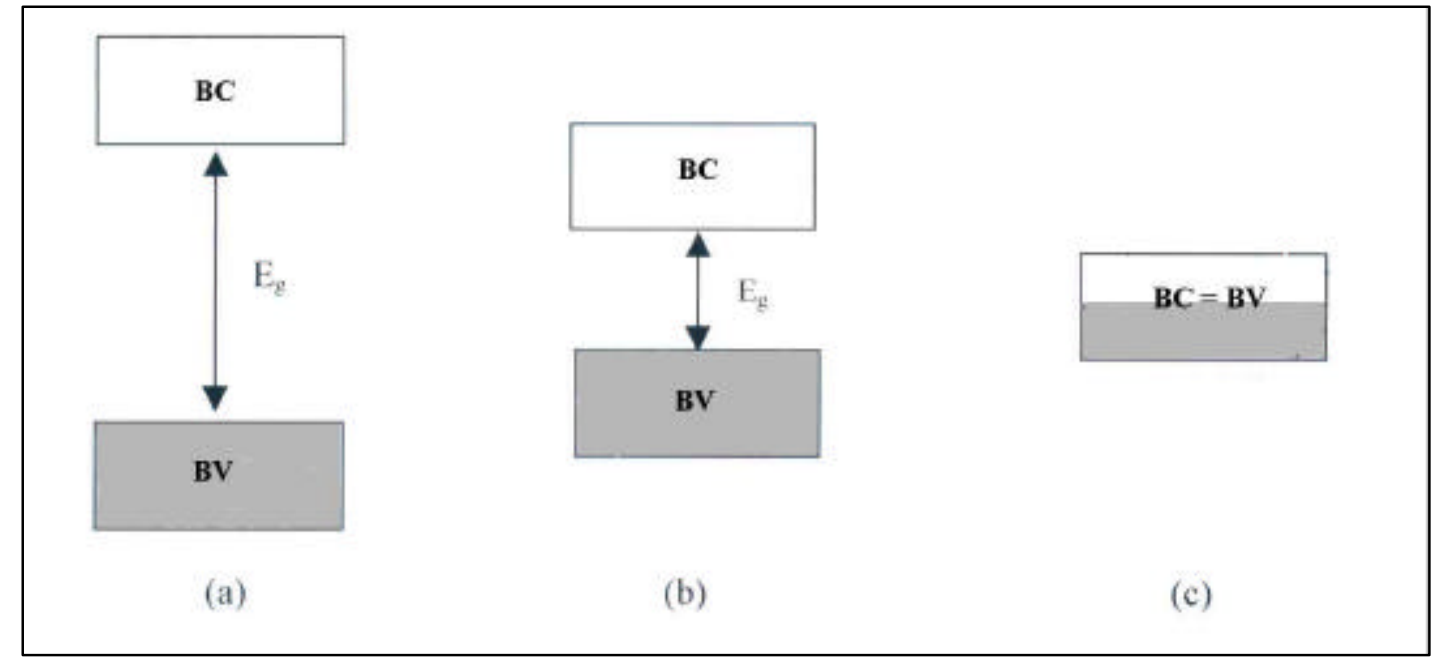

Figura 2.4: Estruturas típicas de bandas para (a) isolante, (b) semicondutor e (c) metal em 0 K. A cor cinza significa que a banda está ocupada.

\subsubsection{Gap direto e indireto}

Assumindo-se que um único elétron viaje por uma rede periódica perfeita. A função de onda do elétron é assumida como sendo o movimento de uma onda plana, na direção $x$ com constante de propagação $k$, também denominado vetor de onda. A dependência espacial da função de onda para o elétron é descrita pelo teorema de Bloch, conforme equação 2.1 


$$
\Psi_{k}(x)=U\left(k_{x}, x\right) e^{j k_{x} x}
$$

onde a função $U\left(k_{x}, x\right)$ modula a função de onda de acordo com a periodicidade da rede.

Calculando as bandas (esse cálculo foge da abordagem da tese), pode-se graficar valores de energia vs. a constante de propagação $k$. As figuras 2.5 (a), (b) e (c) ilustram as estruturas de bandas de energia do germânio $(\mathrm{Ge})$, do silício ( $\mathrm{Si})$, e do arseneto de gálio (GaAs), respectivamente.

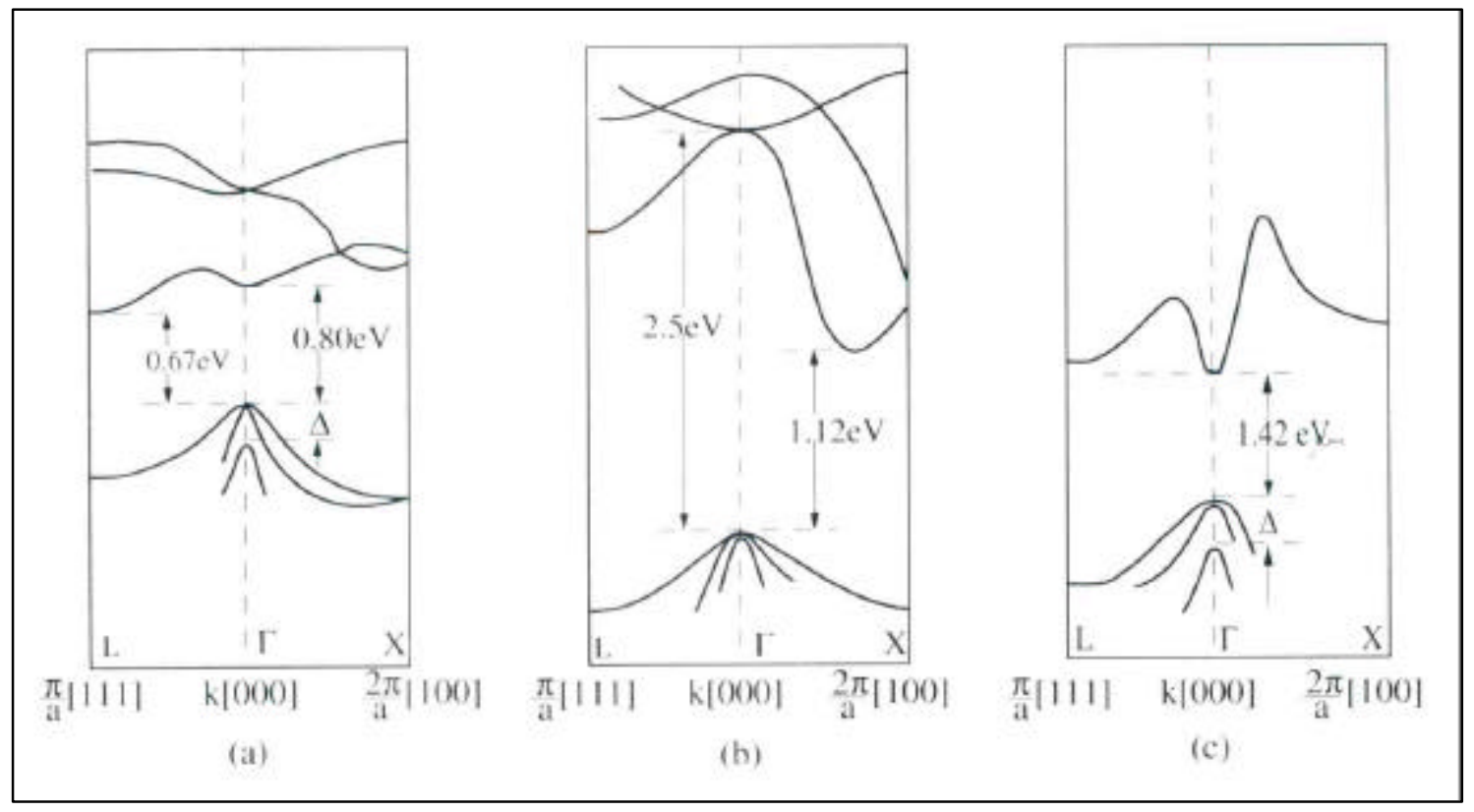

Figura 2.5: Diagramas ilustram a variação de energia do elétron no (a) Ge, (b) Si e (c) GaAs na direção do espaço $k$.

Como a periodicidade na maioria das redes é diferente em várias direções, o diagrama $(\mathrm{E}, \mathrm{k})$ pode ser graficado para várias direções do cristal. No silício o máximo da banda de valência ocorre em $k=0$, o ponto $\Gamma$ da zona de Brillouin. $O$ topo da banda de valência é tomado como referência na escala de energia, i.e. $E=0$. O mínimo da banda de condução ocorre num vetor de onda $k \neq 0$ na direção [100], próximo ao ponto $X$ na fronteira da zona de Brillouin, com energia $1.12 \mathrm{eV}$. Este é então o valor do gap de energia do silício. Semelhante ao silício, o germânio possui energia de gap de $0.67 \mathrm{eV}$. Conforme figura 2.5 (c), pode-se notar que o mínimo da banda de condução ocorre para o mesmo vetor de onda, $k=0$, que o máximo da banda de valência, sendo o valor do gap de 1.42 eV. Dessa maneira, o elétron realiza uma transição a partir da banda de condução para a banda de valência. No GaAs a transição ocorre sem variar o valor de $k$, por outro 
lado, a transição a partir do ponto mínimo na banda de condução do silício para o ponto máximo na banda de valência requer alguma mudança em $k$. Assim, existem duas classes de gaps de energia em semicondutores: direto e indireto, que estão mostrados na figura 2.6.

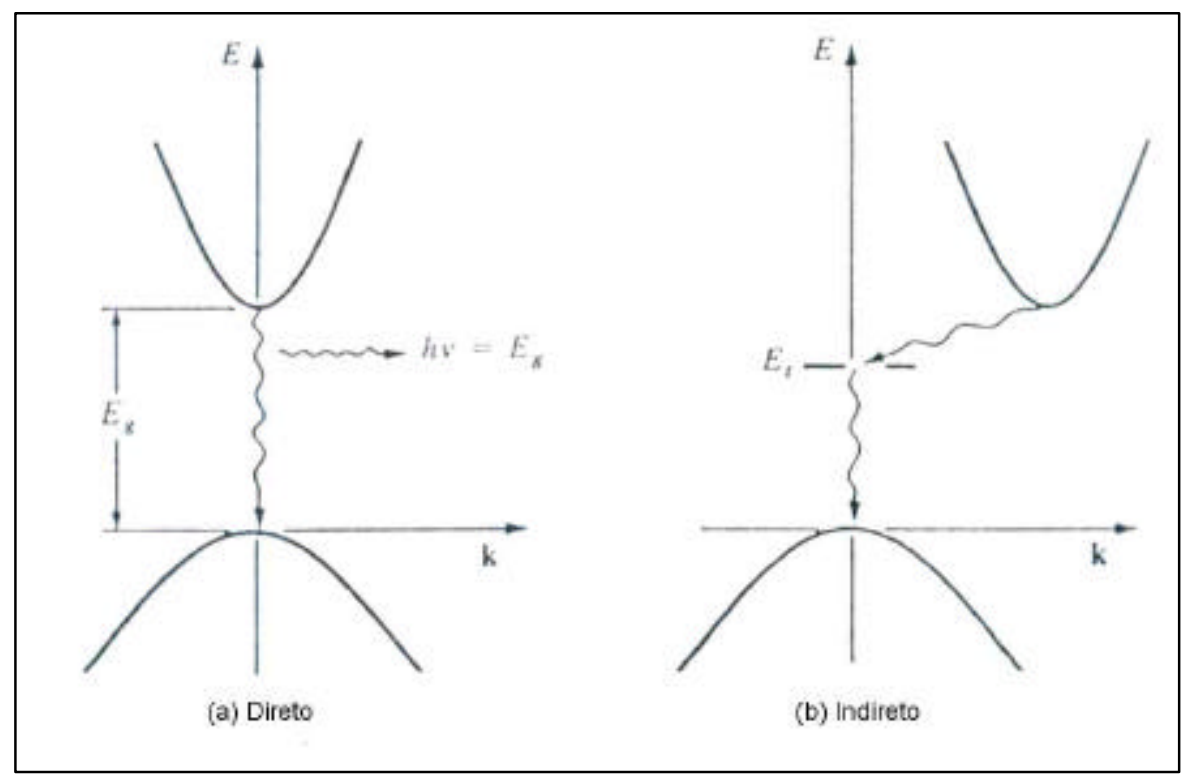

Figura 2.6: Transições de elétrons em semicondutores direto e indireto. (a) transições direta acompanhada da emissão de um fótom. (b) transição indireta via nível de defeito.

A transição indireta, implica numa variação em $k$, requerida pela variação de momentum para o elétron. É possível então, ter uma transição através do gap com a emissão, ou absorção de um fóton, desde que acompanhada da emissão ou absorção de um fônon. Como a transição em semicondutores de gap indireto envolve fônons e fótons, a probabilidade de emissão ou absorção de fótons é muito menor que no caso de gap direto. Por esta razão é preciso utilizar semicondutores de gap direto para comunicação óptica [18].

\subsection{Dopagem}


Impurezas introduzidas intencionalmente no material, também denominadas dopantes, podem ser introduzidas durante o crescimento epitaxial. Semicondutores com impurezas são denominados extrínsecos. Através da dopagem é possível fazer com que o número de elétrons seja maior que o número de buracos, ou vice-versa. Os semicondutores com predominância de elétrons são chamados tipo $n$, enquanto que os de maior concentração de buracos são do tipo $p$.

O mecanismo de dopagem utilizado pela técnica MOVPE é a adsorção. Os átomos de impureza desejada são provenientes de uma fonte, como brometo de carbono $\left(\mathrm{CBr}_{4}\right)$ no caso de carbono, que adsorve na superfície de crescimento. Assim, a impureza vai sendo incorporada. Este processo é realizado numa câmara de reação, onde o material e o gás que fornece a impureza são aquecidos numa determinada temperatura. A profundidade da camada superficial que fica dopada e a concentração de impurezas dependem de inúmeros fatores, dentre os mais importantes podemos citar a temperatura, o tempo de exposição e o fluxo do dopante.

\subsubsection{Elementos dopantes}

Os elementos dopantes utilizados em semicondutores III-V podem ser subdivididos em: (a) dopantes do grupo IIa, (b) dopantes do grupo IIb, (c) Dopantes do grupo IV e (d) dopantes do grupo VI.

\section{a) Dopantes do Grupo IIa}

Impurezas do grupo IIa incluem berílio $(\mathrm{Be})$, magnésio $(\mathrm{Mg})$, cálcio $(\mathrm{Ca})$, bário (Ba) e rádio $(\mathrm{Ra})$. Os elementos próximo ao fundo da coluna IIa possuem elevado raio atômico, por conseguinte não é esperada uma fácil incorporação em semicondutores IIIV. Os elementos próximos ao topo da coluna são incorporados nos sítios dos cátions dos semicondutores III-V. Os átomos de impureza do grupo IIa possuem dois elétrons na sua camada de valência, i.e. um elétron a menos que o cátion que substitui. 


\section{b) Dopantes do grupo IIb}

Impurezas do grupo IIb incluem zinco $(\mathrm{Zn})$, cádmio $(\mathrm{Cd})$ e mercúrio $(\mathrm{Hg})$. O mercúrio possui elevada pressão de vapor, portanto é muito volátil. Um baixo coeficiente de incorporação é esperado para a incorporação de mercúrio [19]. O zinco é um aceitador raso em semicondutores III-V com elevada atividade elétrica. A dopagem com zinco é usualmente empregada no crescimento pela técnica MOVPE.

\section{c) Dopantes do grupo IV}

As impurezas do grupo IV, são carbono (C), silício (Si), germânio (Ge), estanho $(\mathrm{Sn})$ e chumbo $(\mathrm{Pb})$. O último elemento possui um elevado raio atômico e portanto não é esperado uma incorporação fácil em semicondutores III-V. As impurezas restantes do grupo IV, i.e. C, $\mathrm{Si}, \mathrm{Ge}$ e $\mathrm{Sn}$ partilham quatro características chaves que serão descritas a seguir. Primeiramente, todas as impurezas do grupo IV são anfotéricas, i.e. podem ocupar os sítios do grupo III ou do grupo $\mathrm{V}$ do cristal zincblend. Como resultado, as impurezas do grupo IV são doadoras ou aceitadoras para a ocupação no sítio do cátion ou no sítio do ânion, respectivamente. Segundo, as impurezas do grupo IV podem levar à autocompensação, como resultado da anfotericidade. Considere a impureza da coluna IV que possui uma predominância de ocupação do sítio do cátion, i.e. é um doador. Se algum átomo de impureza ocupar um sítio do ânion, i.e. sítio aceitador, então esse aceitador compensará parcialmente o doador, resultando numa redução na concentração de portadores livres. Desde que as mesmas espécies causem a compensação, o fenômeno é denominado autocompensação. Terceiro, a atividade elétrica satura com o aumento na concentração de impurezas. Juntamente com o aumento na concentração de dopagem a tendência das impurezas do grupo IV é aumentar a autocompensação e finalmente conduzir à saturação na concentração de portadores livres. Quarta, a concentração de portadores livres depende da temperatura de crescimento e da taxa de fluxo V/III durante o crescimento epitaxial em MOVPE. Característica essa, comum à incorporação de todos os dopantes.

\section{d) Grupo VI}


As impurezas do grupo VI incluem oxigênio (O), enxofre (S), selênio (Se), telúrio (Te) e polônio (Po) e são denominadas calcogênios. Polônio possui um elevado raio atômico, por conseguinte sua fácil incorporação não é esperada. O oxigênio forma níveis profundos em GaAs $[20,21]$. A incorporação de oxigênio em qualquer semicondutor IIIV deve ser evitada. As impurezas restantes do grupo VI, S, Se e Te, são úteis, ocupam o sítio do ânion em semicondutores III-V e são doadores rasos. Doadores do grupo VI não são anfotéricos.

Todas as impurezas do grupo VI possuem elevada pressão de vapor. A pressão de vapor diminui juntamente com o aumento do número atômico. Portanto, S possui a maior e Te a menor pressão de vapor entre os três elementos. Como consequência da elevada pressão de vapor, as impurezas do grupo VI tendem a reevaporar a partir da superfície epitaxial.

\subsubsection{Aspectos da dopagem}

A incorporação e ativação de impurezas é governada por um determinado número de leis físicas e químicas. É essencial a compreensão das mesmas, para predizer o comportamento dos dopantes. A incorporação de muitas impurezas depende, entre muitos fatores, principalmente da temperatura de crescimento epitaxial e da razão de fluxo V/III. Conseqüentemente a atividade elétrica e a compensação dependem desses fatores. Com o objetivo de minimizar a autocompensação e obter elevadas concentrações de dopantes, é desejável que se conheça a dependência funcional da incorporação da impureza anfotérica. Outro exemplo de característica de impurezas é a eficiência de dopagem, definida como a proporção da concentração de portadores livres e da concentração de dopantes. Denominamos dopagem ideal quando a eficiência de dopagem é unitária. Entretanto, pode ser muito pequena. Obter uma elevada concentração de dopantes tem se tornado muito atrativo em semicondutores III-V [22].

Os dopantes podem ser incorporados em semicondutores por meio de diversas técnicas incluindo, (i) dopagem durante o crescimento epitaxial, (ii) dopagem por implantação e (iii) dopagem por difusão. Nesta presente tese será tratada a dopagem durante o crescimento. 


\subsubsection{Incorporação de dopantes durante o crescimento}

A incorporação de impurezas dopantes durante o crescimento depende da natureza do método de crescimento epitaxial. A incorporação de dopantes é completamente diferente para as duas técnicas mais proeminentes de crescimento eiptaxial, ou seja, molecular-bem epitaxy (MBE) e organometallic vapor-phase epitaxy (MOVPE). A incorporação de dopantes no MOVPE é regida pelas leis químicas e termodinâmicas da dopagem e do processo de crescimento. No MBE, a incorporação de dopantes é principalmente controlada pela cinética, como exemplo, taxa de impurezas que chegam à superfície, taxa de reevaporação, etc. A lei de ação das massas é útil para avaliar e predizer a tendência de incorporação de impurezas. Considere a reação química, onde os reagentes iniciais são $A$ e $B$ e os produtos da reação são $C$ e $D$

$$
A+B \rightarrow C+D
$$

onde $A, B, C$ e $D$ podem ser elementos ou compostos. Quando ocorre a reação química apresentada em 2.2, a uma certa temperatura e a uma certa pressão, os reagentes formam os produtos, e a entalpia ( $\Delta H$ ) e a entropia ( $\Delta S$ ) variam. Essas variações da entalpia e entropia provocam variação da energia livre $\Delta G$, dada pela equação 2.3 .

$$
\Delta G=\Delta H-T \Delta S
$$

onde a entalpia pode ser reescrita como:

$$
\Delta H=\sum \Delta E+P \Delta V
$$

onde $P$ e $V$ são a pressão e o volume para o sistema e $P \Delta V$ é o trabalho realizado no sistema. Exemplos de contribuições que variam a energia interna ( $\Delta E$ ) são: (i) energia de ligação química, (ii) energia eletrostática e magnetostática, (iii) energia eletrônica e (iv) energia elástica. Para a incorporação de impurezas em semicondutores, a energia elástica pode ser importante, especialmente se a impureza possui tamanho diferente em comparação ao átomo que substitui. A entropia está relacionada à desordem do sistema. Boltzmann relacionou a entropia, $S$, a uma grandeza, $W$, denominada de parâmetro de desordem:

$$
S=k \ln W
$$

Nesta expressão, $k$ é a constante de Boltzmann. 
Considere a reação química na equação (2.2), a mudança na energia livre total é dada pela equação (2.3), pela lei da ação das massas obtemos:

$$
\frac{[C][D]}{[A][B]}=K=c e^{-\frac{\Delta G}{k T}}
$$

onde os parênteses [...] representam a concentração dos compostos e $K$ é a constante de equilíbrio. A lei de ação das massas será aplicada para compreender a incorporação de impurezas durante o crescimento epitaxial.

As impurezas são idealmente incorporadas em sítios substitucionais. Qualquer incorporação na forma de complexos, ou em sítios interticiais são indesejáveis. Considerando que a incorporação resulte em apenas sítios substitucionais, como exemplo, consideremos que uma impureza $I$ seja incorporada em GaAs, predominantemente em sítios substitucionais de As $\left(\mathrm{I}_{\mathrm{As}}\right)$, devemos também considerar uma segunda possibilidade, de que a impureza seja incorporada em sítio intersticial $\left(\mathrm{I}_{\text {Int }}\right)$ e desprezar as outras possibilidades. Logo, a reação atômica pode ser escrita na forma:

$$
\text { Int }+I_{A s} \leftrightarrow I_{\text {Int }}+V_{A s}
$$

onde Int e $V_{A s}$ representam o sítio intersticial sem a incorporação da impureza e a vacância de As, respectivamente. Aplicando a lei da ação das massas na equação 2.7, obtemos

$$
\frac{\left[I_{\text {Int }}\right]\left[V_{A s}\right]}{\left[I_{A s}\right][\text { Int }]}=c e^{-\Delta E / K T}
$$

A concentração de sítios intersticiais no cristal, [Int], é muito elevada e não é alterada significantemente se algumas impurezas ocuparem sítios intersticiais. Podemos rescrever 2.8 como:

$$
\frac{\left[I_{I n t}\right]}{\left[I_{A s}\right]}=\left[V_{A s}\right]^{-1} c^{*} e^{-\Delta E / K T}
$$

onde $c^{*}=c[$ Int $]$ é uma constante.

Duas importantes conseqüências podem ser deduzidas da equação 2.9. Primeiro, para a incorporação de impurezas predominantemente em sítios de As, elevada concentração de vacâncias de As é vantajoso. Isto pode ser conseguido com uma baixa razão de fluxos V/III, ou seja, a baixa razão de fluxos V/III é vantajoso para a incorporação de $I$ que ocupa o sítio do ânion. Por outro lado, alta razão de fluxos V/III 
pode ser vantajoso para e.g. Zn e Si que ocupam sítios cátion. Para posteriores efeitos de simplificação, consideramos a impureza intersticial eletricamente inativa.

A segunda consequência da equação 2.9, diz respeito à dependência da temperatura na incorporação. A equação 2.9 prediz que:

$$
\frac{\left[I_{I n t}\right]}{\left[I_{A s}\right]} \propto \exp ^{-\Delta E / K T}
$$

onde $\Delta E$ é a variação de energia livre na reação 2.7. Para maximizar a concentração de impurezas é desejável uma elevada $\left[I_{A s}\right]$, conseqüentemente uma menor temperatura de crescimento. Em temperaturas baixas, o termo exponencial $\exp (-\Delta E / K T)$ é pequeno; i.e. a concentração de impurezas no sítio da As, $\left[I_{A s}\right]$, é elevada. Analisando para temperaturas de crescimento elevadas, o que realmente é impraticável por determinadas razões, nessas temperaturas o termo exponencial $\exp (-\Delta E / K T)$ é aproximadamente um; i.e. a concentração de átomos de impureza intersticiais é elevada.

No caso de uma impureza anfotérica, como exemplo, carbono em GaAs, a reação é escrita na forma:

$$
C_{G a}+V_{A s} \leftrightarrow C_{A s}+V_{G a}
$$

onde $C_{G a}$ e $C_{A s}$ representam o carbono no sítio do gálio (doador) e no sítio do arsênio (aceitador), respectivamente; $V_{A s}$ e $V_{G a}$ representam vacâncias de As e Ga, respectivamente. Esse efeito conforme discutido anteriormente, é denominado autocompensação. A taxa de autocompensação ou a anfotericidade, é definida como a razão entre a concentração de carbono aceitador e a concentração de carbono doador, i.e. $\left[C_{A s}\right] /\left[C_{G a}\right]$. Posteriormente, a anfotericidade será representada por $\left[C_{V}\right] /\left[C_{I I I}\right]$. Aplicando a lei da ação das massas, obtemos

$$
\frac{\left[C_{A s}\right]\left[V_{G a}\right]}{\left[C_{G a}\right]\left[V_{A s}\right]}=c e^{-\Delta E / K T}
$$

A equação 2.12, possui dois termos com dependência da temperatura, sendo um $\left[V_{A s}\right] \mathrm{e}$ o outro o termo exponencial. Ambos os termos aumentam exponencialmente para temperaturas elevadas. Considerando a taxa de reevaporação do $\mathrm{Ga}$ pequena, podemos assumir que para um determinado intervalo de temperatura $\left[V_{G a}\right]$ é constante. Desta maneira, pela dependência da temperatura de $\left[V_{A s}\right]$ e do termo exponencial, resulta num aumento da autocompensação para temperaturas de crescimento elevado [23-25]. Baixas 
temperaturas de crescimento são de extrema importância para obter elevadas concentrações. Estudos mais detalhados foram apresentados por G. B. Stringfellow et al [26-28]. 


\section{Técnica de crescimento e detalhes experimentais}

\subsection{MOVPE}

Metalorganic vapor-phase epitaxy (MOVPE), também denominada metal-organic chemical vapor deposition (MOCVD), é uma importante técnica de crescimento de heteroestruturas, poços quânticos e superredes. Lasers com baixa corrente de limiar e eficientes fotodetectores são exemplos de dispositivos fabricados com camadas crescidas pela técnica MOVPE. MOVPE é muito usada na fabricação de dispositivos optoeletrônicos, que utilizam estruturas de multicamadas.

A técnica de crescimento epitaxial realiza-se a partir de organometálicos e hidretos como precursores do grupo III e do grupo IV, respectivamente. Trimetil-alumínio (TMAl), trimetil-índio (TMIn), trimetil-gálio (TMGa) e arsina $\left(\mathrm{AsH}_{3}\right)$ são exemplos de fontes utilizadas na técnica MOVPE. Historicamente, o desenvolvimento da técnica MOVPE começou com o pionerismo de Manasevit na década de 60 [29, 30].

Dispositivos de boa qualidade foram crescidos no final da década de 70 [31]. Atualmente, o esforço associado ao desenvolvimento da técnica MOVPE, está centralizado em aumentar sua produtividade [32].

O fluxo viscoso de gases no sistema MOVPE necessita que a câmara de reação tenha um formato suave, i.e., não possua "cantos" e defeitos. A figura 3.1 mostra uma típica câmara de reação num sistema MOVPE. As paredes da câmara de reação são de quartzo, livre de cantos e defeitos, a fim de possibilitar um fluxo de gás laminar. A câmara de reação contém um susceptor. Os requisitos para um susceptor são: (i) baixa pressão de vapor com o objetivo de evitar incorporação do material do susceptor no processo de crescimento e (ii) alta condutividade elétrica e térmica. O grafite é frequientemente usado como material susceptor. A alta condutividade térmica do susceptor é desejável a fim de obter uma distribuição homogênea de calor na área do susceptor. 


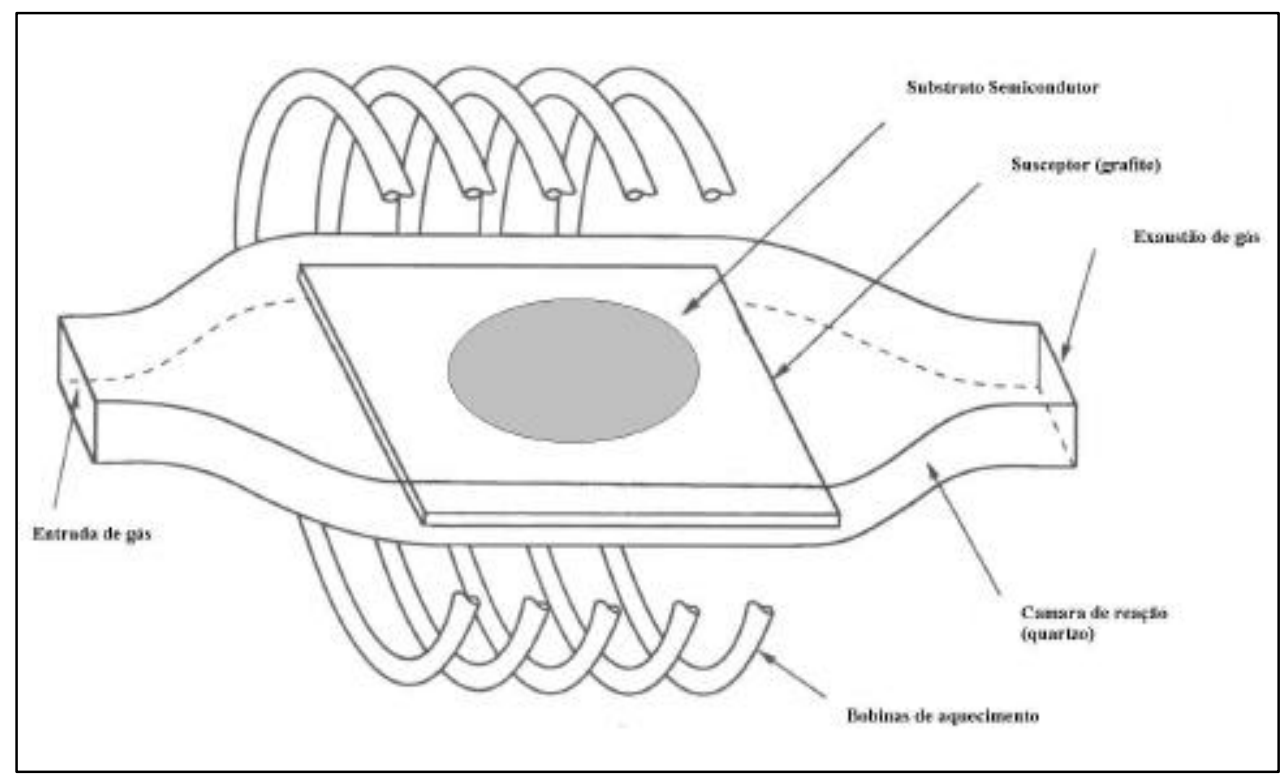

Figura 3.1: Ilustração esquemática de uma câmara de crescimneto do sistema MOVPE.

O susceptor é aquecido por indução de rádio freqüência (rf) conforme indicado na figura 3.1. Para induzir corrente no susceptor, este deve ser condutivo. A indução de calor é fornecida por uma bobina em volta da câmara de radiação. A bobina gera um campo de alta freqüência dentro da câmara de reação, gerando uma corrente induzida no susceptor aquecendo o substrato.

O fluxo laminar de gases dentro da câmara de reação é necessário a fim de evitar o efeito de memória.

O maior atrativo dessa técnica em comparação com outras técnicas é a sua versatilidade e habilidade para produção em larga escala. Tem-se mostrado a técnica mais econômica, particulamente para a produção de dispositivos que requerem grandes áreas, como, LEDs [33] e células solares [34]. Em geral, favoravelmente econômico, requer possibilidade de produção em larga escala, altas taxas de crescimento, uniformidade e reprodutibilidade do material.

Uma das desvantagens da técnica MOVPE em relação ao MBE (molecular beam epitaxy), é a não possibilidade de caracterização in-situ do material, ou seja, a possibilidade de caracterizar o material durante o seu crescimento [35]. A maior 
desvantagem da técnica de crecimento MOVPE é a utilização em grande quantidade de gases venenosos, como por exemplo a arsina $\left(\mathrm{AsH}_{3}\right)$ e a fosfina $\left(\mathrm{PH}_{3}\right)$ [36].

O reator MOVPE utilizado para o crescimento das amostras é um AIX 200 fabricado pela AIXTRON.

\subsection{SIMS}

Secondary ion mass spectrometry (SIMS), também conhecida como ion microscope e ion microprobe, é uma das técnicas analíticas mais poderosas e versáteis para análise de impurezas em semicondutores [37-40].

A representação esquemática do SIMS é ilustrada na figura 3.2. O feixe de íon primário colide na amostra e átomos são arrancados da mesma. Muitos desses átomos arrancados são neutros e não podem ser analisados, porém, uma pequena fração arrancada é composta por íons positivos e negativos. Essa fração foi estimada em $1 \%$ do total arrancado [41, 42]. A razão massa-carga (m/e) dos íons é detectada e analisada por um espectrômetro de massa, apresentando resultados por meio de números, gráficos, espectros ou imagens.

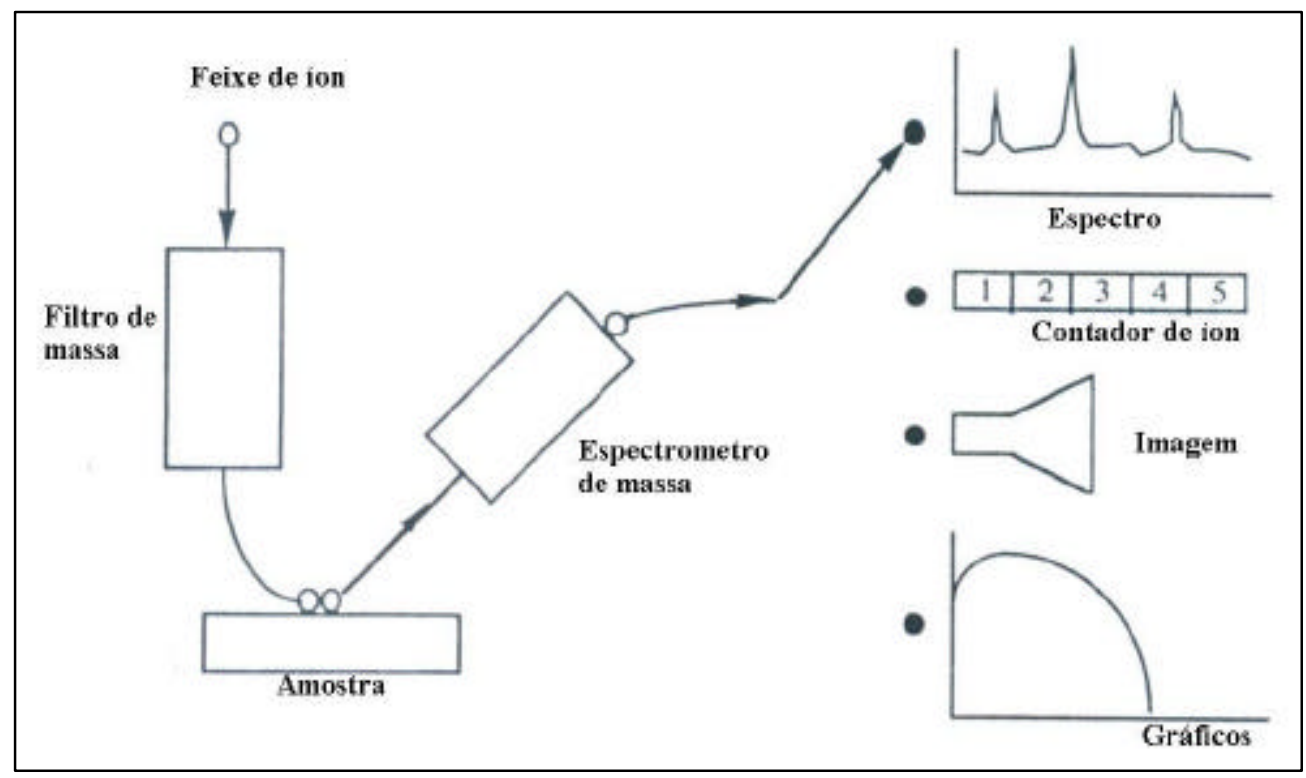

Figura 3.2: Respresentação esquemática da técnica de SIMS. 
SIMS possui uma boa sensibilidade para detectar muitos elementos. Dentre todas as técnicas de feixe é a de maior sensibilidade e pode detectar densidades de dopantes abaixo de $10^{15} \mathrm{~cm}^{-3}$. Permite detectar simultaneamente diferentes elementos. É uma técnica destrutiva, pois o feixe de íons provoca uma erosão superficial na amostra, ocasionando o surgimento de crateras. O SIMS determina a densidade atômica total de impurezas e não a atividade elétrica da densidade de impurezas. Para as medidas de SIMS, preparou-se referências de InAlAs dopadas com concentrações conhecidas de carbono (C) por implantação iônica no Departamento de Física da Universidade Federal do Rio Grande do Sul (UFRGS).

\subsection{Difração de raios-x}

A difração de raios-x de alta resolução é uma importante ferramenta não destrutiva na investigação de camadas epitaxiais binárias, ternárias, quaternárias, heteroestruturas, superredes e ligas.

Informações são obtidas por meio de linhas de difração que evidenciam a composição e a uniformidade das camadas epitaxiais, sua espessura, tensão interfacial e a perfeição cristalina. Além disso, pode-se obter informações a respeito da interface decorrente por exemplo da interdifusão.

A energia de um fóton é relacionada com o seu comprimento de onda $\lambda$ por $E=h v=h c / \lambda$, onde $\lambda$ é o comprimento de onda e $E$ é a energia em elétronvolt (eV). Para o estudo dos cristais, os fótons devem possuir energia no intervalo entre 10 e 50 $\mathrm{KeV}[43]$.

Os raios-x podem ser gerados tanto pela desaceleração dos elétrons num alvo metálico quanto pela excitação dos elétrons dos átomos do alvo. $\mathrm{O}$ primeiro processo fornece um espectro contínuo largo; o segundo fornece linhas acentuadas. Um alvo de cobre $(\mathrm{Cu})$ bombardeado por elétrons possui uma linha forte de $\mathrm{CuK}_{\alpha}$ em 1,54056 ̊̊ no centro do intervalo.

As ondas eletromagnéticas são espalhadas elasticamente por estruturas periódicas, por exemplo, estruturas de materiais semicondutores. A magnitude do vetor de onda 
incidente $\left(K_{i}\right)$ e espalhado $\left(K_{s}\right)$ são idênticos devido à natureza elástica do espalhamento, i.e.

$$
k_{\text {incidente }}=k_{\text {espalhado }}=\frac{2 \pi}{\lambda}
$$

onde $k$ é a magnitude do vetor de onda e $\lambda$ é o comprimento da onda eletromagnética. A reflexão total da radiação eletromagnética numa estrutura periódica é denominada reflexão de Bragg e ocorre para um comprimento de onda específico. A condição de Bragg para interferência construtiva é dada por

$$
n \lambda=2 d \operatorname{sen} \theta
$$

onde $\theta$ é o ângulo entre o vetor incidente e a superfície do cristal e $d$ é a distância entre dois planos atômicos paralelos de interesse. Freqüentemente, a reflexão de Bragg (004) é usada para determinar o parâmetro de rede.

A construção da esfera de Ewald correspondente é demostrada na figura $3.3 \vec{G}_{h k l}$ denota o vetor da rede recíproca, onde $h k l$ são os índices de Miller e $\omega$ o ângulo entre o vetor de onda incidente e a superfície.

$$
\vec{K}_{s}=\vec{K}_{i}+\vec{G}_{h k l}
$$

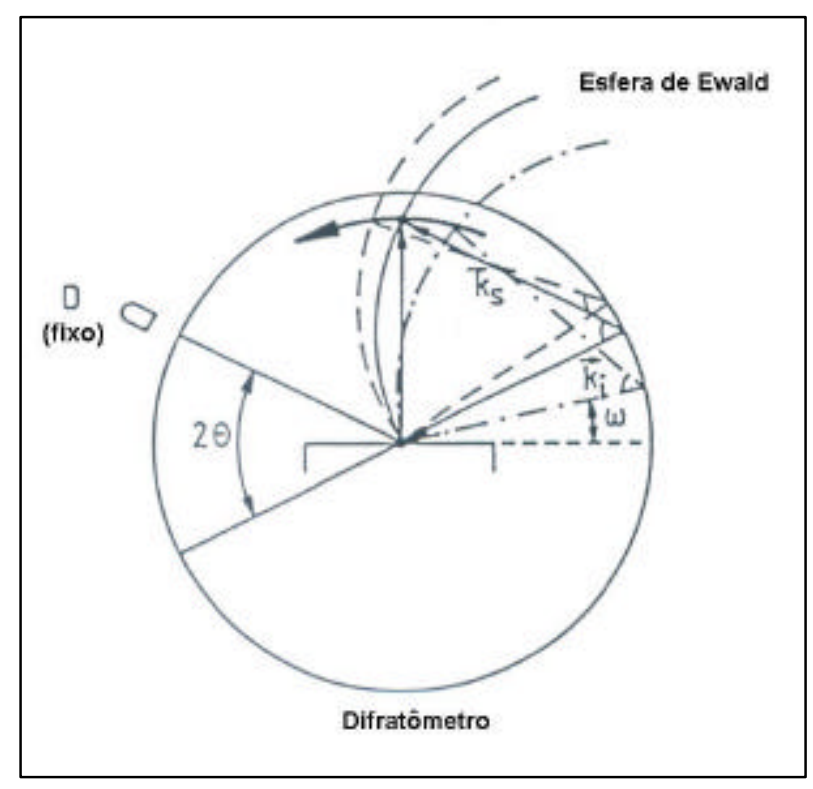

Figura 3.3: Construção da esfera de Ewald para uma varredura em $\omega$. 
A varredura para medir a intensidade de Bragg devido a um ponto $(h k l)$ na rede recíproca está indicado na figura 3.3. Numa varredura em $\omega$, o detector é fixo em uma posição e a amostra é girada, i.e. $\omega$ muda. No espaço recíproco, isto corrresponde ao caminho indicado pela seta sólida. Medindo-se a intensidade da reflexão de Bragg em função do ângulo $\omega$, obtemos a rocking-curve. É indispensável a presença de pelo menos um cristal monocromador na saída do tubo de raios-x, cortando a emissão $K_{\alpha 2}$ e aumentando a monocromacidade do feixe [44]. O monocromador, disposto na saída do tubo de raios-x é de GaAs (004). A posição desse cristal deve obedecer à geometria (+n,n) que é chamada de geometria de duplo cristal [44, 45], conforme figura 3.4. Ou seja, a radiação policromática ao colidir com o primeiro cristal (monocromador) é refletida conforme o ângulo de Bragg correspondente. O segundo cristal é posicionado na posição de Bragg equivalente $\left(-\theta_{B}\right)$, refletindo todos os comprimentos de onda, se orientado paralelamente ao primeiro, veja figura 3.4. Então na geometria $(+n,-n)$, a difração de raios-x é não dispersiva, isto é, raios-x com diferentes comprimentos de onda difratam num mesmo $\omega$.

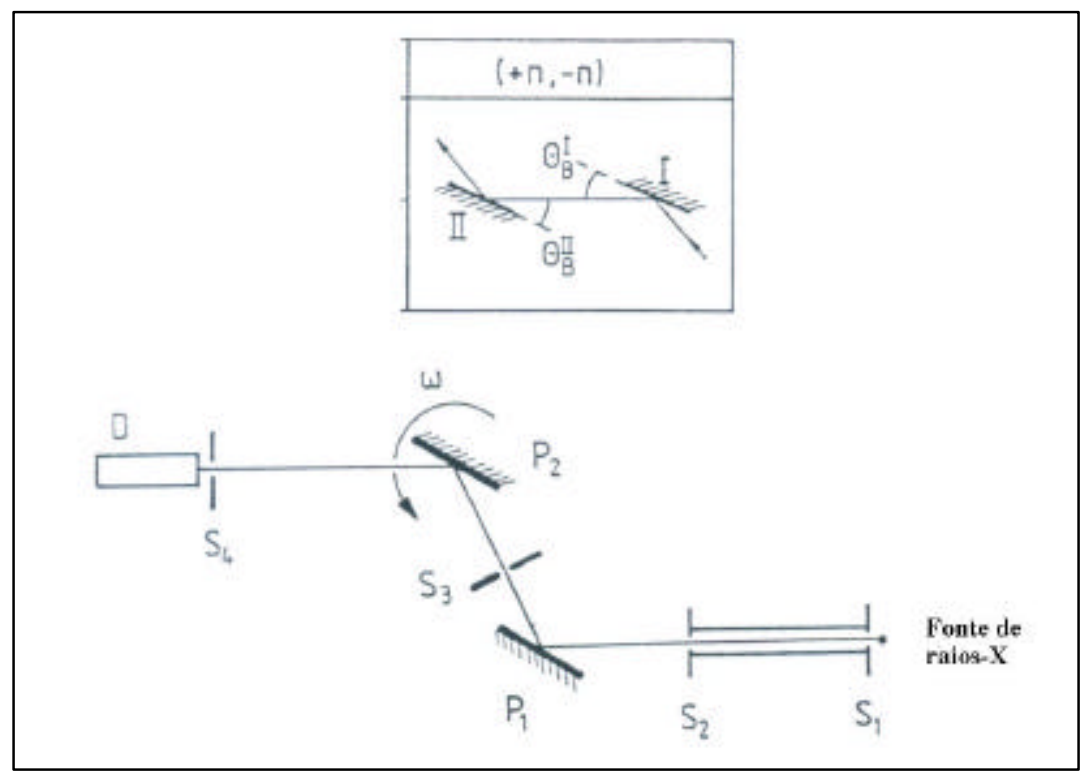

Figura 3.4: Geometria $(+n,-n)$ para Difratometria de Duplo-Cristal. $S_{1} \ldots S_{4}$ representam as fendas e $P_{1}$ e $P_{2}$ representam o cristal monocomador e a amostra respectivamente.

As medidas de raios- $x$ foram obtidas através de um difratômetro da Bede Scientific QC2a. 


\subsection{Efeito Hall}

Medidas por efeito Hall permitem determinar a concentração de portadores Hall (majoritários) num semicondutor. A concentração de portadores Hall difere de um fator numérico, $\mathrm{r}_{\mathrm{H}}$, denominado fator Hall.

Utilizou-se a técnica de van der Pauw. A geometria típica da técnica van der Pauw está ilustrada na figura 3.5. A amostra é cortada na geometria quadrada e os contatos metálicos pontuais são feitos nos quatro vértices do quadrado. Os contatos são feitos de índio-estanho (InSn) ou índio-zinco (InZn) para o caso de amostras tipo $n$ e tipo $p$, respectivamente.

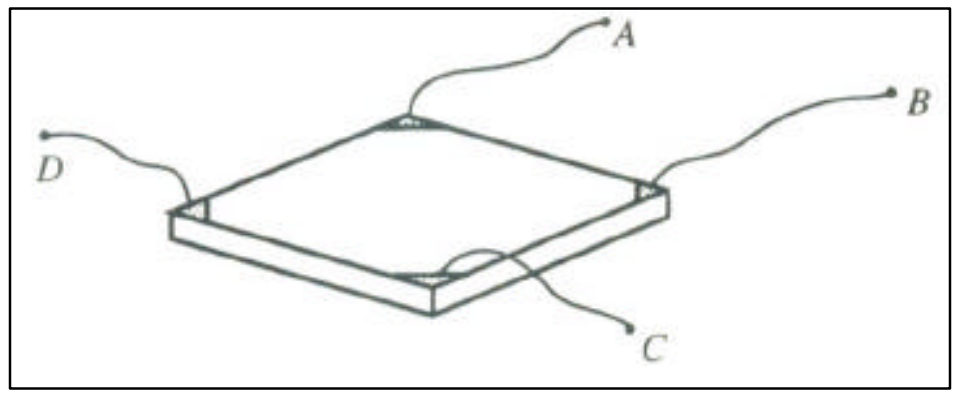

Figura 3.5: Geometria van der Pauw para medidas de efeito Hall em semicondutores.

Na medida de van der Pauw, a amostra é submetida a uma corrente constante de intensidade $I$, aplicada em dois contatos não adjacentes e a um campo magnético constante de intensidade $B$ perpendicular à superfície da amostra. Sobre os portadores livres atua uma força de Lorentz de magnitude

$$
F_{L}=(-e v) B
$$

onde $-e$ é a carga dos elétrons e $v$ é a velocidade dos portadores. Os portadores são desviados pela força Lorentz. Como resultado desse deslocamento, surgirá um campo elétrico denominado campo Hall. A intensidade da força Hall é dada por

$$
F_{H}=-e E_{H}
$$

O movimento de desvio dos portadores persiste até que a força de Lorentz seja balanceada com a força Hall. Equacionado as equações 3.4 e 3.5 obtemos a concentração de portadores 


$$
n_{H}^{2 D}=\frac{I B}{e V_{H}}
$$

onde $V_{H}$ é a voltagem Hall, e $n_{H}^{2 D}$ é a concentração de portadores em duas dimensões (2D), i.e. a concentração Hall por unidade de área. A concentração em três dimensões (3D) é obtida a partir da concentração $2 \mathrm{D}$.

$$
n_{H}=n_{H}^{3 D}=\frac{n_{H}^{2 D}}{t}
$$

onde $t$ é a espessura da amostra. O sinal de $V_{H}$ permite determinar o tipo de portador.

A verdadeira concentração de portadores e a concentração de portadores Hall está relacionada ao fator Hall, $r_{H}$, conforme

$$
n=r_{H} n_{H}
$$

onde

$$
r_{H}=\frac{\left\langle\tau_{m}^{2}\right\rangle}{\left\langle\tau_{m}\right\rangle^{2}}
$$

e $\tau_{m}$ é o tempo de relaxação do momentum, o qual depende da energia e $<\tau_{m}>$ é o valor esperado de $\tau_{m}$ para a temperatura ambiente. Para efeitos de simplificação o fator Hall é unitário, i.e. $n_{H}=n$.

O coeficiente Hall é dado por

$$
R_{H}=\frac{r_{H}}{e n}=\frac{1}{e n_{H}}
$$

Medidas de efeito Hall e de condutividade $(\sigma)$ permitem determinar a mobilidade dos portadores

$$
\sigma=e n \mu
$$

onde $\mu$ é a mobilidade que pode ser determinada se a condutividade e a concentração de portadores forem conhecidas. Reescrevendo,

$$
\mu_{H}=\frac{\sigma}{e n_{H}}
$$

onde $\mu_{H}$ é denominada mobilidade Hall.

As medidas do efeito Hall, foram realizadas no equipamento da Bio-Rad, modelo HL5500. 


\subsection{CV}

A técnica de CV (capacitância-voltagem) é uma segunda técnica de caracterização elétrica de materiais semicondutores. O perfil da técnica de CV [46-49] permite medir a concentração CV, [CV], em função da profundidade.

O princípio da medida consiste em colocar a amostra a ser analisada em contato com uma superfície bem definida de eletrólito e aplicar uma diferença de potencial na interface semicondutor-eletrólito. Numa medida CV eletro-química, o eletrólito faz o papel do metal, portanto, a junção é equivalente a um contato Schottky e as informações sobre a concentração CV são obtidas analisando a capacitância na zona de depleção.

O diagrama de banda para uma junção metal-semicondutor está ilustrado na figura 3.6.

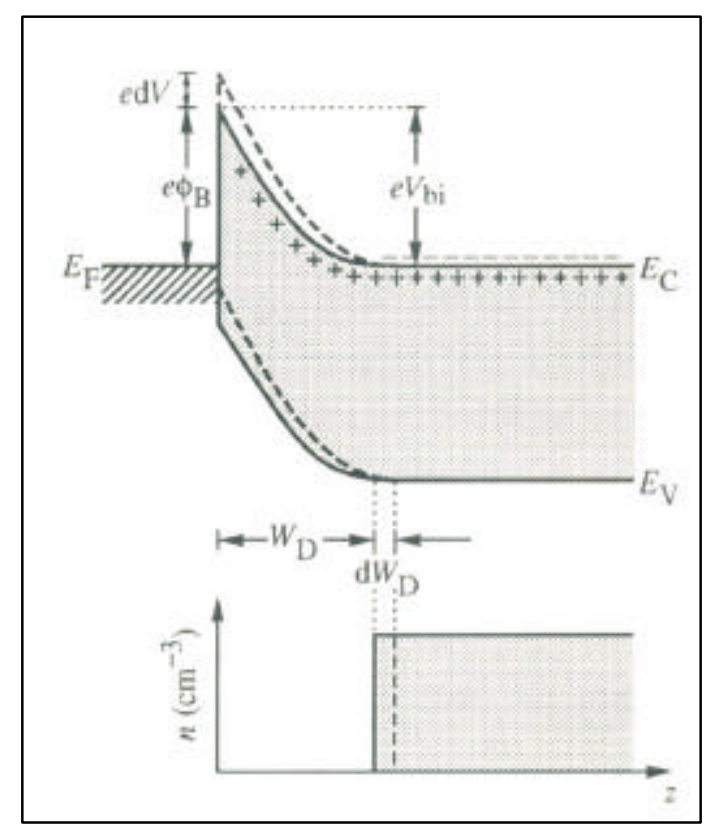

Figura 3.6: Diagrama de bandas e portadores livres próximo à região de depleção. Aplicando uma pequena voltagem $\mathrm{dV}$ a espessura da camada de depleção muda de $\mathrm{dW}_{\mathrm{D}}$.

A altura da barreira na junção é $\phi_{B}$. O semicondutor possui dopagem homogênea tipo $n$. A largura da região de depleção, é determinada pela resolução da equação de Poisson [19]. 


$$
W_{D}=\sqrt{\frac{e \varepsilon}{e N_{D}}\left(V_{b i}-V\right)} \cong \sqrt{\frac{e \varepsilon}{e N_{D}}\left(\phi_{B}-V\right)}
$$

onde $\varepsilon$ é a constante dielétrica do semicondutor, $V_{b i}$ é o potencial built-in da junção, $N_{D}$ é a densidade de doadores ionizados no semicondutor e $V$ é a voltagem externa aplicada ao diodo Schottky. Aplicando-se um incremento na voltagem, a largura da barreira aumenta de um valor

$$
d W_{D}=-\frac{1}{2} \sqrt{\frac{2 \varepsilon}{e N_{D}\left(\phi_{B}-V\right)}} d V
$$

A variação da concentração de cargas por unidade de área, $d Q$, na região de depleção é proporcional a um incremento na voltagem, $d V$, logo,

$$
d Q=e N_{D} d W_{D}
$$

A capacitância na região de depleção por unidade de área é definida como:

$$
C=\frac{d Q}{d V}=-\frac{1}{2} \sqrt{\frac{2 e \varepsilon N_{D}}{\phi_{B}-V}}=\frac{\varepsilon}{W_{D}}
$$

A concentração CV é então definida como:

$$
N_{C V}=-\frac{2}{e \varepsilon}\left[\frac{d C^{-2}}{d V}\right]^{-1}=\frac{C^{3}}{e \varepsilon} \frac{d V}{d C}
$$

Reescrevendo a concentração CV em função da área de contato da amostra com o eletrólito (A), obtemos

$$
N_{C V}=\frac{C^{3}}{e \varepsilon A^{2}} \frac{d V}{d C}
$$

A concentração $N_{C V}$ ocorre para uma determinada profundidade, $Z_{C V}$, definida por:

$$
Z_{c V}=\frac{\varepsilon A}{C}
$$

Realizou-se as medidas CV num equipamento de fabricação da Bio-Rad modelo PN4300. 


\subsection{Fotoluminescência}

A fotoluminescência investiga os processos de recombinação radiativa. Podemos classificá-los em intrínsecos e extrínsecos. O primeiro envolve transições que ocorrem entre a banda de valência e a de condução, e o segundo, transições que envolvem pelo menos um nível de energia situado no gap.

Elevada concentração de pares elétron-buraco fora do equilíbrio são excitados por uma fonte externa. O sistema de detecção consiste num monocromador e num detector. A técnica de Lock-In é usada para aumentar a taxa sinal-ruído do sistema de detecção.

As medidas de luminescência foram realizadas na montagem experimental ilustrada na figura 3.7.

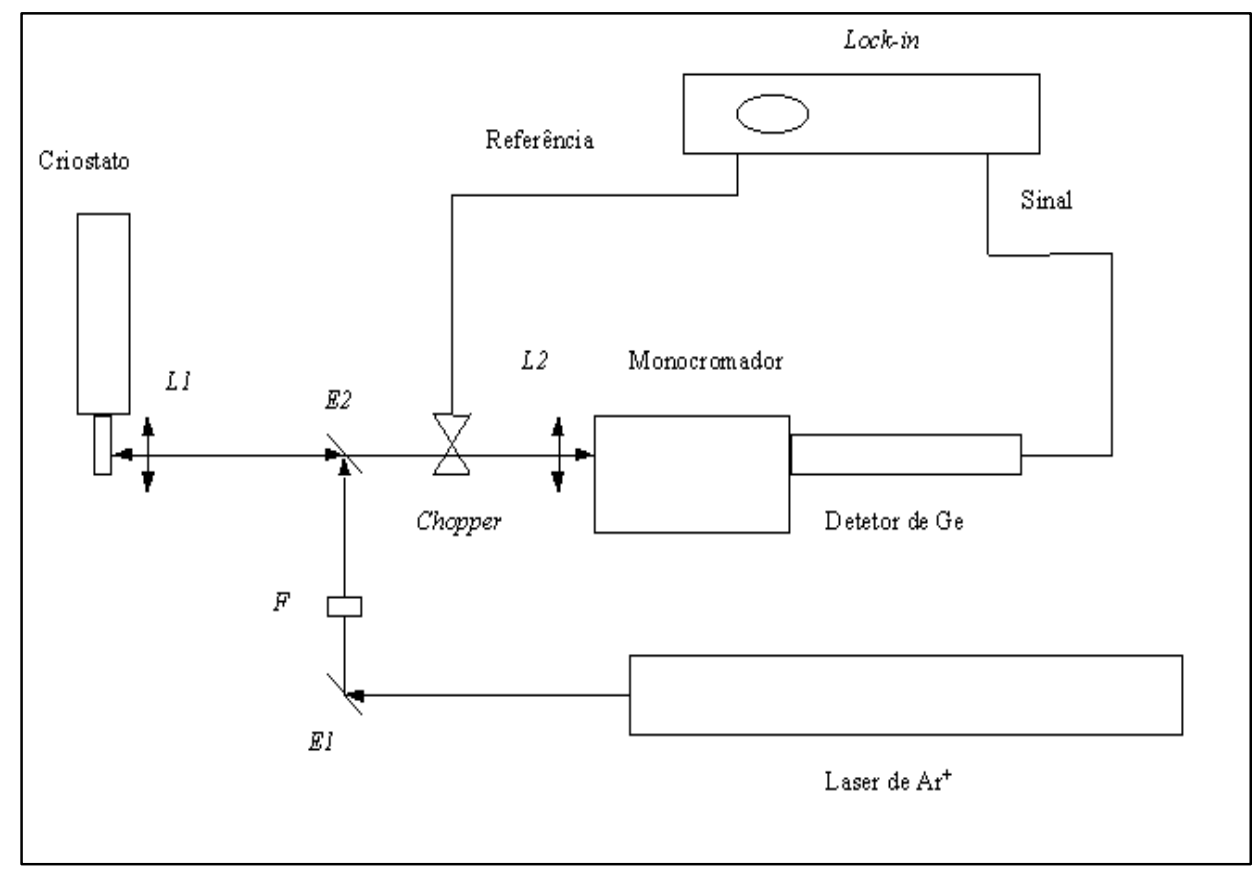

Figura 3.7: Ilustração esquemática da experiência de fotoluminescência.

A fonte de excitação utilizada foi um laser de argônio ( $\left.\mathrm{Ar}^{+}\right)$modelo 95, fabricado pela Lexel Laser. O comprimento de onda utilizado foi de $514 \mathrm{~nm}$. A variação de potência do laser é obtida através do controle da corrente. Pode-se utilizar filtros de densidade neutra para atenuar a intensidade do raio laser e variar a potência de excitação sobre a 
amostra. Na saída do laser, o feixe é desviado por espelhos planos de alta refletividade (E1). Após a reflexão nos espelhos, o feixe passa por um filtro interferencial (F) cuja finalidade é eliminar comprimentos de onda diferentes de $514 \mathrm{~nm}$, garantindo uma excitação essencialmente monocromática. Passando pelo filtro interferencial, o feixe incide num espelho dicróico (E2), ou seja, um espelho seletivo que possui alta refletância para os comprimentos de onda na região do espectro correspondente à excitação (verde) e alta transmissão para o infra-vermelho próximo, região de comprimento de onda emitido pela amostra. Refletido pelo espelho dicróico, o feixe é focalizado por uma lente planoconvexa de distância focal $80 \mathrm{~nm}$ na amostra (L1). A amostra está situada no interior de um criostato de ciclo fechado de hélio, de fabricação da Leybold modelo RDK 10-320, onde a temperatura pode ser variada numa faixa entre 13 e $300 \mathrm{~K}$.

A luminescência emitida pela amostra, percorre o mesmo caminho óptico que o feixe de excitação, é colimada por L1, sendo transmitida por meio de E2 para a segunda lente plano-convexa de distância focal $100 \mathrm{~nm}$, que focaliza a radiação proveniente da luminescência na fenda de entrada de um monocromador, utilizado para efetuar a análise espectral. O monocromador utilizado foi um Jobim Yvon H $250 \mathrm{~mm}$, com rede de difração de 600 linhas/mm e dispersão espectral de $60 \AA / \mathrm{mm}$ de abertura de fendas. A resolução depende da largura da fenda. Entre L2 e a fenda de entrada do monocromador, foi colocado um filtro passa alta (em comprimento de onda), com o objetivo de bloquear a passagem de excitação que é transmitida pelo espelho dicróico. Através de um motor de passo, o monocromador é acionado pelo computador. A detecção do sinal é obtida por um detector de germânio $(\mathrm{Ge})$ resfriado por nitrogênio líquido $\left(\mathrm{N}_{2}\right)$. Foi realizada a detecção síncrona com o objetivo de aumentar a relação sinal-ruído. Para isto, utilizamos um chopper mecânico cuja finalidade é modular o laser em onda quadrada em $150 \mathrm{~Hz}$. O sinal de referência do chopper é direcionado para a referência de um amplificador Lock-In.

A obtenção dos espectros é controlada por uma CPU utilizando um software desenvolvido no Labview. A aquisição de dados foi realizada por meio de um conversor A/D da Real Time device modelo AD5000. 
As transições radiativas observadas na fotoluminescência estão representadas na figura 3.8 .

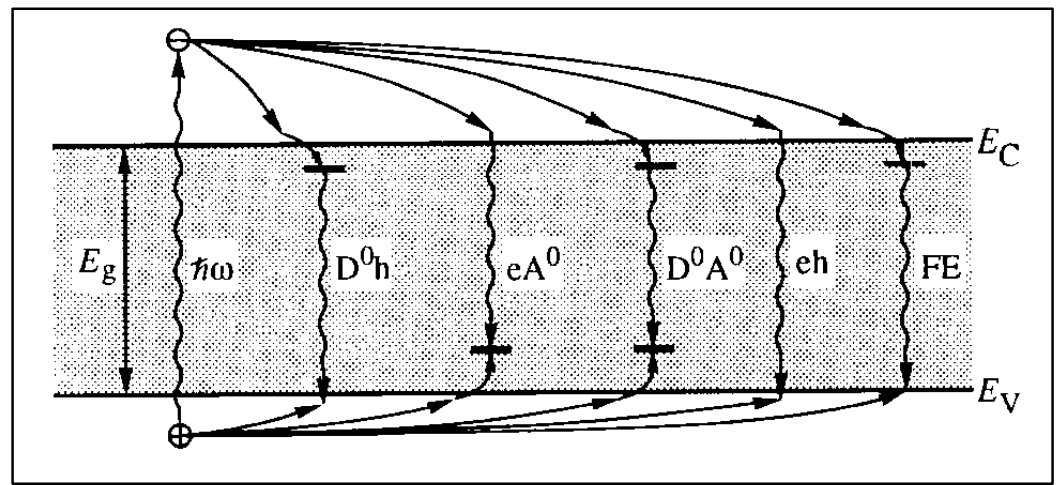

Figura 3.8: Esquema das transições radiativas em semicondutores de gap direto incluindo doador-buraco $\left(D^{\circ} h\right)$, elétron-aceitador $\left(e A^{\circ}\right)$, par doador-aceitador $\left(D^{\circ} A^{\circ}\right)$, banda-banda $(e h)$ e transições de excitons livres $(F E)$.

Elétrons são bombeados por uma radiação de excitação de energia $h v$ da banda de valência para a banda de condução. Para $h v>>E_{g}$, inicialmente os portadores terão elevada energia cinética, seguido de uma termalização rápida via óptica ou espalhamento acústico de fônon. As transições ópticas num semicondutor de gap direto ocorrem sem emissão de fônon.

\section{a) Banda-banda (eh)}

Esse tipo de recombinação envolve elétrons livres na banda de condução que recombinam juntamente com buracos livres na banda de valência. A recombinação bandabanda, ocorre predominantemente em temperaturas mais elevadas, como por exemplo, temperatura ambiente. A energia da transição banda-banda que ocorre numa temperatura finita é dada por:

$$
E_{e h}=E_{g}+\frac{1}{2} k T
$$

A distribuição da intensidade da recombinação $e h$ é obtida a partir da densidade de estados e da distruição de Fermi-Dirac [19] e é dada por: 


$$
I_{e h}(\hbar \omega) \propto \int_{E_{c}}^{\hbar \omega} \rho_{D o s, C}(E) F_{e}(E) \rho_{D o s, V}\left[1-F_{e}(E-\hbar \omega)\right] d E
$$

onde $\rho_{D O S}$ e $F_{e}$ é a densidade de estados e a distribuição da função de Fermi-Dirac e os subescritos $C$ e $V$ referem-se à banda de condução e valência respectivamente. Resolvendo a integral obtemos:

$$
I_{e h}(\hbar \omega) \propto(\hbar \omega)^{2}\left(\hbar \omega-E_{g}\right)^{1 / 2} \exp \left[\frac{-\left(\hbar \omega-E_{g}\right)}{k T}\right]
$$

a equação pode ser simplificada para $E_{g}>k T$

$$
I_{e h}(\hbar \omega) \propto\left(\hbar \omega-E_{g}\right)^{1 / 2} \exp \left[\frac{-\left(\hbar \omega-E_{g}\right)}{k T}\right]
$$

\section{b) Excitons livres (FE)}

Excitons são pares elétron-buraco ligados por uma interação coulombiana. A interação coulombiana é similar ao átomo de hidrogênio. Pares elétron-buraco ligados por interação coulombiana são denomindos excitons livres caso não interajam juntamente com outro centro qualquer. A energia de ligação de excitons livres pode ser obtida em analogia ao átomo de hidrogênio [19]

$$
E_{F E}=E_{g}-\frac{m_{r}^{*} e^{4}}{32 \pi^{2} \varepsilon^{2} \hbar^{2}}
$$

onde $\varepsilon$ é a permissividade do semicondutor e $m_{r}^{*}$ é a massa efetiva do sistema elétronburaco

$$
\frac{1}{m_{r}^{*}}=\frac{1}{m_{e}^{*}}+\frac{1}{m_{h}^{*}}
$$

$m_{e}^{*}$ e $m_{h}^{*}$ são respectivamente as massas efetivas dos elétrons e dos buracos. A emissão por recombinação de excitons livres só é observada em baixas temperaturas e em cristais de alta pureza. No caso de materiais menos puros, os excitons se ligam a defeitos e/ou impurezas, dando origem aos excitons ligados. Não apresentaremos maiores detalhes sobre excitons ligados, pois os mesmos não foram observados nas medidas realizadas. 


\section{c) Recombinação banda impureza-rasa}

As impurezas espacialmente delocalizadas que estão, no máximo, a $100 \mathrm{meV}$ de uma das bandas são ditas impurezas rasas [50]. As transições envolvendo impurezas rasas são doador-banda de valência $\left(D^{\circ} h\right)$ e banda de condução-aceitador $\left(e A^{\circ}\right)$. A energia dessas transições para $k T \cong 0$ é dada por:

$$
\begin{aligned}
& E_{D^{\circ} h}=E_{g}-E_{d} \\
& E_{e A^{\circ}}=E_{g}-E_{a}
\end{aligned}
$$

onde $E_{d}$ e $E_{a}$ são as energias de ionização do doador e do aceitador, respectivemente. Para uma temperatura finita, a energia do pico de transição aumenta de um fator $1 / 2 k T$ [51]

$$
\begin{aligned}
& E_{D^{\circ} h}=E_{g}-E_{d}+1 / 2 k T \\
& E_{e A^{\circ}}=E_{g}-E_{a}+1 / 2 k T
\end{aligned}
$$

A intensidade da transição $\left(D^{\circ} h\right)$ ou da $\left(e A^{\circ}\right)$ é determinada conforme a equação $3.27[51,52]$.

$$
I_{D^{\circ} h, e A^{\circ}}(\hbar \omega) \propto\left(\hbar \omega-E_{g}+E_{d, a}\right)^{1 / 2} \exp \left[\frac{-\hbar \omega-E_{g}+E_{d, a}}{k T}\right]
$$

Com o aumento da temperatura, as impurezas mais rasas se ionizam, favorecendo as impurezas menos rasas. Para temperaturas mais elevadas, onde todas as impurezas rasas estão ionizadas, é a transição banda-banda que predomina no espectro.

\section{d) Par doador-aceitador $\left(D^{\circ} A^{\circ}\right)$}

A transição par doador-aceitador ocorre em semicondutores com alta concentração de doadores e aceitadores residuais. A energia de uma transição doador-aceitador é determinada por:

$$
E_{D^{\circ} A^{\circ}}=E_{g}-E_{a}-E_{d}+\frac{e^{2}}{4 \pi \varepsilon r}
$$


onde $e^{2} / 4 \pi \varepsilon r$ é o termo coulombiano e $r$ é a separação espacial entre doadores e aceitadores e $\varepsilon$ a constante dielétrica. Os critérios para a identificação de uma transição $\left(D^{\circ} A^{\circ}\right)$ estão descritos a seguir. A probabilidade de transição $\left(D^{\circ} A^{\circ}\right)$ depende do recobrimento das funções de onda do elétron no doador e do buraco no aceitador. Assim, para pares mais próximos, a probabilidade de transição é maior, ou seja, o tempo de recombinação é menor. A partir deste argumento conclui-se que, com o aumento da potência de excitação, os pares mais distantes (mais lentos) saturam, favorecendo os pares mais próximos (mais rápidos). Em outras palavras, de acordo com a equação 3.29, à medida que a potência de excitação aumenta, o pico da emissão $\left(D^{\circ} A^{\circ}\right)$ se move na direção de mais altas energias e a largura a meia altura diminui.

\subsection{Tratamento térmico}

Átomos de hidrogênio provenientes da pirólise da molécula de arsina, são incorporados juntamente com átomos de carbono, levando à passivação dos mesmos [1]. Tratamentos térmicos podem ser usados com a finalidade de remover os átomos de hidrogênio e reestabelecer a atividade elétrica do carbono. Empregou-se a técnica face a face para realizar os tratamentos térmicos. A amostra é colocada num cadinho de grafite, tendo o seu fundo encoberto com pequenos pedaços de substrato de GaAs. Sobre um maior pedaço de substrato se coloca a amostra com sua face crescida voltada para cima. Sobre sua face crescida se coloca um pedaço maior, de modo a encobrir toda a amostra, juntamento com pequenos pedaços de substratos que tem por finalidade de manter uma atmosfera de arsina, evitando assim, a evaporação do arsênio e obter um gradiente homogêneo de temperatura no interior do mesmo. O cadinho é posto sobre uma barquinha, que é empurrada para o interior do tubo de quartzo. O tubo de quartzo é envolto por bobinas de aquecimento. A temperatura é monitorada através de um controlador de temperatura. Os tratamentos térmicos foram realizados nas temperatura de 500, 550, 600 e $700^{\circ} \mathrm{C}$ numa atmosfera de específica de mistura de hidrogênio e argônio $\left(10 \% \mathrm{H}_{2} / \mathrm{Ar}\right)$ com fluxo constante de $1 \mathrm{ml} / \mathrm{min}$ por um período de 15 minutos. 


\section{Resultados e discussão}

As amostras de $\operatorname{In}_{\mathrm{x}} \mathrm{Al}_{1-\mathrm{x}} \mathrm{As}$ não dopadas e dopadas com carbono foram crescidas em diferentes temperaturas $\left(\mathrm{T}_{\mathrm{g}}\right)$ numa faixa de $530^{\circ} \mathrm{C}$ a $650^{\circ} \mathrm{C}$. A tabela 4.1 , descreve as amostras analisadas na presente tese. Na tabela 4.1 a dopagem tipo delta significa que os átomos de carbono estão confinados numa região de cerca de uma a três monocamadas [53].

\begin{tabular}{cccccc}
\hline Amostra & Tipo de Dopagem & $\mathrm{T}_{\mathrm{g}}\left({ }^{\circ} \mathrm{C}\right)$ & Espessura $(\mu \mathrm{m})$ & Fluxo Carbono $(\mathrm{sccm})$ & Razão V/III \\
\hline$\# 349$ & não dopada & 650 & 0.67 & $* * *$ & 80.6 \\
$\# 350$ & não dopada & 650 & 0.67 & $* * *$ & 80.2 \\
$\# 353$ & homogênea & 650 & 0.6 & 15.56 & 80.2 \\
$\# 359$ & delta & 625 & $* * *$ & 28.97 & 80.4 \\
$\# 360$ & delta & 600 & $* * *$ & 28.97 & 80.4 \\
$\# 363$ & homogênea & 575 & 0.375 & 28.97 & 80.4 \\
$\# 364$ & homogênea & 550 & 0.375 & 28.97 & 81.5 \\
$\# 365$ & homogênea & 530 & 0.6 & 28.97 & 81.5 \\
$\# 366$ & não dopada & 530 & 0.575 & $* * *$ & 80.4 \\
\hline
\end{tabular}

Tabela 4.1: Condições de crescimento das amostras de $\operatorname{In}_{\mathrm{x}} \mathrm{Al}_{1-\mathrm{x}} \mathrm{As}$.

A temperatura de crescimento normalmente usada para $\operatorname{In}_{\mathrm{x}} \mathrm{Al}_{1-\mathrm{x}} \mathrm{As}$ é de $630^{\circ} \mathrm{C}$ [32]. Conforme descrito na seção 1, o carbono é preferencialmente um dopante tipo $p$ em semicondutores III-V, entretanto, observamos que para a temperatura de crescimento superiores a $575^{\circ} \mathrm{C}$, as camadas são do tipo $n$ e não do tipo $p$. Em princípio, dois diferentes fatores podem contribuir para este efeito: (i) o carbono é um dopante anfotérico e a probabilidade de ocupar sítios III ou V é dependente da temperatura e (ii) átomos de hidrogênio são incorporados juntamente com átomos de carbono, promovendo a passivação. Tratamentos térmicos foram realizados com o objetivo de remover os átomos de hidrogênio e reativar eletricamente os átomos de carbono. 


\subsection{Transporte}

A figura 4.1 ilustra a concentração bidimensional de cargas livres (Ns) obtida pela técnica Hall em função da temperatura de crescimento $\left(T_{g}\right)$ para as amostras não dopadas e dopadas homogeneamente, representadas por diamantes e círculos, respectivamente. Nas amostras com dopagem delta e $T_{g}$ de $625^{\circ} \mathrm{C}$ e $600^{\circ} \mathrm{C}$ a concentração $N s$ obtida é de $-8.93 \times 10^{11} / \mathrm{cm}^{2}$ e $-3.70 \times 10^{11} / \mathrm{cm}^{2}$, respectivamente. $\mathrm{Na}$ amostra crescida a $625^{\circ} \mathrm{C}, \mathrm{o}$ perfil de CV não revela a presença de uma delta e nem de cargas positivas. Por outro lado na amostra crescida a $600^{\circ} \mathrm{C}$ apesar do perfil não mostrar claramente uma dopagem planar, ele evidencia a presença de cargas positivas na região onde se pretendia crescer a delta. Então, é observada uma temperatura de transição de tipo $n$ para tipo $p$, ou seja, uma temperatura de crescimento na qual as amostras tipo $n$ passam a ser tipo $p$. Esta temperatura está entre $600^{\circ} \mathrm{C}$ e $625^{\circ} \mathrm{C}$.

Pode-se observar também na figura 4.1 que a concentração de buracos livres aumenta conforme a temperatura de crescimento diminui.

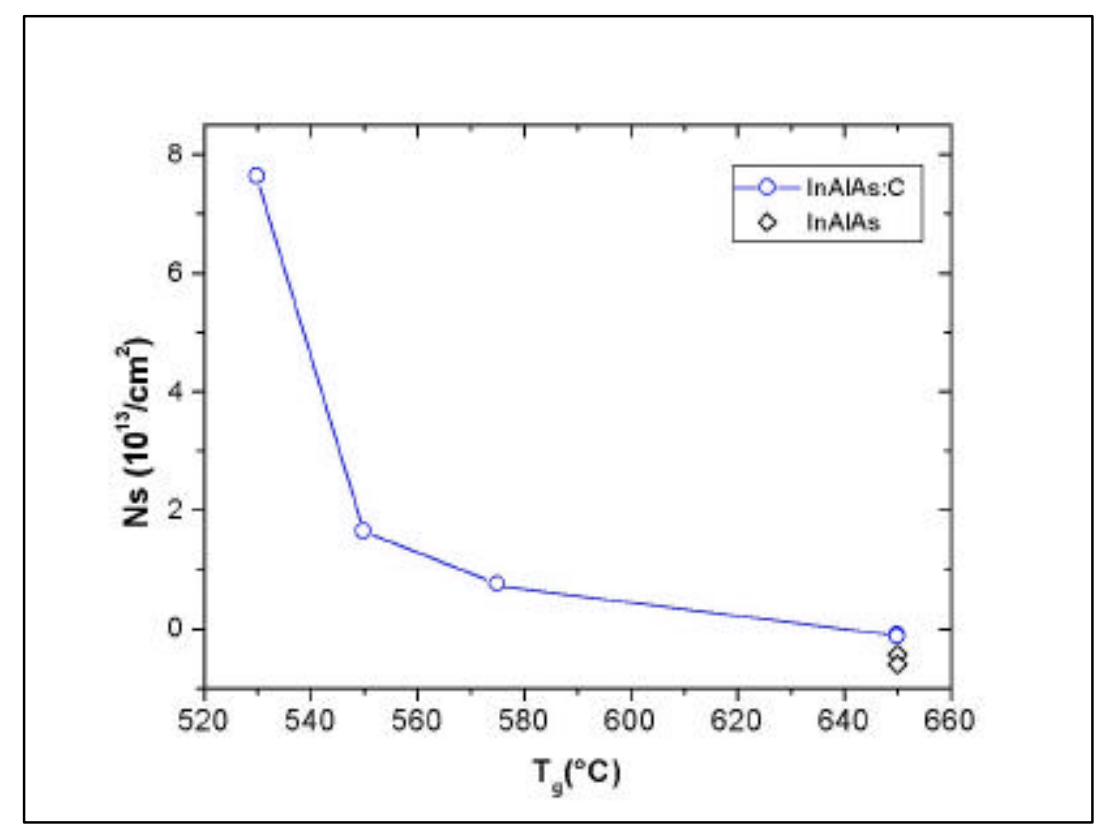

Figura 4.1: Dependência de portadores livres com a temperatura de crescimento. A concentração de portadores livres aumenta conforme a $\mathrm{T}_{\mathrm{g}}$ diminui. 
A figura 4.2 demonstra que a condutividade também aumenta conforme a temperatura de crescimento diminui. A condutividade $(\sigma)$ é obtida pela equação 4.1 , onde $N, \mu_{H}$ e $e$ são respectivamente a concentração volumétrica Hall, a mobilidade Hall e a carga elementar do elétron $\left(1.6 \times 10^{-16} \mathrm{C}\right)$.

$$
\sigma=N \mu_{H} e
$$

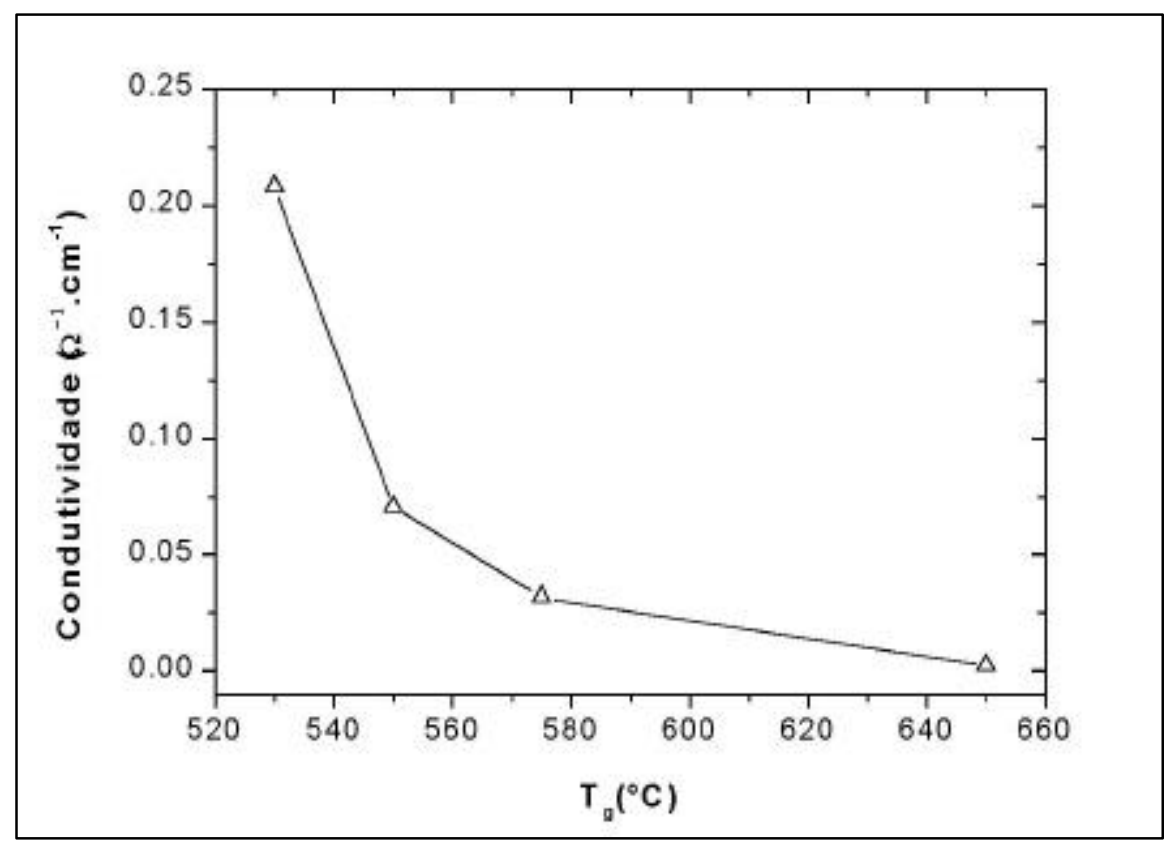

Figura 4.2: Dependência da condutividade com a temperatura de crescimento. A condutividade aumenta conforme a $\mathrm{T}_{\mathrm{g}}$ diminui.

H. Ito e T. Ishibashi realizaram um estudo onde se observa a transição de amostras tipo $n$ para tipo $p$ em função da fração molar de InAs na liga $\operatorname{In}_{x} \mathrm{Al}_{1-x}$ As [54]. A figura 4.3 ilustra a dependência de portadores livres e o tipo de condução em ligas de $\operatorname{In}_{\mathrm{x}} \mathrm{Al}_{1-\mathrm{x}} \mathrm{As}$ dopadas com carbono em função da fração molar de InAs. Conforme figura 4.3, ocorre uma inversão na condução do tipo $p$ para tipo $n$ para uma fração molar de 0.9 de InAs. É observado também que a concentração de portadores livres decresce significativamente em valores próximos ao ponto de inversão. Este fato está associado ao caráter anfotérico do carbono. 


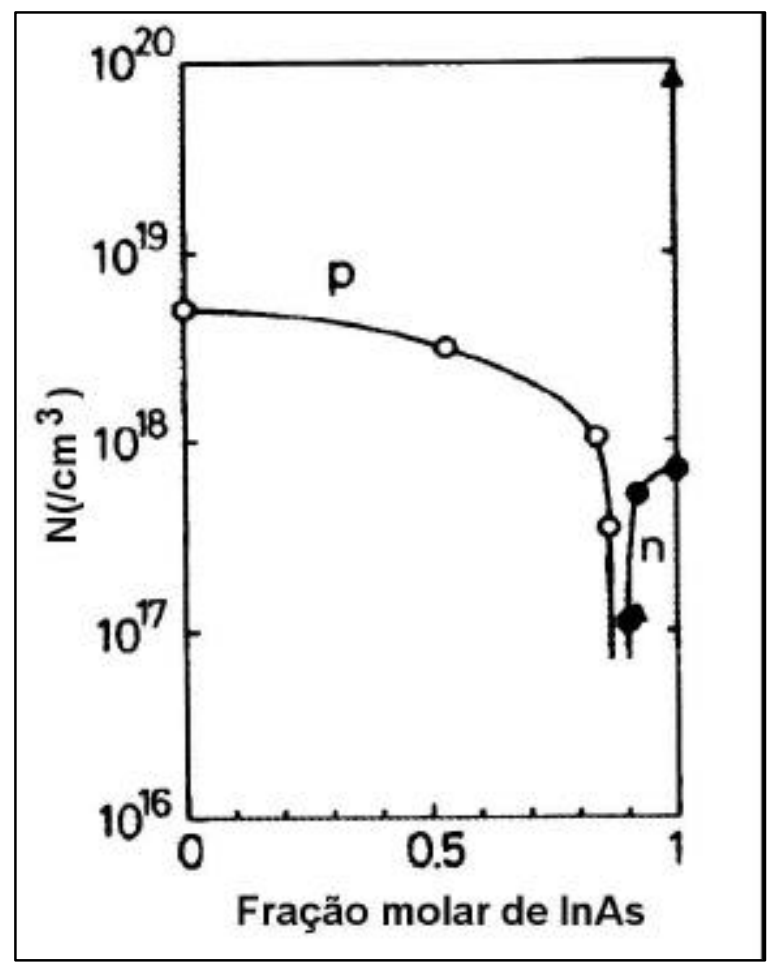

Figura 4.3: Dependência da concentração de portadores vs. a fração molar de InAs [54].

Após o crescimento das amostras, foi realizado um tratamento térmico em diferentes temperaturas por um período de 15 minutos numa atmosfera específica de hidrogênio e argônio (10\% $\left.\mathrm{H}_{2} / \mathrm{Ar}\right)$ conforme descrito na seção 3.7. Em todos os casos, a concentração de portadores livres aumentou com o aumento da temperatura do tratamento térmico, conforme figura 4.4 (a) e (b) para amostras crescidas em $650^{\circ} \mathrm{C}$ e $530^{\circ} \mathrm{C}$ respectivamente, o que está de acordo com resultados publicados por outros autores $[1,2,55,56]$. 

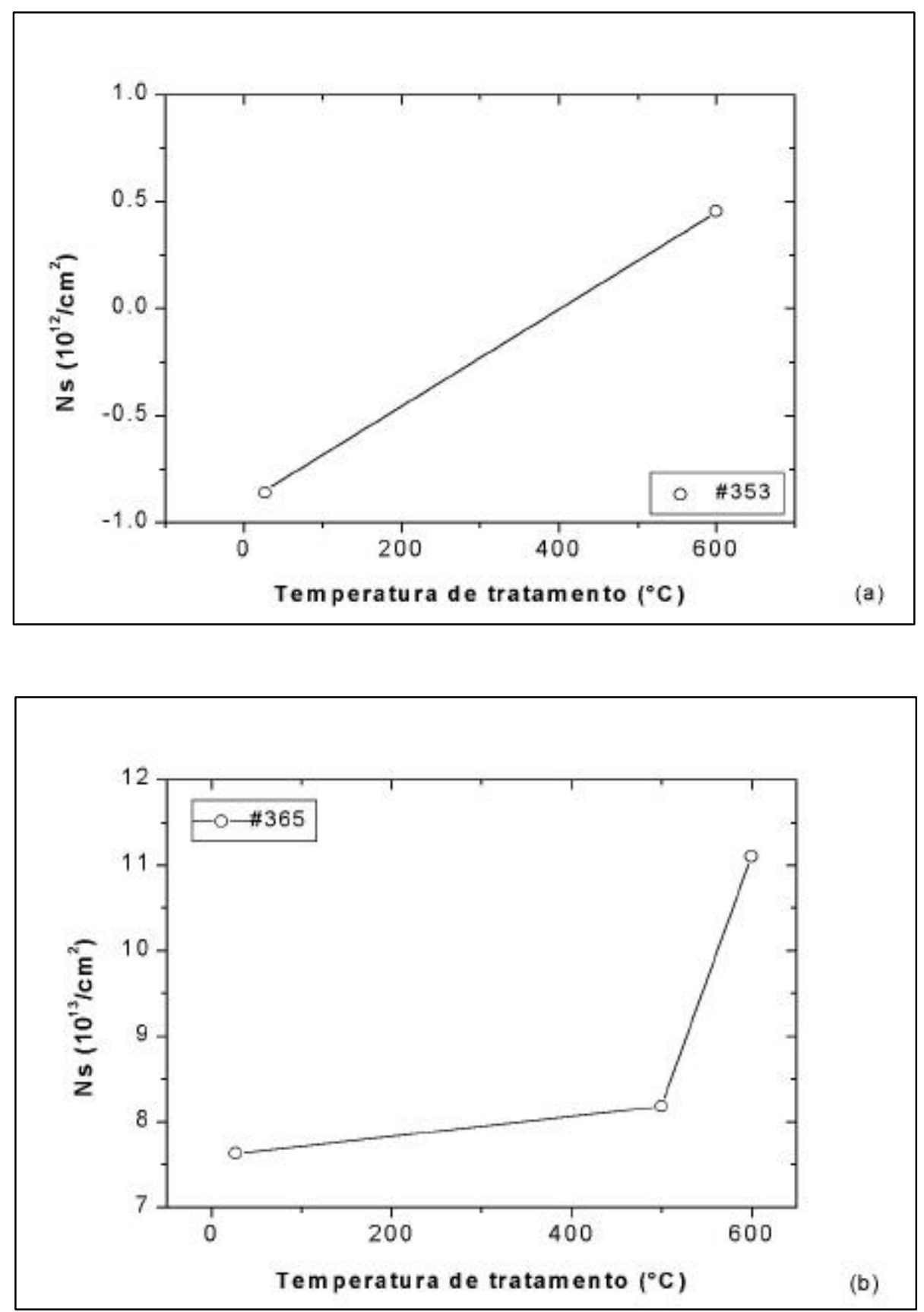

Figura 4.4: (a) e (b) Dependência da concentração de portadores livres com o tratamento térmico. $\mathrm{O}$ tratamento foi realizado em atmosfera $10 \% \mathrm{H}_{2} / \mathrm{Ar}$ por um período de 15 minutos. 
Medidas SIMS foram realizadas com o objetivo de se determinar a concentração atômica do carbono $\left(/ \mathrm{cm}^{3}\right)$, [SIMS], e comparar com as concentrações volumétricas de portadores livres e de carga $\left(/ \mathrm{cm}^{3}\right)$ obtidas pelas técnicas de Hall e $C V$ para amostras com e sem tratamento térmico. Estes resultados estão representados na tabela 4.2, onde $[\mathrm{H}]$, $\left[\mathrm{H}_{600}\right]$ e $\left[\mathrm{H}_{700}\right]$ representam as concentrações Hall para amostras sem tratamentos térmicos, e com tratamentos a $600^{\circ} \mathrm{C}$ e a $700^{\circ} \mathrm{C}$ e $[\mathrm{CV}],\left[\mathrm{CV}_{600}\right]$ e $\left[\mathrm{CV}_{700}\right]$ representam as concentrações $C V$ obtidas para amostras sem tratamentos térmicos e com tratamentos numa temperatura de $600^{\circ} \mathrm{C}$ e $700^{\circ} \mathrm{C}$, respectivamente.

\begin{tabular}{cccccccc}
\hline Amostra & {$[\mathrm{SIMS}]$} & {$[\mathrm{H}]$} & {$\left[\mathrm{H}_{600}\right]$} & {$\left[\mathrm{H}_{700}\right]$} & {$[\mathrm{CV}]$} & {$\left[\mathrm{CV}_{600}\right]$} & {$\left[\mathrm{CV}_{700}\right]$} \\
\hline$\# 353$ & $2.24 \times 10^{17}$ & $-1.44 \times 10^{16}$ & $7.5 \times 10^{15}$ & $\mathrm{NM}$ & $-2.83 \times 10^{16}$ & $\mathrm{NM}$ & $\mathrm{NM}$ \\
$\# 363$ & $1.3 \times 10^{18}$ & $2 \times 10^{17}$ & $2.77 \times 10^{17}$ & $* * *$ & $1.17 \times 10^{17}$ & $1.37 \times 10^{17}$ & $* * *$ \\
$\# 364$ & $2.37 \times 10^{18}$ & $4.4 \times 10^{17}$ & $\mathrm{NR}$ & $7.06 \times 10^{17}$ & $1.36 \times 10^{17}$ & $* * *$ & $1.37 \times 10^{17}$ \\
$\# 365$ & $5 \times 10^{18}$ & $1.3 \times 10^{18}$ & $1.85 \times 10^{18}$ & $* * *$ & $1.06 \times 10^{17}$ & $7.36 \times 10^{17}$ & $* * *$ \\
\hline
\end{tabular}

Tabela 4.2: Medidas de SIMS, Hall e CV para amostras \#353, \#363, \#364 e \#365. Medidas realizadas que não forneceram resultados mensuráveis estão representadas por $\mathrm{MN}$, enquanto *** representa medidas não realizadas.

A figura 4.5 ilustra [SIMS $],[H]$ e $[\mathrm{CV}]$ em função da $\mathrm{T}_{\mathrm{g}}$.

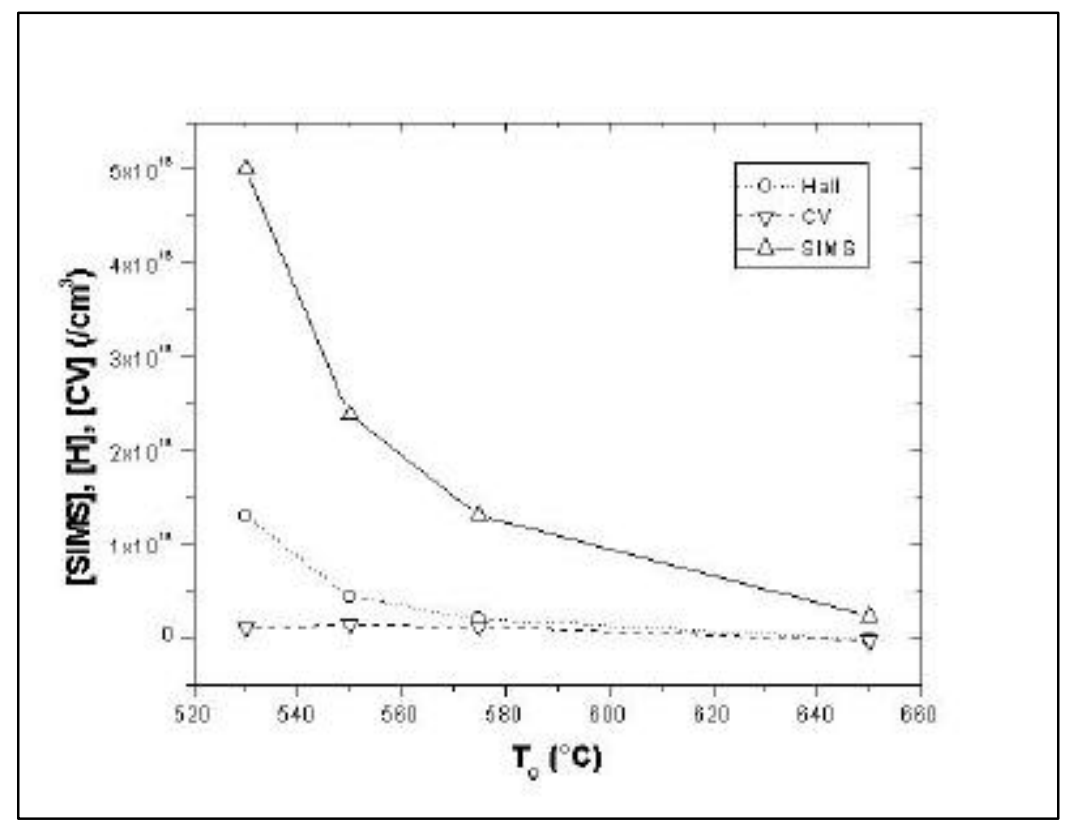

Figura 4.5: Concentração volumétrica de portadores livres, de carga e de átomos obtidas pelas técnicas Hall, CV e SIMS, respectivamente vs. temperatura de crescimento para as amostras \#353, \#364, \#365 e \#366. 
Pela figura 4.5 é observado a presença de carbonos inativos pelo fato de existir uma diferença entre a concentração atômica de carbono, obtida pela técnica SIMS, e a concentração Hall de portadores livres (eletricamente ativos, ou seja, elétrons que contribuem para a corrente). Conforme citado anteriormente, tratamentos térmicos foram realizados com o objetivo de remover os átomos de hidrogênio e reativar eletricamente os átomos de carbono. A figura 4.6 mostra o efeito do tratamento térmico nas concentrações Hall e CV para amostras \#363, \#364 e \#365.

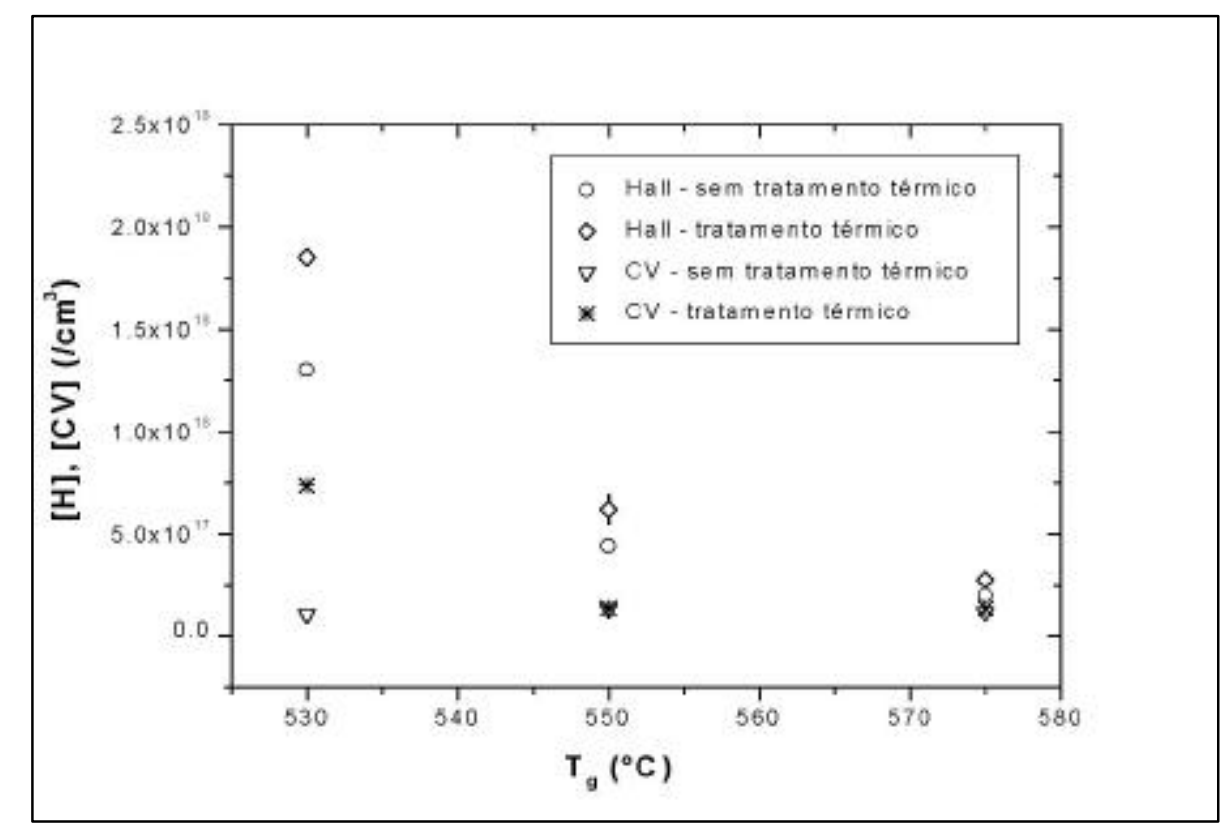

Figura 4.6: Efeito do tratamento térmico na concentração Hall e CV para amostras \#363, \#364 e \#365.

De acordo com a literatura, a concentração de buracos livres em InAlAs dopado com carbono satura com uma temperatura de tratamento térmico de $600^{\circ} \mathrm{C}$ numa atmosfera de nitrogênio $\left(\mathrm{N}_{2}\right)$ por um período de 5 minutos mesmo para as amostras crescidas a temperatura de $650^{\circ} \mathrm{C}$ [1]. Na prática, não chegamos a observar esse efeito em função da não disponibilidade de mais amostras, portanto, não foi possível realizar os tratamentos térmicos necessários para alcançar essa saturação. Então, vamos assumir a veracidade dos resultados da literatura para as amostras analisadas no presente trabalho. Assumindo que após o tratamento térmico todos os carbonos passivados com hidrogênio estejam eletricamente ativos, é observada uma diferença entre a concentração SIMS e as concentrações Hall e $C V$ obtidas após o tratamento térmico, ou seja, a concentração de 
portadores livres e de cargas continua sendo inferior à concentração atômica de carbono. A medida de efeito Hall nos fornece a concentração líquida de portadores livres. Calculando a diferença entre a concentração SIMS e Hall após o tratamento térmico a $600^{\circ} \mathrm{C}$, obtemos a concentração total de átomos de carbono que não estão contribuindo para a corrente $\mathrm{Hall}$, ou seja, a concentração de carbono eletricamente inativo. A tabela 4.3 indica a concentração de carbono eletricamente inativa para diferentes temperaturas de crescimento.

\begin{tabular}{ccc}
\hline Amostra & $\mathrm{T}_{\mathrm{g}}\left({ }^{\circ} \mathrm{C}\right)$ & {$[$ SIMS $]-[$ Hall $]\left(\mathrm{cm}^{3}\right)$} \\
\hline$\# 353$ & 650 & $2.16 \times 10^{17}$ \\
$\# 363$ & 575 & $1.02 \times 10^{18}$ \\
$\# 364$ & 550 & $1.66 \times 10^{18}$ \\
$\# 365$ & 530 & $3.15 \times 10^{18}$ \\
\hline
\end{tabular}

Tabela 4.3: Concentração de portadores eletricamente inativos para diferentes temperaturas de crescimento.

Os átomos de carbono eletricamente inativos podem se encontrar em interstícios da rede, formando complexos ou divididos igualmente entre doadores e aceitadores rasos que se compensam. Essa concentração "inativa" não pode ser apenas de doadores e aceitadores rasos que se autocompensam, pois nesse caso a concentração $C V$ se igualaria à concentração Hall, ou seja, $[C V]=[$ Hall $]$. Observamos, na figura 4.6 que a concentração Hall é maior que a concentração $C V$. Lembramos que as medidas capacitivas fornecem dados sobre a carga líquida (cargas positivas menos cargas negativas fixas) e, contrariamente às medidas de efeito Hall, permitem um acesso a níveis mais profundos. Esse resultado, $[$ Hall $]>[\mathrm{CV}]$, pode ser compreendido se doadores profundos são incorporados não intencionalmente. Na figura 4.7, temos o diagrama de bandas formado na medida $\mathrm{CV}$, onde um eletrólito em contato com o semicondutor, produz uma barreira Schottky. Esta barreira apresenta um diagrama de bandas ilustrado na figura 4.7, no caso do material ser tipo $p$. No diagrama da figura 4.7, estão representados somente os aceitadores rasos. 


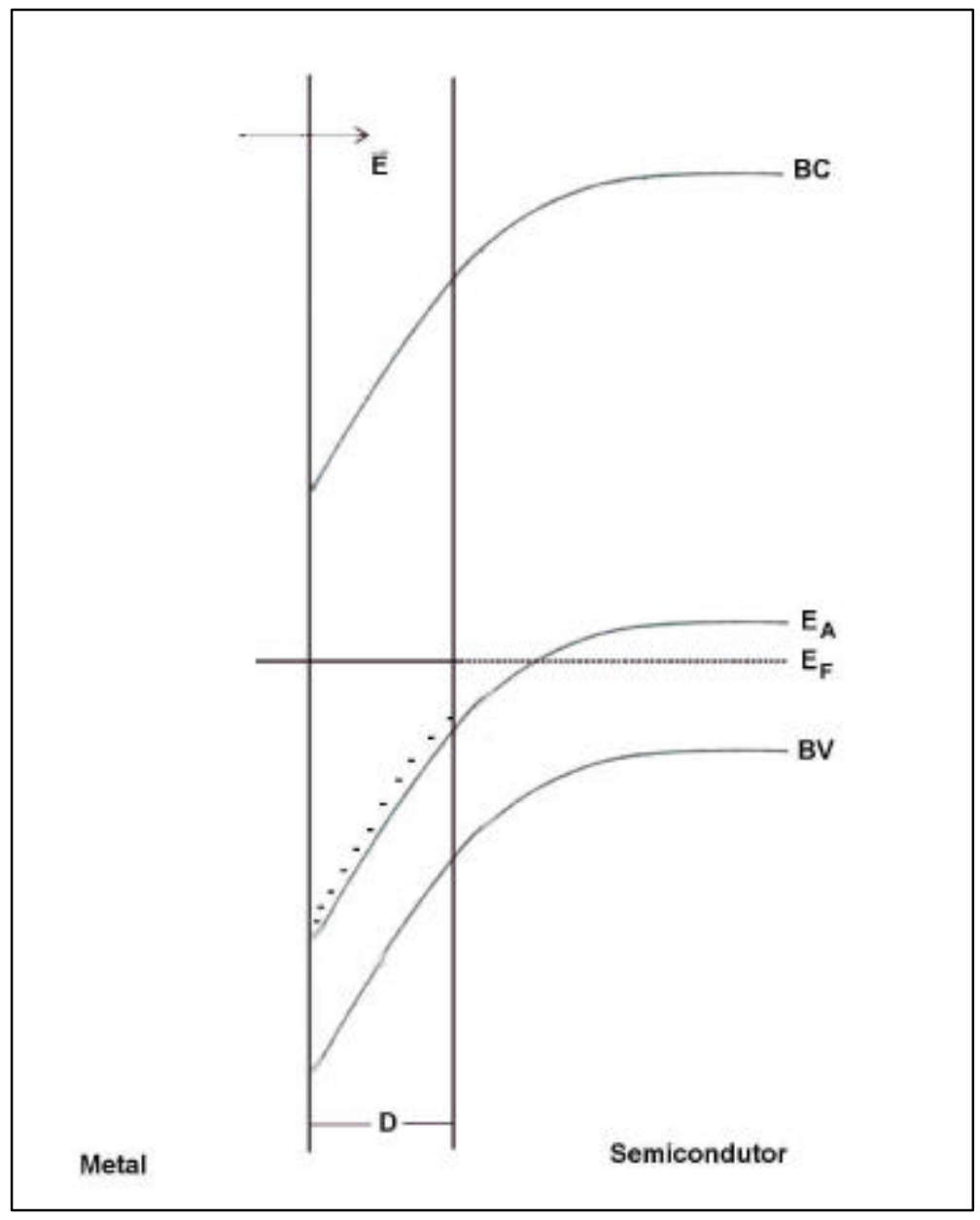

Figura 4.7: Representação do diagrama de banda de uma barreira Schottky, onde o metal é um eletrólito e o semicondutor é do tipo $p$, contendo aceitadores rasos. $D$ é a região de depleção. $\vec{E}$ representa o campo elétrico. As cargas negativas são os aceitadores ionizados. $\mathrm{BC}, \mathrm{E}_{\mathrm{A}}, \mathrm{E}_{\mathrm{F}}$ e $\mathrm{BV}$ representam banda de condução, nível aceitador, nível de Fermi e banda de valência, respectivamente.

Quando são incorporados doadores profundos, o diagrama de bandas nas medidas de $C V$ é modificado. A figura 4.8 ilustra o diagrama de bandas, onde o semicondutor tipo $p$, apresenta aceitadores rasos e doadores profundos. Nesse caso, os doadores profundos ionizados compensarão os aceitadores rasos. Esses doadores não são observados em medidas Hall, pois o doador profundo não libera o elétron para a corrente Hall. Por outro lado, o campo elétrico da junção eletrólito/semicondutor ioniza os doadores profundos. Lembramos que a técnica de $C V$ é realizada na presença de um potencial reverso aplicado. Portanto, a presença de doadores profundos explica a concentração Hall ser superior à concentração $C V$. 


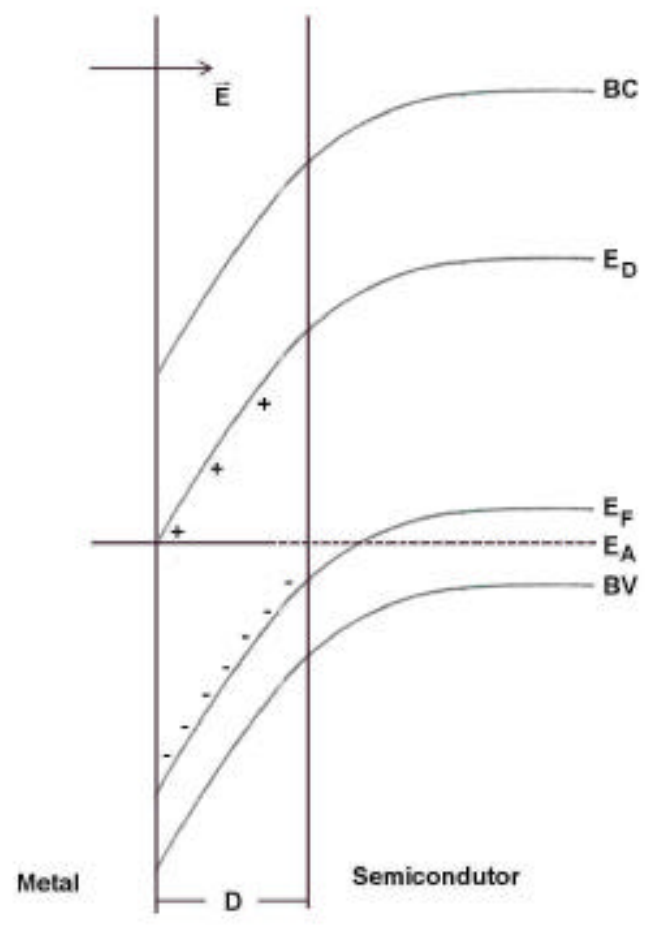

Figura 4.8: Representação do diagrama de banda de uma barreira Schottky, onde o metal é um eletrólito e o semicondutor é do tipo $p$, contendo aceitadores rasos e doadores profundos. $D$ é a região de depleção. BC, $\mathrm{E}_{\mathrm{A}}, \mathrm{E}_{\mathrm{F}}$ e $\mathrm{BV}$ representam banda de condução, nível aceitador, nível de Fermi e banda de valência. respectivamente. $\vec{E}$ representa o campo elétrico na junção metal/semicondutor.

Podemos então estimar a concentração de doadores profundos, dada pela diferença entres as concentrações Hall e $C V$. A tabela 4.4, indica que à medida que a temperatura de crescimento diminui a concentração de doadores profundos aumenta. A figura 4.9 ilustra a concentração de doadores profundos em função da temperatura.

\begin{tabular}{ccc}
\hline Amostra & $\mathrm{T}_{\mathrm{g}}\left({ }^{\circ} \mathrm{C}\right)$ & {$[$ Hall $]-[\mathrm{CV}]\left(\mathrm{cm}^{3}\right)$} \\
\hline$\# 353$ & 650 & $1.39 \times 10^{16}$ \\
$\# 363$ & 575 & $8.30 \times 10^{16}$ \\
$\# 364$ & 550 & $3.04 \times 10^{17}$ \\
$\# 365$ & 530 & $1.20 \times 10^{18}$ \\
\hline
\end{tabular}

Tabela 4.4: Concentração de doadores profundos. 
$\mathrm{Na}$ amostra não dopada crescida na temperatura de $530^{\circ} \mathrm{C}$ (\#366), não se consegue obter medidas de $\mathrm{Hall}$ e nem de $C V$, devido a sua elevada resistividade. Se a concentração de doadores profundos independesse do carbono, por conseguinte, deveríamos obter elevada concentração $C V$ na amostra \#366. Ou seja, se a concentração de doadores profundos dependesse somente da temperatura de crescimento, logo, ela deveria estar presente na amostra \#366. Portanto, esses resultados indicam que o carbono participa na formação desses doadores profundos.

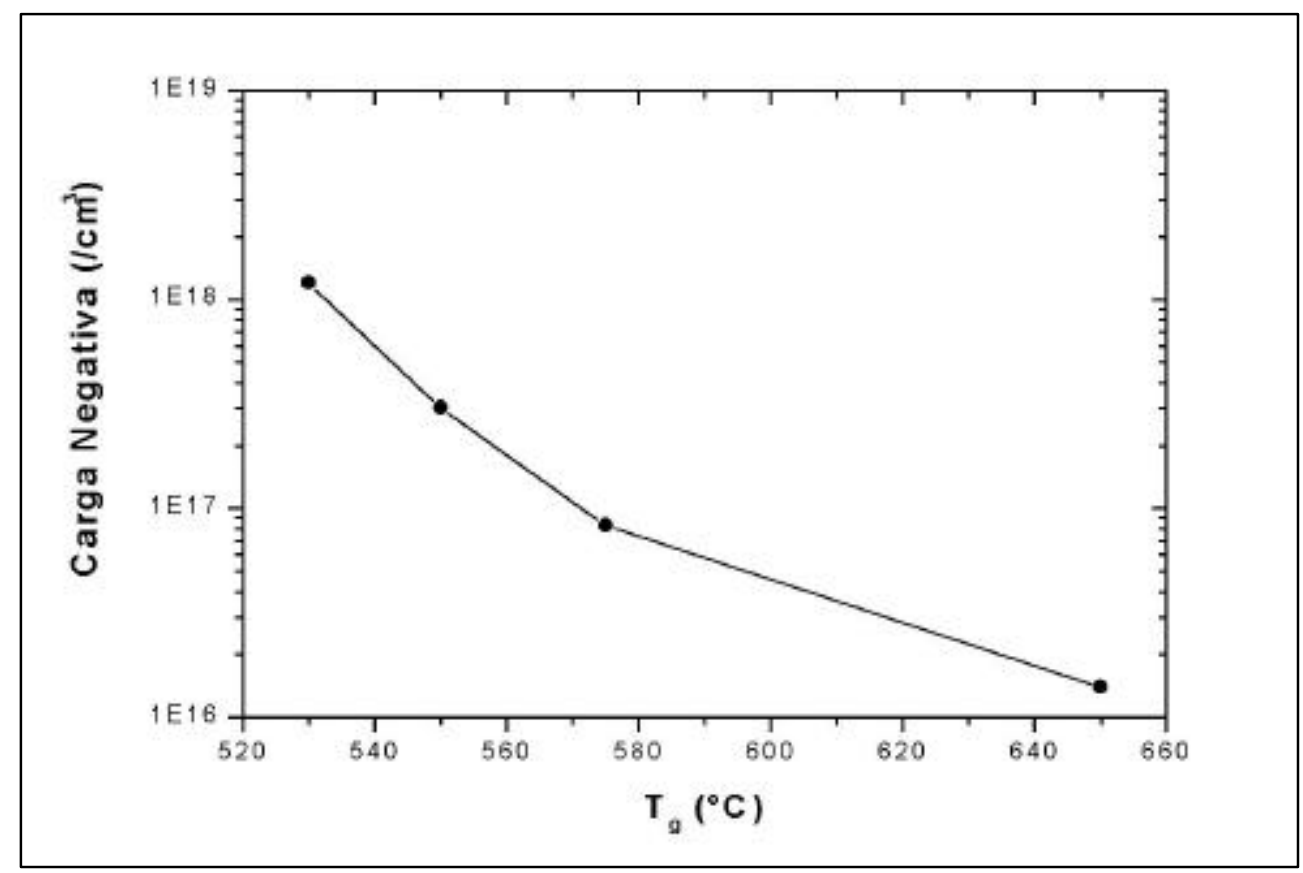

Figura 4.9: Concentração de doadores profundos vs. temperatura de crescimento.

Supondo que o carbono deva estar associado à formação de doadores profundos, esboçamos o gráfico da concentração de doadores profundos vs. concentração atômica de carbono, mostrado na figura 4.10 . 


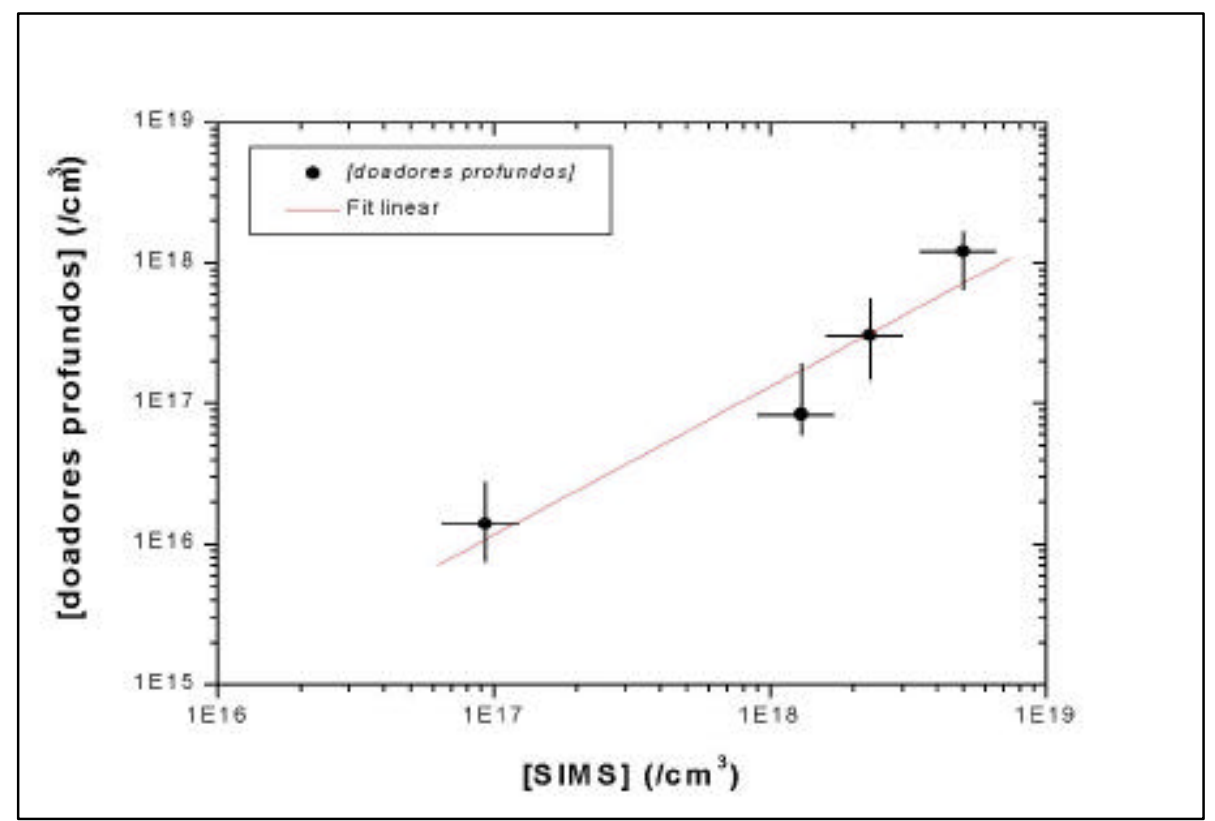

Figura 4.10: Concentração de doadores profundos vs. concentração atômica de carbono.

No gráfico 4.10 foi realizado um ajuste linear dos dados, representado pela linha contínua, de modo a obter uma relação entre a concentração de doadores profundos e a concentração atômica de carbono. A equação da reta pode ser escrita como:

$$
\log [\text { doadores profundos] }=\log A+x \log [S I M S \text { ] }
$$

onde [doadores profundos] é a concentração de doadores profundos. Reescrevendo 4.2

$$
\log [\text { doadores profundos] }=-1.86+1.05 \log [\text { SIMS ] }
$$

simplificando a equação 4.3 obtemos:

$$
\text { [doadores profundos] }=0.0138[\text { SIMS }]^{1.05}
$$

Pela equação 4.4, observamos que a concentração de doadores profundos é proporcional à concentração SIMS, ou seja, a concentração de doadores profundos varia linearmente com a concentração atômica de carbono e é da ordem de $1.4 \%$ do total de átomos de carbonos.

Conforme apresentado no item 2.2.1, o carbono possui um caráter anfotérico, ou seja, o carbono pode ser um doador raso caso ocupe o sítio do cátion, i.e. sítio III, ou um aceitador raso caso ocupe o sítio do ânion, i.e. sítio V. Assumindo que o carbono é incorporado somente dessas três maneiras, ou seja, aceitador raso, doador raso e doador profundo, podemos calcular a concentração de carbono no sítio III e no sítio V. A diferença entre a concentração $\operatorname{SIMS}$ e a soma da concentração $\left[\mathrm{H}_{600}\right]$ com a concentração 
de doadores profundos fornece a concentração de carbonos inativos. Assumindo que os carbonos inativos estão distribuídos igualmente em sítios III e V, então somente metade da concentração de carbonos inativos está presente no sítio V. Logo, a soma da concentração $\left[\mathrm{H}_{600}\right]$ com a concentração de carbonos inativos presentes no sítio $\mathrm{V}$, indica a concentração total de carbono no sítio V. A concentração de carbono no sítio III é dada pela concentração SIMS menos a soma da concentração de doador profundo com a concentração total de carbono no sítio V. Na tabela $4.5,\left[C_{V}\right]$ e $\left[C_{I I I}\right]$ representam a concentração total de carbono no sítio III e V, respectivamente, para as amostra \#353, \#363, \#364 e \#365, e $\left[C_{V}\right] /\left[C_{I I I}\right]$ que é o fator anfotericidade,definido na seção 2.2 .3 como sendo a razão entre as concentrações totais de carbono no sítio V e III.

\begin{tabular}{cccccc}
\hline Amostra & $\mathrm{T}_{\mathrm{g}}\left({ }^{\circ} \mathrm{C}\right)$ & {$\left[C_{V}\right]$} & {$\left[C_{I I I}\right]$} & {$[$ doadores profundos $]$} & {$\left[C_{V}\right] /\left[C_{I I I}\right]$} \\
\hline$\# 353$ & 650 & $1.09 \times 10^{17}$ & $1.01 \times 10^{17}$ & $1.39 \times 10^{16}$ & 1.08 \\
$\# 363$ & 575 & $7.47 \times 10^{17}$ & $4.70 \times 10^{17}$ & $8.30 \times 10^{16}$ & 1.59 \\
$\# 364$ & 550 & $1.39 \times 10^{18}$ & $6.80 \times 10^{17}$ & $3.04 \times 10^{17}$ & 2.04 \\
$\# 365$ & 530 & $2.83 \times 10^{18}$ & $9.7 \times 10^{17}$ & $1.20 \times 10^{18}$ & 2.92 \\
\hline
\end{tabular}

Tabela 4.5: Resultados da concentração de carbono em diferentes formas e da razão entre sua concentração nos sítios III e V.

Esboçando o gráfico da razão $\left[C_{V}\right] /\left[C_{I I I}\right]$ vs. $\mathrm{T}_{\mathrm{g}}\left({ }^{\circ} \mathrm{C}\right)$ na figura 4.11 , obtém-se o fator de anfotericidade em função da temperatura de crescimento. Olhando o gráfico, $\left[C_{V}\right] /\left[C_{I I I}\right]=1$ só vai ocorrer para temperaturas elevadas, ou seja, sempre haverá mais incorporação no sítio V do que no sítio III para nossas condições de crescimento. 


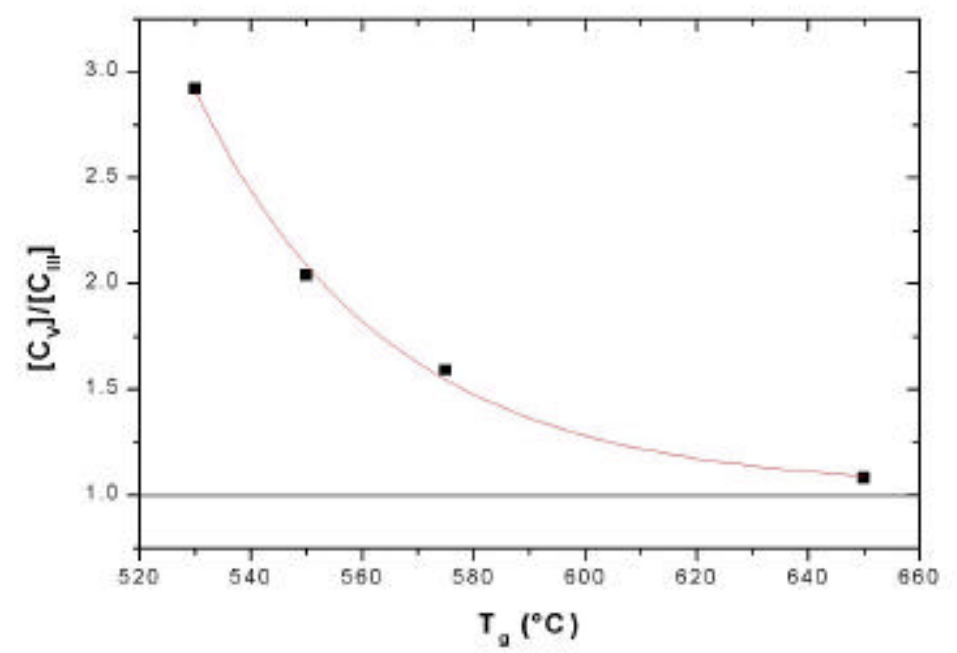

Figura 4.11: Razão $\left[C_{V}\right] /\left[C_{I I I}\right]$ vs. temperatura de crescimento $\left({ }^{\circ} \mathrm{C}\right)$. A linha cheia representa um ajunte de decaimento exponencial de primeira ordem.

Podemos também determinar a temperatura para qual se espera a transição do tipo $n$ para o tipo $p$, ou vice-versa nas amostras as grown. Para isso, basta graficar a concentração Hall em função da temperatura, conforme figura 4.12.

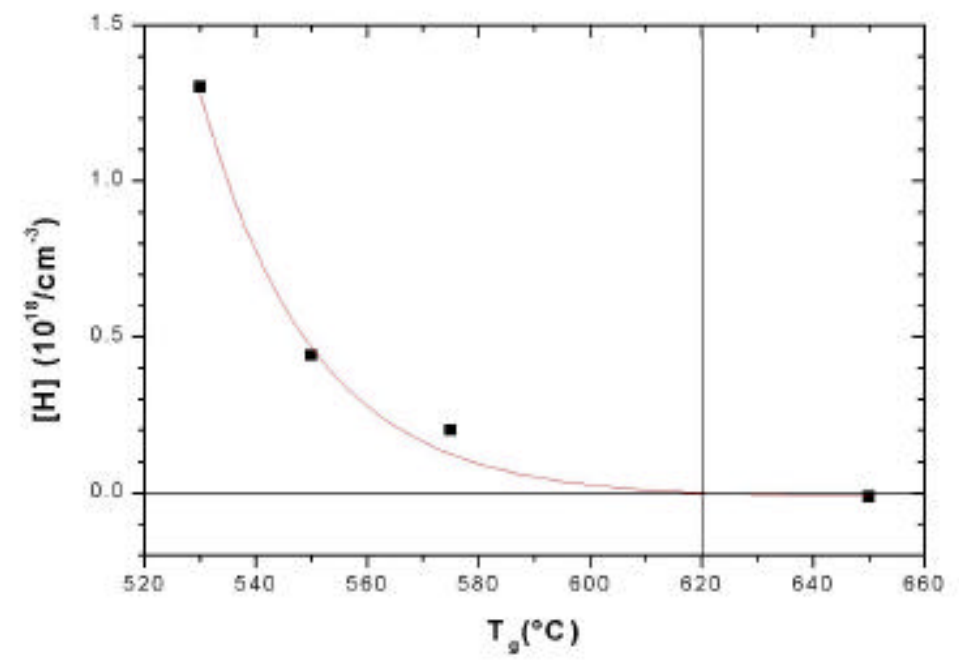

Figura 4.12: Concentração Hall, $[\mathrm{H}]$, vs. temperatura de crescimento $\left({ }^{\circ} \mathrm{C}\right)$. A linha cheia representa um ajuste de decaimento exponencial de primeira ordem.

Realizou-se um ajuste do decaimento exponencial de primeira ordem, representado pela linha contínua na figura 4.12, de modo a obter uma relação entre a 
concentração Hall e a temperatura de crescimento. A expressão 4.5 representa o decaimento exponencial de primeira ordem.

$$
[H]=[H]_{0}+A \exp \left(-\left(T-T_{0}\right) / B\right)
$$

Reescrevendo 4.5 obtemos:

$$
[H]=-0.015+1.29 \exp (-(T-530) / 20.16)
$$

onde $[\mathrm{H}]$ e $\mathrm{T}$ são a concentração $H a l l$ e a temperatura de crescimento em ${ }^{\circ} C$, respectivamente. Fazendo $[H]=0$, obtemos a temperatura de transição do tipo $n$ para o tipo $p$ ou vice-versa. A temperatura de transição do tipo $p$ para tipo $n$ e vice-versa é aproximadamente $620^{\circ} \mathrm{C}$, que conforme citado anteriormente, no início desta seção, estaria numa faixa de $600^{\circ} \mathrm{C}$ à $625^{\circ} \mathrm{C}$ evidenciado experimentalmente.

A eficiência da atividade elétrica pode ser definida como a concentração de carbonos que contribuem para a corrente $\mathrm{Hall}$, ou seja, $[\mathrm{H}]$ dividida pela concentração atômica de carbono. A tabela 4.6 mostra que a eficiência da atividade elétrica aumenta à medida que a temperatura de crescimento decresce.

\begin{tabular}{ccccc}
\hline Amostra & $\mathrm{T}_{\mathrm{g}}\left({ }^{\circ} \mathrm{C}\right)$ & {$[\mathrm{H}]$} & {$[\mathrm{SIMS}]$} & $\begin{array}{c}\text { Eficiência da } \\
\text { Atividade elétrica }(\%)\end{array}$ \\
\hline$\# 365$ & 530 & $1.3 \times 10^{18}$ & $5 \times 10^{18}$ & 26 \\
$\# 364$ & 550 & $4.4 \times 10^{17}$ & $2.37 \times 10^{18}$ & 18.6 \\
$\# 363$ & 575 & $2 \times 10^{17}$ & $1.3 \times 10^{18}$ & 15.4 \\
$\# 353$ & 650 & $-1.44 \times 10^{16}$ & $2.24 \times 10^{17}$ & - \\
\hline
\end{tabular}

Tabela 4.6: Cálculo da eficiência da atividade elétrica.

\subsection{Estrutura}

Medidas de raios-x foram realizadas com o objetivo de se determinar a composição da liga e avaliar a qualidade estrutural. Mediante a obtenção do parâmetro de rede da liga é possível obter sua composição. A composição da liga $\operatorname{In}_{\mathrm{x}} \mathrm{Al}_{1-\mathrm{x}} \mathrm{As}$ é determinado pela lei de Vergard [19], conforme equação 4.7.

$$
a_{I n_{x} A l_{1-x} A s}=x a_{I n A s}+(1-x) a_{A I A s}
$$


Por meio de uma sub-rotina de análise no programa Bede Control versão 1.79 da Bede Scientific Instruments Limited é possível determinar a composição das amostras. A tabela 4.7 mostra a percentagem de alumínio presente na liga, $\{\mathrm{Al}\}$, obtida pela técnica de raios-x.

\begin{tabular}{ccc}
\hline Amostra & $\mathrm{T}_{\mathrm{g}}\left({ }^{\circ} \mathrm{C}\right)$ & $\{\mathrm{Al}\}$ \\
\hline$\# 349$ & 650 & 0.475 \\
$\# 350$ & 650 & 0.482 \\
$\# 353$ & 650 & 0.508 \\
$\# 359$ & 625 & 0.477 \\
$\# 360$ & 600 & 0.478 \\
$\# 363$ & 575 & 0.485 \\
$\# 364$ & 550 & 0.464 \\
$\# 365$ & 530 & 0.457 \\
$\# 366$ & 530 & 0.474 \\
\hline
\end{tabular}

Tabela 4.7: Composição das amostras de $\operatorname{In}_{1-x} \mathrm{Al}_{\mathrm{x}} \mathrm{As}$ não dopadas e dopadas com carbono

A largura à meia altura, representada por $\beta$, está associada à qualidade estrutural do material [57]. Quanto menor $\beta$, mais perfeito é o cristal. A tabela 4.8 mostra os valores de $\beta$ em diferentes temperaturas de crescimento.

\begin{tabular}{ccc}
\hline Amostra & $\mathrm{T}_{\mathrm{g}}\left({ }^{\circ} \mathrm{C}\right)$ & $\beta(\mathrm{sec})$ \\
\hline$\# 349$ & 650 & 31.45 \\
$\# 350$ & 650 & 30.77 \\
$\# 353$ & 650 & 32.98 \\
$\# 363$ & 575 & 58.80 \\
$\# 364$ & 550 & 84.39 \\
$\# 365$ & 530 & 99.09 \\
$\# 366$ & 530 & 86.28 \\
\hline
\end{tabular}

Tabela 4.8: Valores da largura à meia altura $(\beta)$ para amostras crescidas em diferentes temperaturas.

Conforme tabela 4.8, é observado que para amostras crescidas em temperaturas mais baixas, obtêm-se uma maior concentração de defeitos fato este, que irá influenciar na 
qualidade ótica das mesmas. Tratamentos térmicos foram realizados com o objetivo de eliminar defeitos no material e consequentemente, obter uma melhor qualidade estrutural dos mesmos. Não se observou nenhuma mudança estrutural em virtude dos tratamentos térmicos. Fato esse corroborado em experimentos de fotoluminescência.

Numa etapa seguinte, para efeito de verificação das medidas obtidas, realizou-se uma simulação dos espectros de raios-x obtidos, vide figura 4.13. A simulação foi realizada no programa RADS Mercury versão 3.5.6 também da da Bede Scientific Instruments Limited. O espectro de raios-X da amostra não dopada (\#349) está ilustrado na figura 4.13. A curva esperimental está representada pela linha contínua, enquanto a simulação numérica é representada por círculos abertos. O pico 1 é a camada crescida de InAlAs e o pico 2 refere-se ao substrato de InP.

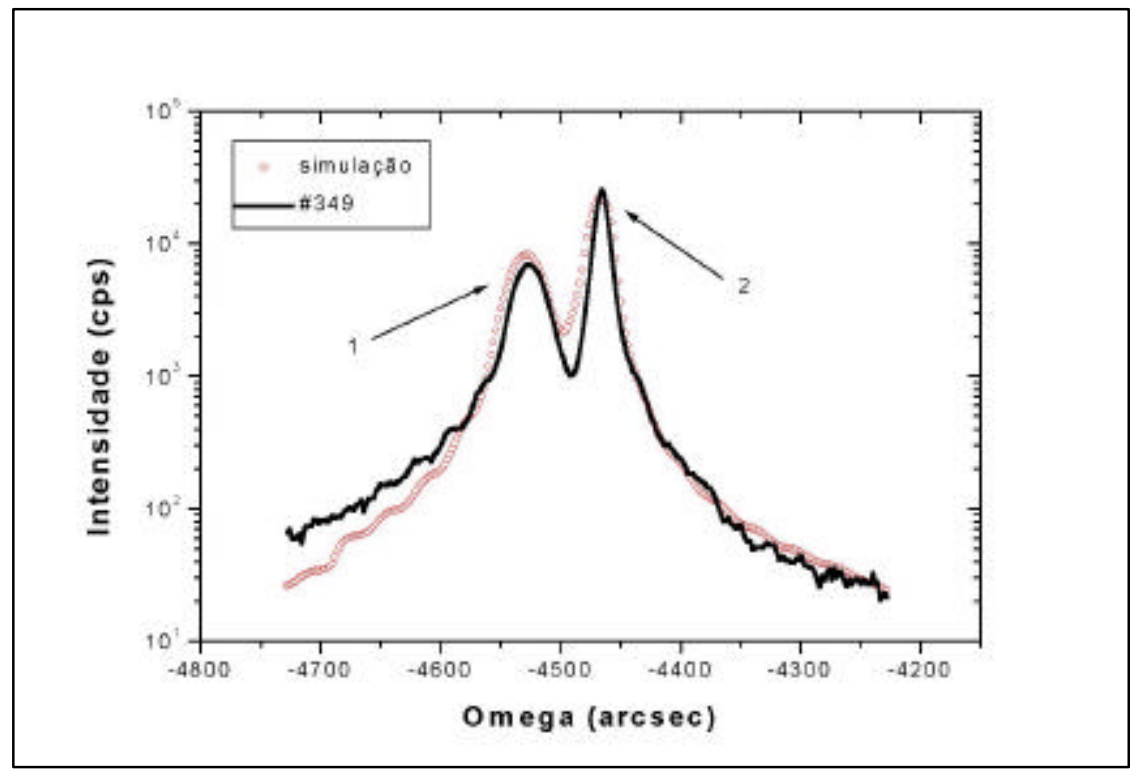

Figura 4.13: Espectro de raios-x da amostra \#349, e sua respectiva simulação numérica, representados pelas linha continua e por círculos, respectivamente. Observa-se que a simulação é coerente com o resultado experimental, o que indica uma medida experimental de boa qualidade.

\section{3. Ótica}

Mediante a composição da liga é possível determinar as energias de gap para uma melhor compreensão dos espectros de fotoluminescência a serem discutidos na presente seção. Na literatura foram encontradas quatro equações diferentes para o cálculo da energia de gap à temperatura ambiente $(300 \mathrm{~K})$ e uma expressão que determina a energia 
de gap na temperatura de $4 \mathrm{~K}$, onde $\{\mathrm{Al}\}$ representa a percentagem de alumínio presente na liga. As equações para o cálculo da energia de gap e suas respectivas considerações estão reproduzidas na tabela 4.9 .

\begin{tabular}{ll}
\hline $\mathrm{E}_{\mathrm{g}}(\mathrm{meV})$ & Considerações \\
\hline$E_{g}=0.36+2.35\{A l\}+0.24\{A l\}^{2}$ & em $300 \mathrm{~K}$ \\
$E_{g}=0.357+2.29\{A l\}$ & em $300 \mathrm{~K}$ para $0.44<\{A l\}<0.54$ \\
$E_{g}=0.360+2.012\{A l\}+0.698\{A l\}^{2}$ & em $300 \mathrm{~K}$ \\
$E_{g}=0.370+1.91\{A l\}+0.74\{A l\}^{2}$ & em 300K \\
$E_{g}=0.447+2.22\{A l\}$ & em $4 \mathrm{~K}$ para $0.44<\{A l\}<0.54$ \\
\hline
\end{tabular}

Tabela 4.9: Cálculo da energia de gap em função da composição da liga. As equações (3.8a), (3.8b) e (3.8e) foram publicadas por S. L. Chuang, Physics of optoelectronic devices, Awiley-Interscience Publication, New York, 1995, (3.8c) por H. C. Casey e M. B. Panish, Heterostructure Lasers, Academic Press, New York, 1978 e (3.8d) por O. Madelung, Semiconductors: Gruup IV Elements and III-V Compounds, Springer-Verlag, Germany, 1991.

Em dispositivos óticos e optoeletrônicos é extremamente crucial uma boa qualidade ótica das camadas epitaxiais. Nas medidas de fotoluminescência foi realizado um estudo da qualidade ótica das camadas epitaxiais em função da temperatura de crescimento das mesmas. É observado que, conforme a temperatura de crescimento decresce a partir de $650^{\circ} \mathrm{C}$ até $600^{\circ} \mathrm{C}$, a qualidade ótica das mesmas é gradualmente deteriorada, ou seja, o pico da transição ótica banda-banda (eh) diminui de intensidade conforme a temperatura de crescimento decresce. Para temperaturas de crescimento iguais ou inferiores a $575^{\circ} \mathrm{C}$ não se observa a emissão banda-banda. Este fato, é independente da presença de carbono, uma vez que a transição banda-banda não é observada nas amostras não dopadas utilizadas como referência.

Conforme discutido na seção 4.1, obtêm-se amostras tipo $p$ para temperaturas de crescimento inferiores à $620^{\circ} \mathrm{C}$. Este fato, está relacionado à eficiência de pirólise da molécula de arsina em função da temperatura de crescimento. $\mathrm{Na}$ temperatura de $530^{\circ} \mathrm{C}$ a eficiência de decomposição da molécula de arsina é de aproximadamente 20\% [32]. Então em temperaturas de crescimento mais baixas, existe uma menor concentração de átomos de arsênio (As) e consequentemente uma maior concentração de vacâncias de arsênio, $\left[\mathrm{V}_{\mathrm{As}}\right]$. Por conseguinte, mais átomos de carbono são incorporados. Além deste fato, ocorre 
uma menor passivação dos átomos de carbono pois existe uma menor concentração de átomos de hidrogênio disponíveis.

Conforme citado acima, a redução na eficiência da fotoluminescência depende apenas da temperatura de crescimento. Essa redução, não está relacionada à incorporação de carbono, estando provavelmente associada à incorporação de outros tipos de defeitos que é favorecida em baixas temperaturas de crescimento. Esses defeitos são centros não radiativos. É importante ressaltar que não há participação dos doadores profundos discutidos na seção 4.1 nesses centros não radiativos responsáveis pela deterioração da fotoluminescência, pois a concentração daqueles depende diretamente da concentração de carbono incorporada no material.

O efeito da dopagem próxima ao pico banda-banda é observado na figura 4.14 para as amostras não dopada (\#349) e dopada (\#353) crescidas na temperatura de $650^{\circ} \mathrm{C}$, representada por triângulos e por círculos, respectivamente.

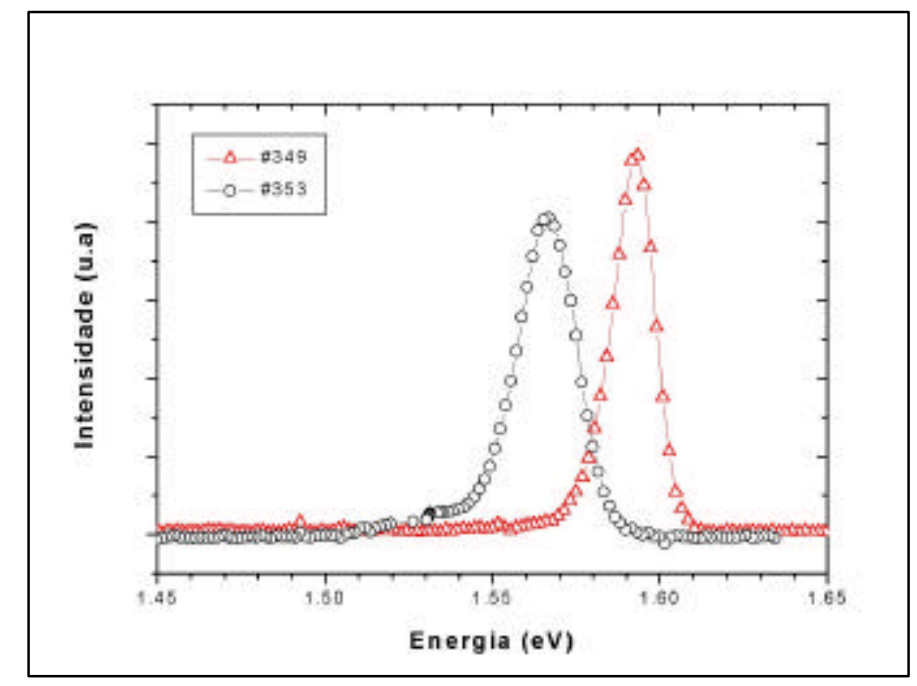

Figura 4.14: Comparação entre os espectros de fotoluminescências, obtidas em uma temperatura $30 \mathrm{~K}$, para as amostra \#349 e \#353, representadas por triângulos e círculos, respectivamente.

Os espectros da fotoluminescência foram obtidos numa temperatura de $30 \mathrm{~K}$ e uma densidade de potência de excitação de $300 \mathrm{~mW} / \mathrm{cm}^{2}$. Na amostra dopada, a energia no pico da fotoluminescência é $26 \mathrm{meV}$ inferior ao pico banda-banda na amostra não dopada, conforme figura 4.14. Realizou-se também a mesma análise para amostras com dopagem tipo delta crescidas em diferentes temperaturas. A figura 4.15 (a) e (b) ilustra os espectros de luminescência para amostras crescidas em $625^{\circ} \mathrm{C}$ e $600^{\circ} \mathrm{C}$, amostras \#359 e 
\#360, respectivamente. Na figura 4.15 a referência está representada por triângulos, enquanto as amostras dopadas estão representadas por círculos.

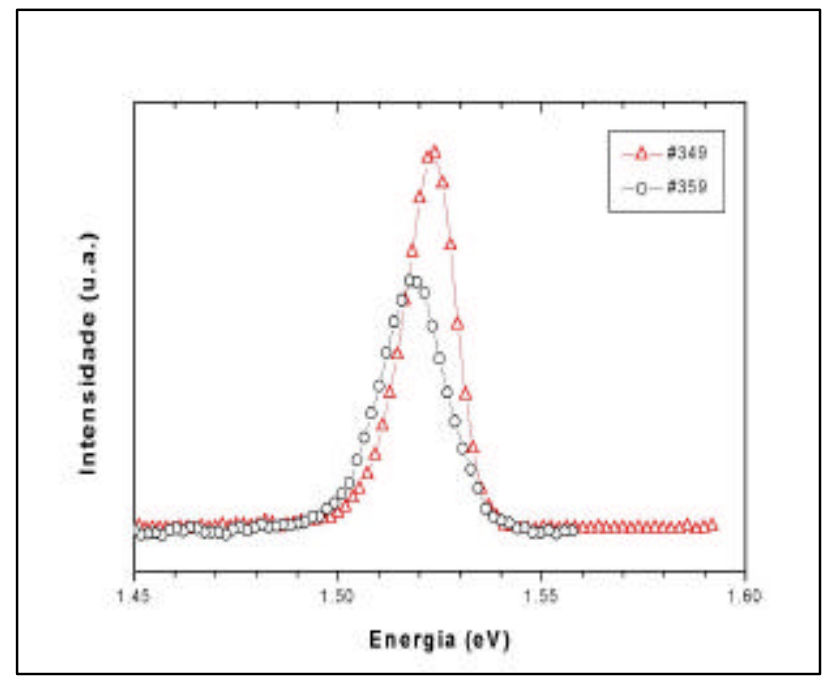

(a) Efeito da dopagem próximo ao pico banda-banda na amostra \#359 vs. \#349.

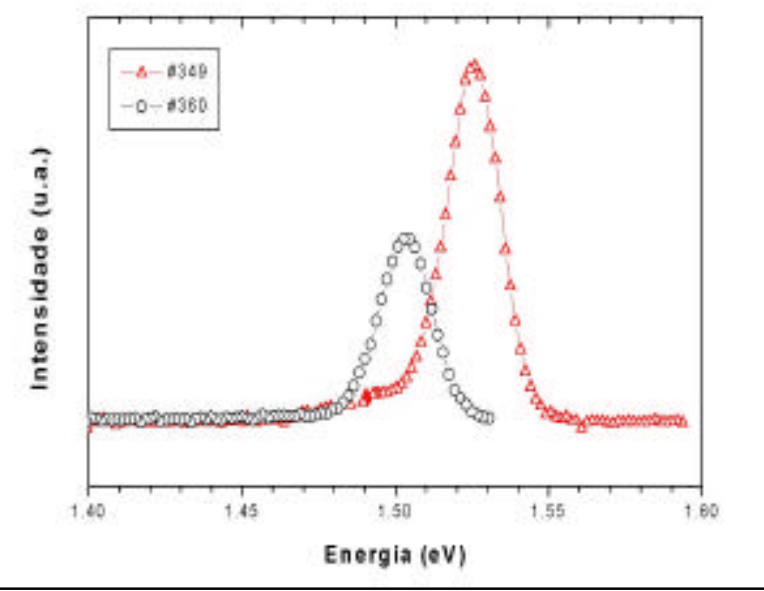

(a) Efeito da dopagem próximo ao pico banda-banda na amostra \#360 vs. \#349.

Figura 4.15: Comparação entre os espectros de fotoluminescência, obtido em uma temperatura de aproximadamente $30 \mathrm{~K}$, entre as amostras com dopagem delta e a referência, representadas por triângulos e círculos, respectivamente.

Nas amostras \#359 e \#360, a energia do pico da fotoluminescência é $6.2 \mathrm{meV}$ e $21.4 \mathrm{meV}$ inferior ao pico banda-banda na amostra não dopada, conforme figura 4.15 (a) e (b), respectivamente. Vale notar, que os espectros foram transladados com a finalidade de eliminar o efeito da composição da liga no gap do material. Na literatura, muito pouco se sabe sobre impurezas em $\operatorname{In}_{\mathrm{x}} \mathrm{Al}_{1-\mathrm{x}} \mathrm{As}$. A energia de ligação de alguns aceitadores e doadores foram determinadas por experimentos de fotoluminescência, entretanto, não se sabe se essas impurezas são defeitos pontuais ou complexos [58]. Comparando os valores 
obtidos com a literatura, é possível associar à emissão na amostra \#360 uma emissão banda de condução-aceitador, onde o aceitador é o carbono, cuja energia de ionização é $21 \pm 1 \mathrm{meV}$ [58]. Em relação à emissão na amostra \#359, na literatura não foram encontrados valores adequados para a energia de ionização de dopantes. Em GaAs a energia de ligação para o silício doador é $5.84 \mathrm{meV}$ [58], porém para AlAs é $70 \mathrm{meV}$ [58].

$\mathrm{Na}$ amostra \#353, é observado que para potências de excitação maiores, o pico da emissão se move na direção de mais altas energia e a largura a meia altura diminui, característica de uma emissão doador-aceitador. Como este fato não ocorre para a amostra de referência, podemos concluir que a transição doador-aceitador é limitada pela presença de carbono aceitador. $\mathrm{O}$ aceitador seria o carbono, cuja energia de ativação é $21 \pm 1 \mathrm{meV}$ e o doador envolvido na transição seria o mesmo que é observado na amostra \#359, cujo a energia de ionização é $6 \mathrm{meV}$. Os doadores não são intencionalmente incorporados durante o crescimento, vale lembrar que a amostra \#353 é do tipo $n$. Os doadores são possivelmente átomos de oxigênio que são usualmente incorporados no crescimento em materiais contendo alumínio, ou silício, dopante residual comum nesses materiais. Porém, nesses casos, as energias de ligação não estão de acordo com a literatura [58].

Medidas de fotoluminescência variando a potência de excitação foram realizadas nas amostras após serem submetidas ao tratamento térmico. Nas amostras crescidas em temperaturas de $575^{\circ} \mathrm{C}$ ou inferiores, mesmo submetidas aos tratamentos térmicos, não se observa a presença da emissão banda-banda. Podemos concluir que os tratamentos térmicos não foram suficientes para melhorar a qualidade ótica do material. Para as amostras dopadas crescidas em temperaturas superiores a $575^{\circ} \mathrm{C}$, não é observado nenhum efeito no espectro da luminescência relacionado ao tratamento térmico. Os espectros das amostras de referência, crescidas a $650^{\circ} \mathrm{C}$, quando submetidas ao mesmo tratamento térmico das amostras dopadas com carbono, apresentam outras duas emissões, além da emissão banda-banda, representada pelo número 1 na figura 4.16. Estas emissões estão indicadas pelos números 2 e 3 no gráfico 4.16 para a amostra \#349. Pode-se concluir que estas emissões não estão relacionadas à impureza carbono, visto que, em amostras dopadas com carbono elas não são observadas. Um tratamento térmico numa amostra de InAlAs dopada com silício foi realizado e foram observadas essas mesmas emissões. Pelo fato de não estarem associadas ao carbono não foi realizada uma análise detalhada das 
mesmas. O fato das amostras dopadas com carbono, contrariamente às não dopadas e dopadas com silício, possuírem impurezas intencionalmente ocupando o sítio $\mathrm{V}$, indica que essas emissões observadas após o tratamento térmico estão relacionadas à ocupação do sítio $\mathrm{V}$ por outros defeitos. Um estudo detalhado é necessário para compreender essas emissões, porém está fora do objetivo desta dissertação.

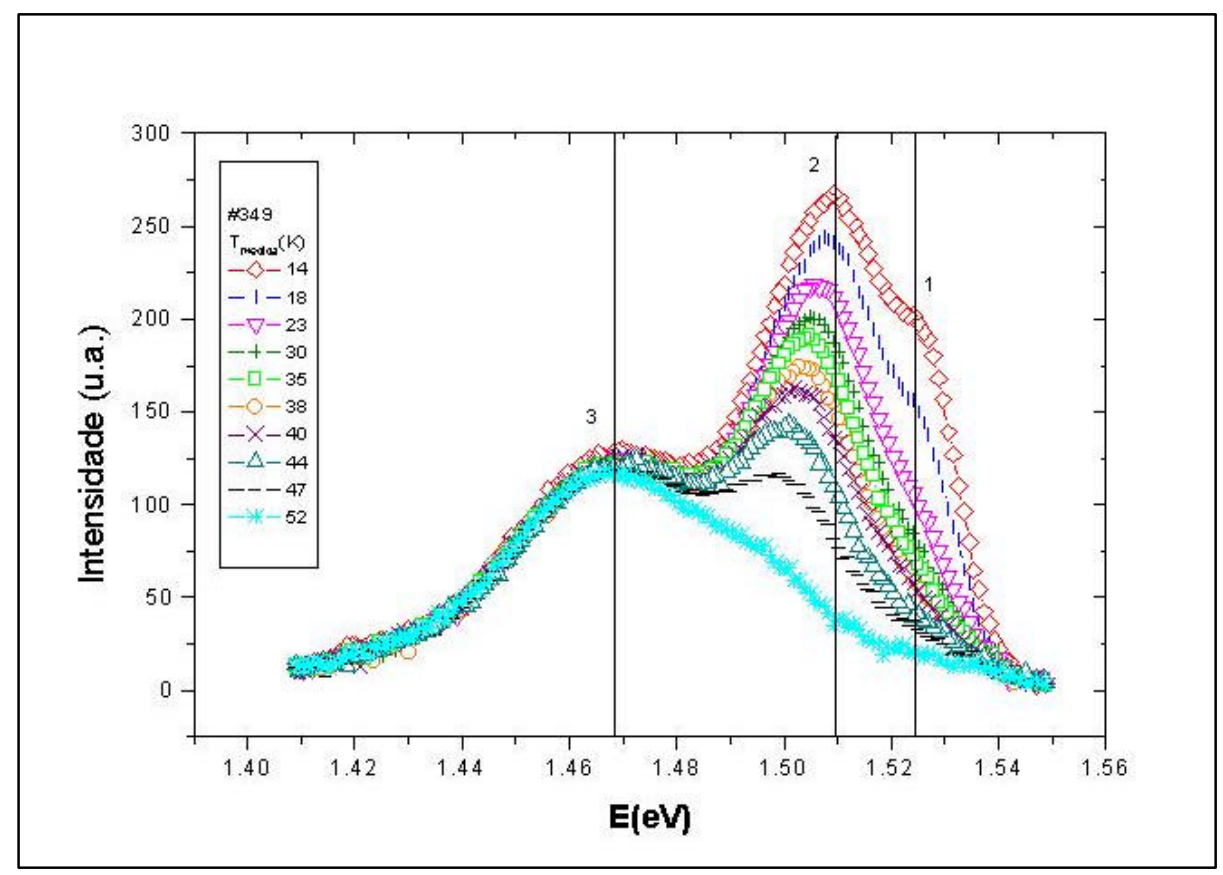

Figura 4.16: Espectros de fotoluminescência para amostra não dopada depois de submetida a um tratamento térmico de $700^{\circ} \mathrm{C} / 15 \mathrm{~min}$. 


\section{Conclusão}

Nesta tese foi apresentado um estudo da dopagem de carbono em camadas de $\mathrm{In}_{\mathrm{x}} \mathrm{Al}_{1-\mathrm{x}} \mathrm{As}$ obtidas pela técnica MOVPE em função da temperatura de crescimento. Foi mostrado que a condutividade aumenta conforme a temperatura de crescimento diminui, devido a uma maior eficiência na incorporação de carbono. É observado que em temperaturas de crescimento mais baixas, ocorre uma menor passivação dos átomos de carbono por átomos hidrogênio devido à pirólise parcial da molécula de arsina e consequentemente, uma menor concentração de hidrogênio na câmara de reação. Observou-se também uma transição na condução de tipo $n$ para tipo $p$ em função da temperatura de crescimento. A temperatura dessa transição foi determinada em aproximadamente $620^{\circ} \mathrm{C}$, ou seja, para amostras crescidas em temperaturas superiores à $620^{\circ} \mathrm{C}$ obtém-se uma condução tipo $n$, enquanto, que para $T_{g}$ menores que $620^{\circ} \mathrm{C}$ obtémse condução tipo $p$. Este fato está associado à anfotericidade do carbono e à incorporação de doadores profundos envolvendo o carbono.

Foi observado que à medida que a temperatura de crescimento diminui, a intensidade do pico banda-banda é reduzida e para temperaturas iguais ou menores que $575^{\circ} \mathrm{C}$ a emissão não é observada. Este fato está associado à incorporação de defeitos não radiativos. Tratamentos térmicos aumentam a atividade elétrica das amostras, pois removem os átomos de hidrogênio, entretanto não se mostraram eficazes em melhorar a qualidade estrutural ou óticas das amostras. Assim, a fim de se obter camadas de boa qualidade ótica e simultaneamente, com elevada dopagem é sugerido a utilização de fontes de arsênio em que as moléculas apresentem uma pirólise completa em temperaturas mais baixas, conforme figura 5.1 . 
A fonte TBAs é uma boa candidata em substituição a fonte $\mathrm{AsH}_{3}$, pois as moléculas de TBAs apresentam elevada taxa de dissociação em temperaturas de $500^{\circ} \mathrm{C}$ e um menor grau de toxidez em relação a outras fontes [32, 59].

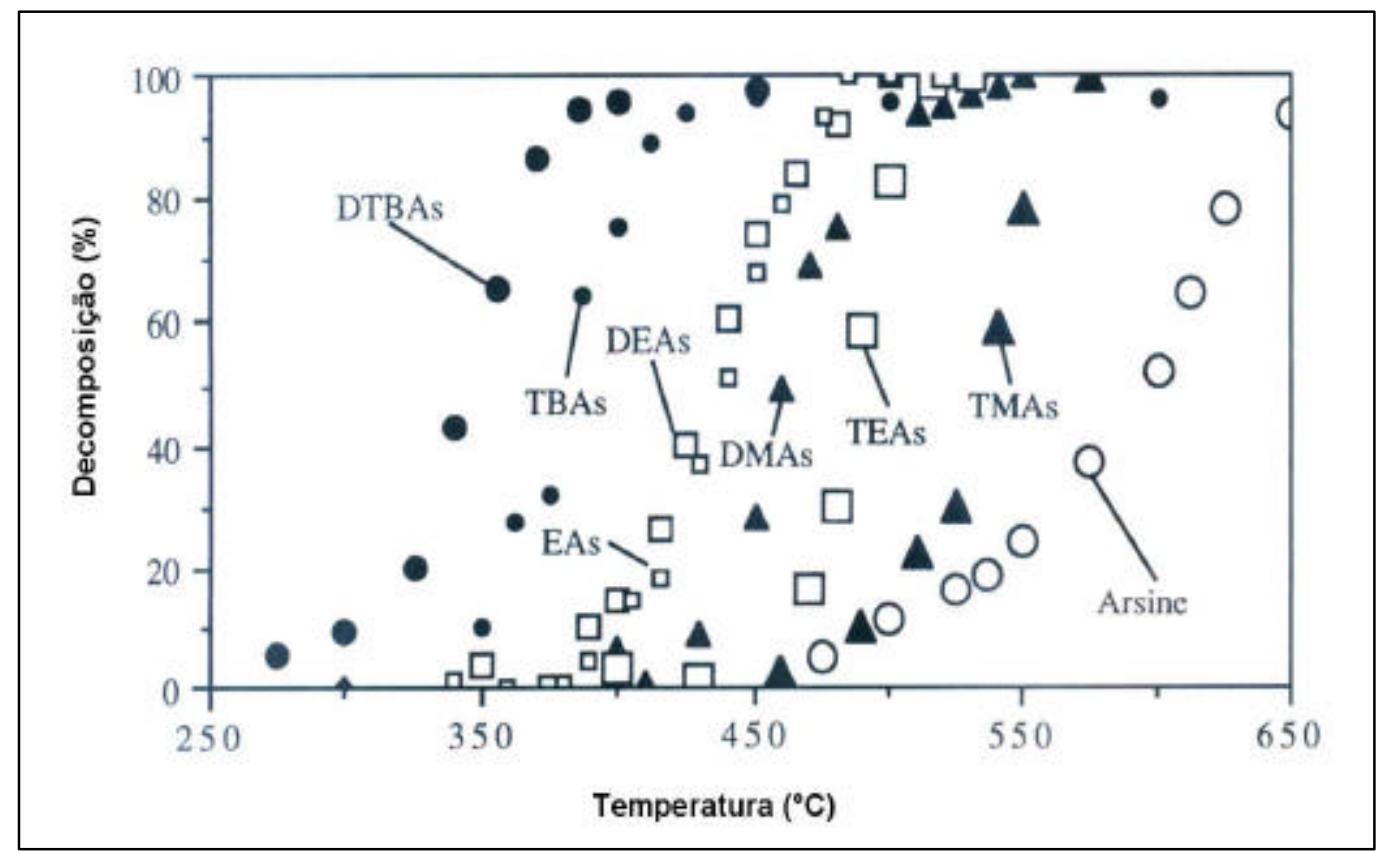

Figura 5.1: Comparação da decompsição térmica das mais importantes fontes de arsina numa atmosfera de pressão no reator MOVPE [32]. 


\section{A. Apêndice}

\section{A.1. O átomo}

Todos os materiais são formados de elementos cuja menor parte estruturada é o átomo [60]. O comportamento dos materiais pode ser compreendido através de um modelo atômico simples que considera a existência de:

i) Um núcleo composto de prótons e nêutrons

Os prótons e nêutrons são partículas com massa que somadas constituirão praticamente toda a massa do átomo, ou seja, a massa atômica. Os diversos elementos puros que constituem a matéria possuem número de prótons em seqüência contínua a partir de 1 correspondente ao átomo de hidrogênio, $\mathrm{H}$, até 94 , correspondente ao plutônio, $\mathrm{Pu}$, que se verifica existir na terra em quantidade muito pequena. A partir deste número, têm sido criados artificialmente outros elementos cuja instabilidade nuclear só permite curto tempo de vida. O número de prótons caracteriza individualmente o elemento sendo conhecido como o número atômico.

A quantidade de nêutrons existentes nos átomos de um mesmo elemento é variável permitindo que um elemento possua átomos individuais com diferentes massas atômicas. Esses átomos são denominados isótopos e a média ponderada da soma de prótons e nêutrons corresponderá à massa atômica do elemento.

O próton possui carga elétrica que se convenciona positiva enquanto que o nêutron é eletricamente neutro. Assim não são forças elétricas que mantém a união entre prótons e nêutrons mas sim forças especiais de grande intensidade chamadas forças moleculares. As forças moleculares não participam diretamente no processo de estruturação da matéria e por isso não serão aqui discutidas. 
ii) Camadas de elétrons orbitando em torno do núcleo

Os elétrons têm comportamento dual, ou seja, ora se comportam como partícula com massa, ora como uma onda. A massa de um elétron é relativamente muito pequena, cerca de $5 \times 10^{-4}$ vezes a massa de um próton ou do nêutron. Por esta razão ela pode ser considerada desprezível no cálculo da massa atômica.

A carga do elétron é numericamente igual à do próton mas com sinal oposto, logo convenciona-se como sendo negativa. A força que mantém os elétrons orbitando em torno do núcleo é a de atração elétrica ou Coulombiana em relação aos prótons. Os orbitais eletrônicos situam-se em níveis energéticos, descontínuos, sendo tanto maior quanto mais afastado estiver o elétron do núcleo. Esses níveis energéticos são denominados níveis quânticos e admitem um número máximo de elétrons que vai crescendo segundo a lei $2 n^{2}$, onde $n$ é a seqüência do nível. A seqüência de níveis é conhecida pelas letras $K, L, M, N, O, P$ e $Q$.

Além dos níveis eletrônicos pode-se identificar também sub-níveis conhecidos como $s, p, d$ e $f$, que podem conter respectivamente 2, 6, 10 e 14 elétrons. A tabela A.1 apresenta a distribuição eletrônica em níveis e sub-níveis orbitais para alguns elementos

\begin{tabular}{|c|c|c|c|c|c|c|c|c|c|c|c|}
\hline \multirow{2}{*}{$\begin{array}{l}\text { Número } \\
\text { Atômico }\end{array}$} & \multirow[t]{2}{*}{ Elemento } & \multirow[t]{2}{*}{ Símbolo } & \multirow{2}{*}{$\begin{array}{c}\mathrm{K}(\mathrm{n}=1) \\
1 \mathrm{~s}\end{array}$} & \multicolumn{2}{|c|}{$\mathrm{L}(\mathrm{n}=2)$} & \multicolumn{3}{|c|}{$M(n=3)$} & \multicolumn{2}{|c|}{$\mathrm{N}(\mathrm{n}=4)$} & \multirow{2}{*}{$\begin{array}{l}O(n=5) \\
5 s 5 p 5 d 5 f\end{array}$} \\
\hline & & & & $2 \mathrm{~s}$ & $2 p$ & $3 \mathrm{~s}$ & $3 p$ & $3 d$ & $4 \mathrm{~s}$ & $4 \mathrm{p} 4 \mathrm{~d} 4 \mathrm{f}$ & \\
\hline 6 & Carbono & $\mathrm{C}$ & 2 & 2 & 2 & & & & & & \\
\hline 13 & Alumínio & $\mathrm{Al}$ & 2 & 2 & 6 & 2 & 1 & & & & \\
\hline 33 & Arsênio & As & 2 & 2 & 6 & 2 & 6 & 10 & 23 & & \\
\hline 49 & Índio & In & 2 & 2 & 6 & 2 & 6 & 10 & 26 & $10-$ & 21 \\
\hline
\end{tabular}

Tabela A.1: Seqüência de elementos com seus respectivos números atômicos e distribuição de elétrons nas camadas e sub-níveis. Somente alguns elementos estão exemplificados. Para cada camada o número máximo de elétrons é dado pela equação $2 n^{2}$.

\section{A.2. Ligações atômicas}

Se os átomos fossem absolutamente estáveis, não seria necessário se unir a outros átomos a fim de obter maior estabilidade para formar a matéria, seriam as estruturas finais da natureza, não havendo formação de compostos. Entretanto sabemos que eles podem reunir-se em estruturas mais complexas formando a matéria como conhecemos na 
prática usual. A união entre os átomos ocorre devido aos mesmos não possuírem orbitais eletrônicos preenchidos, como acontece com todos os elementos, com exceção dos gases nobres. Os átomos tornam-se mais estáveis se puderem ficar com configuração de menor energia por meio de:

- receber elétrons;

- perder elétrons;

- compartilhar elétrons com átomos vizinhos;

- consorciar elétrons com todos os outros átomos.

As ligações resultantes desses processos são conhecidas como:

- ligações iônicas;

- ligações covalentes;

- forças de Van der Waals;

- ligações metálicas .

\section{A.3. Distância interatômica}

Um aspecto importante que surge da possibilidade de ligações atômicas é o da estabilidade dessas ligações. A atração atômica entre os átomos que nasce da ligação varia, como toda força elétrica, com o quadrado da distância $d$ entre os centros dos átomos, onde $k_{1}$ e $k_{2}$ são constantes para a força de atração e repulsão, respectivamente [60].

$$
F_{a t}=\frac{k_{1}}{d^{2}}
$$

Essa atração tem que ser contrabalanceada por algum tipo de repulsão, caso contrário os átomos se interpenetrariam fundindo os seus núcleos. Na verdade quando um átomo se aproxima do outro, sua camada eletrônica exterior começa a sentir a presença da órbita eletrônica mais externa do outro. Por terem cargas negativas, as camadas eletrônicas sofrerão repulsão. Mais ainda, como existem outras camadas eletrônicas internas, a força de repulsão cresce muito à medida que os átomos são forçados uns contra os outros. A intensidade desta força varia com o inverso da décima potência da distância entre centros atômicos [60]. Isto é: 


$$
F_{\text {rep }}=\frac{k_{2}}{d^{10}}
$$

Um gráfico, figura A.1, da variação desta força com a distância, mostra que a soma das mesmas passa por um máximo de atração à medida que os átomos se aproximam, e depois decai rapidamente passando a zero e causando cada vez mais repulsão.

A integral dessa soma $F_{a t}+F_{r e p}$ fornece a variação da energia potencial dos dois átomos com a distância, conforme representado na figura A.1. Observa-se que a energia potencial passa por um mínimo para uma distância $r_{0}$. Isso significa que haverá equilíbrio estável entre os dois átomos na posição $r_{0}$ entre seus centros.

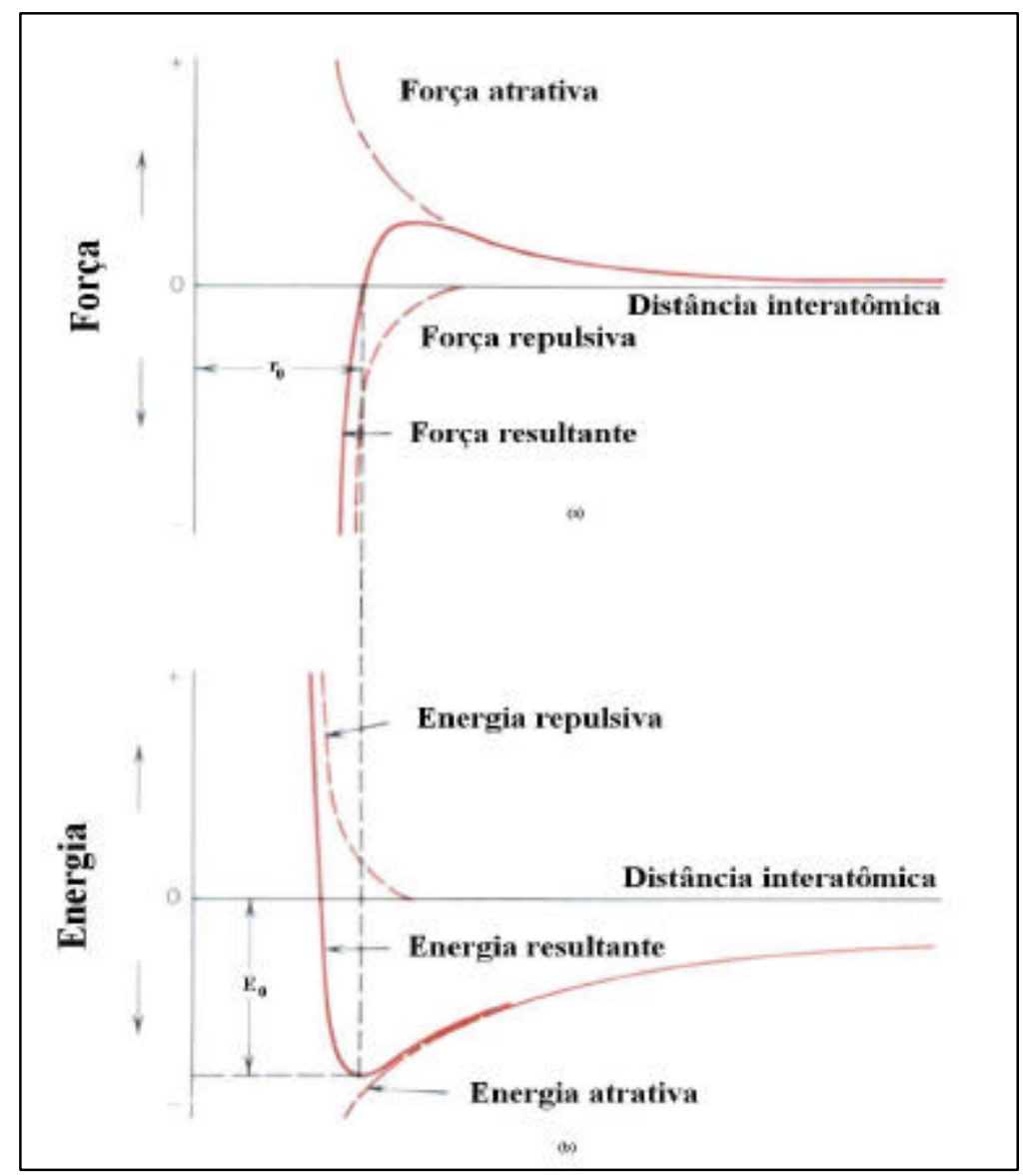

Figura A.1: (a) Dependência da força repulsiva, atrativa e resultante em função da separação interatômica para dois átomos. (b) Dependência da energia atrativa, repulsiva e resultante em função da separação interatômica para dois átomos. 
Essa distância de equilíbrio entre átomos não é constante. Ela varia dependendo de diversos fatores. Entre os quais podemos citar: tipo de átomos, temperatura, solicitação externa (campo elétrico, forças magnéticas, tensão mecânica), etc.

\section{A.4. Estruturas cristalinas}

Sabemos, de um modo geral, que a matéria pode existir em quatro estados gerais: (i) sólido, (ii) líquido, (iii) gasoso e (iv) plasmático.

Os dois últimos, gasoso e plasmático, constituem condições de matéria não condensada, ou seja, não existem estruturas envolvendo grande número de átomos ou moléculas. Os líquidos, por sua vez, correspondem a um estado condensado da matéria que inclusive apresenta coordenação e estrutura atômica. Essa estrutura entretanto é de curto alcance e não caracteriza a periodicidade ou cristalinidade de longa distância. Por isso os líquidos são considerados materiais amorfos. Os sólidos também podem ser amorfos e nestes casos são chamados genericamente de vidros comportando-se muitas vezes como líquidos super-resfriados [61]. A maioria dos sólidos apresenta estrutura com repetição sistemática dos átomos por distâncias relativamente longas para a escala atômica e cobrindo todo o espaço (3D). Esses sólidos com arranjos atômicos periódicos de longa distância são denominados cristais. Os mesmos podem apresentar estrutura intermediária entre a cristalina e a amorfa. Nesse caso, refere-se aos materiais como policristalinos.

Grande parte dos materiais usados na fabricação de dispositivos eletrônicos são de natureza cristalina. Em geral muitas substâncias diferentes cristalizam com a mesma estrutura. Algumas estruturas são simples e são características de certos materiais importantes na eletrônica. As estruturas mais importantes dos semicondutores são a estrutura do diamante e zinc blend [62] que serão detalhadas a seguir.

A estrutura do sulfeto de zinco, $\mathrm{ZnS}$, cúbico (zinc blend), possui uma rede cúbica de face centrada, conforme figura A.2. A base é formada pelo átomo de um dos elementos na posição 000 e por um átomo de outro elemento na posição $\frac{1}{4} \frac{1}{4} \frac{1}{4}$. A estrutura pode ser vista como formada por duas redes cúbicas de faces centradas, uma 
com átomos de Zn e outra com átomos de $\mathrm{S}$, deslocada uma da outra de $\frac{1}{4}$ da diagonal do cubo. Desta forma, como pode ser visto na figura A.2, cada átomo de zinco (Zn) têm quatro vizinhos de enxofre (S) e vice-versa, possibilitando uma ligação covalente tetraédrica entre eles [63]. Cristalizam nessa estrutura vários semicondutores importantes formados por elementos do grupo III e V da tabela periódica.

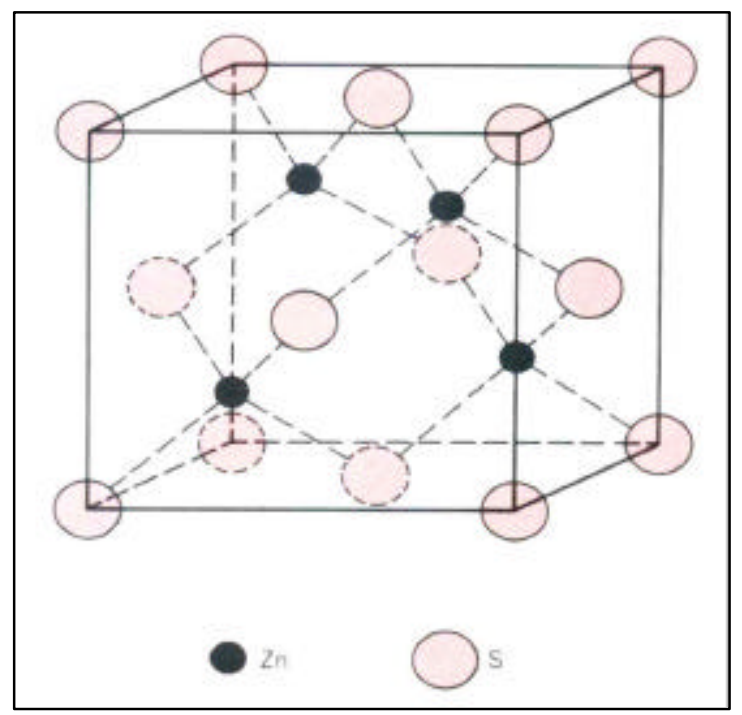

Figura A.2: Célula unitária para um cristal que apresenta estrutura zincblend.

A estrutura do diamante, cuja célula unitária está mostrada na figura A.3 é similar à do $\mathrm{ZnS}$, porém todos os átomos são do mesmo elemento. No caso do diamante o elemento é o carbono. $\mathrm{Na}$ estrutura do diamante se cristalizam importantes semicondutores, como o silício ( $\mathrm{Si}$ ) e o germânio (Ge) [64].

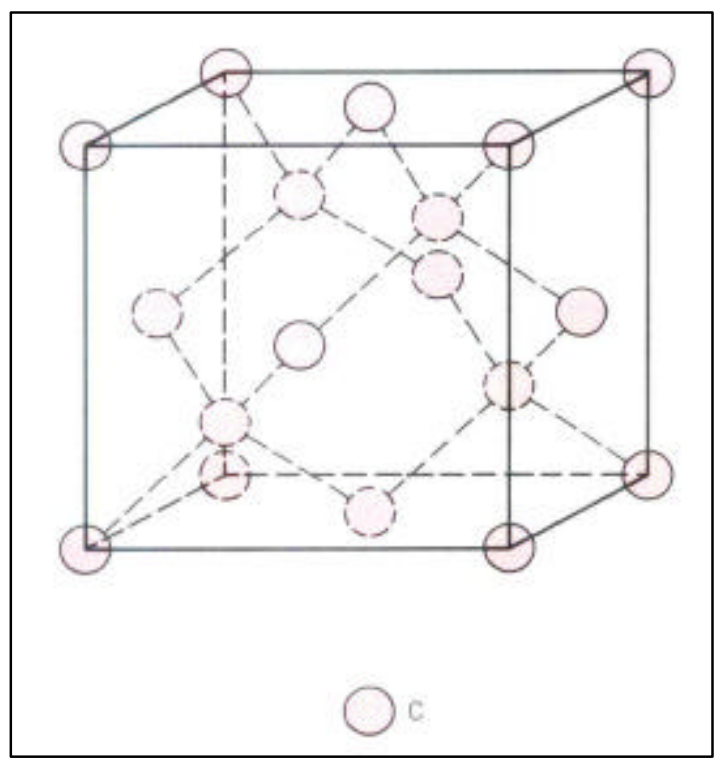

Figura A.3: Célula unitária da estrutura diamante. 


\section{Bibliografia}

[1] H. Ito e H. Yokoyama, J. Cristal Growth 173, 315 (1997).

[2] A. Ougazzaden, J. Holavanahalli, M. Geva e L. Smithh, J. Cristal Growth 221, 66 (2000).

[3] G. Keiser, Optical Fiber Communication, McGraw-Hill, Inc., New York (1983).

[4] C. V. B. Tribuzy, B. Yavich, P. L. Souza e J. G. Menchero, J. Vac. Sci. Technol. B. 18, 741 (2000).

[5] W. Batty e D. W. E. Allsopp, Electron. Lett. 29, 2066 (1993).

[6] T. H. Chiu, J. E. Cunningham, J. A. Ditzenberg, W. Y. Jan e S. N. G. Chu, J. Cristal Growth 111, 274 (1999).

[7] M. Ilegems, J. Appl. Phys 48, 1278 (1977).

[8] S. J. Bass e P. E. Oliver, Inst. Phys. Conf. Ser. No. $33 b$,1 (1977).

[9] K. Tateno e C. Amano, J. Crystal Growth 220, 393 (2000).

[10] F. Brunner, T. Bergunde, E. Richter, P. Kurpas, S. Gramlich, I. Rechenberg, S. Kraus, M. Achouche, J. Würfl e M. Weyers, conferência EW MOVPE VIII, Praga (1999).

[11] B. T. Cunningham, J.E. Baker e G. E. Stillman, Appl. Phys. Lett. 56, 836 (1990).

[12] B. T. Cunningham, J. E. Baker, S. A. Stockmann e G. E. Stillman, Appl. Phys. Lett. 56, 1976 (1990). 
[13] T. J. de Lyon, J. M. Woodall, P. D. Kirchner, D. T. Mclnturff, G. J. Scilla e F. Cardone, J. Vac. Sci. Technol. B. 9, 136 (1991).

[14] T. P. Chin, P. D. Kirchner, J. M. Woodall e C. W. Tu, Appl. Phys. Lett. 59, 2865 (1995).

[15] C. R. Abernathy, J. D. Mackenzie, S. J. Pearton e W. S. Hobson, Appl. Phys. Lett 66, 1969 (1995).

[16] B. G. Streetman, Solid State Electron Devices, 4 ed., Prentice-Hall International, Inc. (1994).

[17] R. Enderlein e N. J. M. Horing, Fundamentals of Semiconductor Physics and Devices, World Scientific Publishing Co. Pte. Ltd., Singapures (1997).

[18] J. Singh, Semiconductor Optoeletronics Physics and Technology, McGraw-Hill, Inc., New York (1995).

[19] E. F. Schubert, Doping in III-V Semiconductors, Cambridge University Press (1993).

[20] A. E. Von Neida, S. J. Pearton, W. S. Hobson, e C. R. Abernathy, Appl. Phys. Lett. 54, 1540 (1990).

[21] S. J. Pearton, Materials Science Report 4, 313 (1990).

[22] Y. Gong, M. Jinji, Y. Haisheng, L. Wang e X. Guanqun, J. Cristal Growth 206, 271 (1999).

[23] Y. G. Chai, R. Chow e C. E. C. Wood, Appl. Phys. Lett. 39, 800 (1981). 
[24] H. Künzel, J. Knecht, H. Jung, K. Wünstel e K. Ploog, Appl. Phys. A28, 167 (1982).

[25] W. E. Hoke, P. J. Lemonias, D. G. Weir, H. T. Hendriks e G. S. J. Jackson, J. Appl. Phys. 69, 511 (1991).

[26] W. E. Hoke, P. J. Lemonias, P. S. Lyman, H. T. Hendriks, D. Weir e P. Colombo, J. Crystal Growth 111, 269 (1991).

[27] G. B. Stringfellow, Semiconductors and Semimetals 22, ed. Tsang, W. T., (Academic, New York) p. 209 (1996).

[28] G. B. Stringfellow, J. Crystal Growth 75, 91 (1986).

[29] H. M. Manasevit, Appl. Phys. Lett. 12, 156 (1968).

[30] H. M. Manasevit e W. I. Simpson, J. Electrochem. Soc 116, 1795 (1969).

[31] R. D. Dupuis e P. D. Dapkus, Appl. Phys. Lett. 32, 406 (1978).

[32] G. B. Stringfellow, Organometallic Vapor-Phase Epitaxy, Academic Press, New York (1999).

[33] R. R. J. Bradley, Crystal Growth 55, 223 (1981).

[34] R. R. Saxena, V. Aebi, C. B. Cooper, M. J. Ludowise, H. A. van de Plas, B. R. Cairns, T. J. Maloney,P. G. Bordern, e P. E. Gregory, J. Appl. Phys. 51, 4501 (1980). 
[35] W. M. Mendes, Tese de Mestrado: Fotoluminescência em Poços Quânticos Assimétricos de GaAlAs/GaAs/GaAlAs:Si, PUC-Rio (1990).

[36] M. P. Pires, Tese de Doutorado: Estruturas de Poços Quânticos Multiplos de InGaAs/InAlAs para Modulação Eletro-ótica de Amplitude, PUC-Rio (1998).

[37] L. C. Feldman e J. W. Mayer, Fundamentals of Surface and Thin Film Analysis, North-Holland, New York (1986).

[38] J. M. Wall, Methods of Surface Analysis, Cambridge University Press, Cambridge (1989).

[39] C. G. Pantano, Secondary Ion Mass Spectroscopy in Metals Handbook, 9 th ed. (R. E. Whan, coord), An. Soc. Metals Park, OH, 10, 610 (1986).

[40] N. S. Murthyr e F. Reidinger, Aguide to Materials Characterization and Chemical Analysis, VCH publisher, New York (1996).

[41] A. Benninghoven, F. G. Rüdenaver e H. W. Wener, , Secondary Ion Spectrometry: Basic Concepts, Instrumental Aspects, Applications and Trends, Wiley, New York (1987).

[42] Schroder, D. K., Semiconductor Material and Device Characterization, 2 th. ed., Wiley, New York (1998).

[43] B. D. Cullit, Elements of X-rays Diffractions, Addison-Wesleys Publishing, New York (1978).

[44] J. B. Campos, Tese de Doutorado: Caracterização de Filmes Finos Cristalinos e Amorfos por Reflexão de Raios-X, PUC-Rio (1998). 
[45] G. Bauer e W. Richter, Optical Characterization of Epitaxial Semiconductor Layers, Springer (1996).

[46] C. O. Thomas, D. Kahng, e R. C. Manz, J. Electrochem. Soc. 109, 1055 (1962).

[47] N. I. Meyer e T. Guldbrandson,, Proc. IEEE 51, 1631 (1963).

[48] I. Amron, Electrochem. Tech. 2, 337 (1964).

[49] I. Amron, Electrochem. Tech. 5, 94 (1967).

[50] P. L. Souza, Tese de Doutorado: A dopagem de silício em camadas epitaxiais $\mathrm{Al}_{0.3} \mathrm{Ga}_{0.7} \mathrm{As}$ sob o ponto de vista da fotoluminescência, PUC-Rio (1989).

[51] D. M. Eagles, J. Phys. Chem. Solids 16, 76 (1960).

[52] C. Pickering, P. R. Tapstem, P. J. Dean, e D. J. Ashen, Inst. Phys. Conf. Ser. 65, 469 (1983).

[53] E. F. Schubert, Delta-doping of semiconductors, Cambridge University Press, Cambridge (1996).

[54] H. Ito e T. Ishibashi, Jpn. J. Appl. Phys. 30, 944 (1991).

[55] N. Watanabe, S. A. K. Kumar, S. Yamahata e T. Kobayashi, J. Crystal Growth 195, 48 (1998).

[56] N. Watanabe, S. Yamahata e T. Kobayashi, J. Crystal Growth 200, 599 (1999).

[57] C. Salles, Tese de Mestrado: Simulação de difração múltipla de raios-x e aplicações, UNICAMP (1989). 
[58] O. Madelung, Semiconductors: Group IV and III-V Compounds, Springer, New York (1991).

[59] P. Velling, Progress in Crystal Growth and Characterization of Materials 41, 85 (2000).

[60] S. N. Monteiro, Materiais para Engenharia, DEMET-EE/UFRJ, Rio de Janeiro, 1991.

[61] L. H. V. Vlack, Princípio de Ciência e Tecnologia dos Materiais, Campus, Rio de Janeiro (1988).

[62] S. M. Rezende, A Física dos Materiais e Dispositivos Eletrônicos, Universitária da Universidade Federal de Pernambuco, Recife (1996).

[63] W. D. Callister, Materials Science and Engineering, Johh Wiley \& SonS, Ney York (1994).

[64] P. Bhattachary, Semiconductor Optoeletronic Devices, Prentice-Hall International, Inc. (1994). 


\section{Trabalhos publicados}

[1] M. L. P. Ribeiro, B. Yavich, C. V. B. Tribuzy e P. L. Souza; "Effect of Growth Temperature on C-doped in InAlAs Layers Grown By LP-MOVPE", aceito para

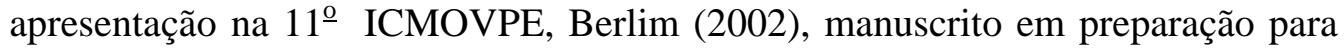
submissão ao Journal of Crystal Growth.

[2] M. L. P. Ribeiro, B. Yavich, C. V. B. Tribuzy e P. L. Souza; "Influence of Growth temperature on the Transport and Optical Properties of InAlAs:C Growth by LPMOVPE”, aceito para apresentação na 25ํㅡㄹ ENFMC, Caxambú (2002).

[3] M. L. P. Ribeiro, B. Yavich, C. V. B. Tribuzy e P. L. Souza; "Carbon Doping of InAlAs Layers Grown by Metalorganic Vapor Phase Epitaxy", apresentado no $10^{\circ}$ BWSP, Guarujá (2001) e aceito para publicação no Brazilian Journal of Phhysics. 